Erster Beratungsgegenstand:

\title{
Die Staatsrechtslehre und die Veränderung ihres Gegenstandes: Konsequenzen von Europäisierung und Internationalisierung
}

1. Bericht von Prof. Dr. Juliane Kokott, St. Gallen

Inhalt

Einleitung

I. Veränderungen des (europäischen) Staates . . . . . . . . 11

1. Zum Begriff Staat . . . . . . . . . . . . . . . 11

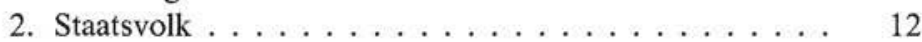

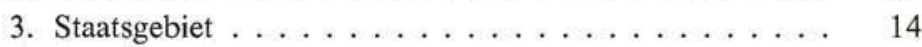

4. Staatsgewalt . . . . . . . . . . . . . . . . 15

a) Einheit der Staatsgewalt ................. 15

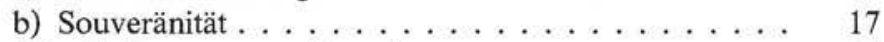

5. Abschied vom souveränen Staat . . . . . . . . 21

II. Erfüllung der Staatsaufgaben im offenen Verfassungs-

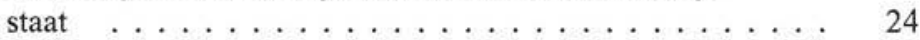

1. Garantie von Freiheit und Sicherheit . . . . . . . . . 24

2. Definition des Gemeinwohls ............ 25

3. Daseinsvorsorge und die Schaffung von Wohlfahrt . . . 26

4. Identität, Integration . . . . . . . . . . . . . . 26

5. Organ der Völkergemeinschaft . . . . . . . . . . 27

III. Postnationale Demokratie? . . . . . . . . . . . . . . . . . . . . . . . . . . . .

1. Demokratiegebot . . . . . . . . . . . . . . . . 29

2. Demokratiebegriff ... . . . . . . . . . . . . . 29

3. Weltstaat, Europastaat . . . . . . . . . . 30

4. Elemente postnationaler guter Herrschaft (,good governance") . . . . . . . . . . . . 31

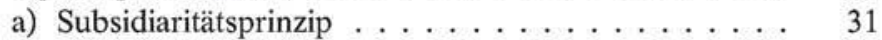

b) Demokratische Prinzipien . . . . . . . . . . 32

c) Kein internationaler Parlamentarismus . . . . . . . 33

d) Optimierungsgebot, Transparenz, responsible government .................. 33 
IV. Konvergenz von Staats- und Völkerrecht, Folgen für die Staatsrechtslehre . . . . . . . . . . . . . . . 34

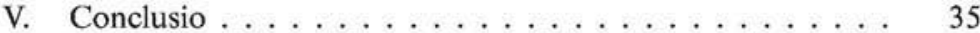




\section{Einleitung}

„Die Epoche der Staatlichkeit geht jetzt zu Ende. Darüber ist kein Wort mehr zu verlieren. ... Der Staat als das Modell der politischen Einheit, der Staat als Träger ... des Monopols der politischen Entscheidung ... wird entthront,"1 so Carl Schmitt bereits 1963. Ähnlich schließt Ernst Forsthoff im „Staat der Industriegesellschaft“, 1971: „Die Übersicht über die Befindlichkeiten der Bundesrepublik läßt keinen Zweifel daran zu, dass sie kein Staat im hergebrachten Sinne des Begriffs mehr ist. ... Von Souveränität im Sinne der höchsten und fortdauernden Gewalt zu sprechen wäre absurd."2 „Warum nicht den Staat als Begriff und Idee verabschieden", fragt Udo Di Fabio. ${ }^{3}$

Frieden, Freiheit und Sicherheit, Demokratie, Umwelt- und Menschenrechtsschutz, gerechte Handelsbedingungen sind solche öffentlichen und herkömmlicherweise staatlichen Aufgaben von höchster Priorität, welche virulent bleiben, doch der Einfluss der einzelnen Staaten schwindet. Wozu, lässt sich mit Peter Saladin fragen, noch Staaten?,4 und wozu so viele Staatsrechtslehrer, die den Staat sehr intensiv beforschen? Erübrigen sich, wie im Kontext des europäischen Gemeinschaftsrechts manchmal postuliert, 5 vertraute Kategorien wie „Volk“, „Staat“ und „Souveränität"? Gerät die Staatsrechtslehre folglich ins Abseits, wenn sie nur auf den Staat und dessen Modifikationen blickt?

Wie oft bei Juristen, handelt es sich auch um eine Frage der Semantik: Je enger man den Staats- und Souveränitätsbegriff fasst, desto eher besteht Bedarf nach Anpassung. Je nach Vorverständnis und Definition von Staat und Souveränität variiert zudem das Ausmaß der Änderungen. Fest

1 C. Schmitt Der Begriff des Politischen, Text von 1932 mit einem Vorwort und drei Corollarien, 1963, 10.

${ }^{2}$ E. ForsthoffDer Staat der Industriegesellschaft, 1971, 158.

3 Vgl. U. Di Fabio Das Recht offener Staaten, 1998, 130: „Warum nicht den Staat als Begriff und Idee verabschieden? Warum nicht Politik und Recht wieder bewußter auseinandertreten lassen ..." auch, historisch begründet, W. Reinhard Geschichte der Staatsgewalt, Eine vergleichende Verfassungsgeschichte Europas von den Anfängen bis zur Gegenwart, 1999, 535f.: „Der moderne Staat ... existiert nicht mehr.“

${ }^{4}$ P. Saladin Wozu noch Staaten?, Zu den Funktionen eines modernen demokratischen Rechtsstaates in einer zunehmend überstaatlichen Welt, 1995.

${ }_{5}$ G. Schuppert Demokratische Legitimation jenseits des Nationalstaates, Einige Bemerkungen zum Legitimationsproblem der Europäischen Union, in: Heyde/Schaber (Hrsg.) Demokratisches Regieren in Europa?, 2000, 65, 70; J. Shaw/A. Wiener The Paradox of the ,European Polity', in: Green/Cowles/Smith (Hrsg.) The State of the European Union, Bd. 5 (Risks, Reform, Resistance and Revival), 2000, 64, 76f. 
steht aber, dass ausgehend vom Staat des 19. Jahrhunderts gravierende Änderungen erfolgt sind. Indiz dafür sind schon die emphatischen $\mathrm{Be}-$ kenntnisse zur Notwendigkeit von Staaten und Souveränität einerseits und andererseits die Beschwörungen des Unterganges des souveränen Staates. ${ }^{6}$

Der Staat wandelt sich vom Typus des souveränen Gebietsherrn zum Typus des gegenüber verselbstständigter supranationaler Hoheitsgewalt offenen Staates. Der Verlust souveräner Staatlichkeit erfolgt dabei graduell und allmählich. ${ }^{7}$ Niemals war zwar der Staat völlig abgeschotteter, impermeabler und autarker Souverän, ${ }^{8}$ niemals aber auch war er so integrationsoffen und so wenig autark wie heute. Vor Augen stehen mir in erster Linie die Mitgliedstaaten der Europäischen Gemeinschaften. Im Rahmen der Europäisierung gehen die Veränderungen besonders weit. Der tief greifende Wandel des Staates und der Souveränität ist aber auch ein Phänomen der Internationalisierung. Prominente Vertreter der amerikanischen Völkerrechtswissenschaft bejahen generell und nicht auf Europa beschränkt den Wegfall des alten Souveränitätskonzepts; allenfalls ein umdefinierter Souveränitätsbegriff scheint mit dem modernen Völkerrecht noch vereinbar. ${ }^{9}$ Die Mitgliedstaaten der Europäischen Gemeinschaften spielen lediglich in vielerlei Hinsicht eine Vorreiterrolle.

\footnotetext{
${ }^{6}$ Emphatisch in diesem Sinne deklamiert beispielsweise Hillgruber. „Wer deshalb Souveränität in Frage oder gar in Abrede stellt, setzt nicht weniger als die Legitimationsgrundlage und damit die Zukunft des Völkerrechts aufs Spiel.“; C. Hillgruber Souveränität - Verteidigung eines Rechtsbegriffs, JZ 2002, 1072, 1077; vgl. auch C. Seiler Der souveräne Verfassungsstaat zwischen demokratischer Rückbindung und überstaatlicher Einbindung, 2003.

${ }^{7}$ AA wohl C. Möllers Staat als Argument, 2000, 224f., 424.

${ }^{8}$ P. Kirchhof Der Staat als Organisationsform politischer Herrschaft und rechtlicher Bindung - Kontinuität des deutschen Verfassungsstaates in Freiheitlichkeit, Weltoffenheit und demokratischer Solidarität, DVBl 1999, 637, 647.

9 Vgl. z.B. den damalige Präsidenten der amerikanischen Völkerrechtsgesellschaft/ ASIL L. Henkin The Mythology of Sovereignty, ASIL Newsletter March-May 1993; und die gegenwärtige (2003) Präsidentin der ASIL A.-M. Slaughter International Law in a World of Liberal States, EJIL 1995, 503, 537 (Umdefinition der Souvernänität). Dazu schon H. Preuss Gemeinde, Staat, Reich als Gebietskörperschaften, Neudruck der Ausgabe 1889, 1964, 104: „Der Souveränitätsbegriff, welchen Brie, Gierke u.a.m. aufstellen, ist mit dem modernen Rechtsstaat wie mit dem modernen Völkerrecht durchaus vereinbar; jedoch nur deshalb, weil er mit dem alten und eigentlichen Souveränitätsbegriff nicht das Wesen, sondern lediglich den Namen gemein hat." Zum eher naturrechtlichen gerade nicht souveränitätsorientierten Ursprung des Völkerrechts $M$. Koskenniemi The Gentle Civilizer of Nations, The Rise and Fall of International Law 1870-1960, 2002, 51 (,common consciousness", „dictates of reason and ethics").
} 


\section{Veränderungen des (europäischen) Staates}

\section{Zum Begriff Staat}

Mit Paul Kirchhoflässt sich der Staat definieren ,als ein sich seiner Zusammengehörigkeit bewusst gewordenes, zum Recht fähiges Staatsvolk, das sich in einem bestimmten Gebiet zu einem körperschaftlichen Herrschaftsverband organisiert, ... eine gesetzte Ordnung hat und den Staatsorganen die letztverantwortliche Befugnis zuweist, Recht zu setzen und durchzusetzen." ${ }^{10}$ Die traditionellen Merkmale von Staatsgebiet, Staatsvolk und Staatshoheit" ergänzt Kirchhof durch die rechtsstaatliche und demokratische Komponente. „Dabei bleibt bewußt das Entstehen von Staaten und Verfassungen im Normativen wie im Faktischen verwurzelt."12 Ähnlich modifiziert das moderne Völkerrecht den Grundsatz der Effektivität der Staatsgewalt als Voraussetzung der Anerkennung von Staaten durch rechtsstaatliche, demokratische und menschenrechtliche Kriterien. ${ }^{13}$

Europäisierung und Internationalisierung beeinträchtigen alle drei Staatsmerkmale tief greifend: Staatsvolk, Staatsgebiet und Staatsgewalt.

${ }^{10}$ P. Kirchhof Die Staatenvielfalt - ein Wesensgehalt Europas, FS Schambeck, 1994, 947, $951 \mathrm{f}$.

11 G. Jellinek Über Staatsfragmente, in: Festgabe zur Feier des siebzigsten Geburtstages Seiner Königlichen Hoheit des Großherzogs Friedrich von Baden dargebracht von den Mitgliedern der juristischen Fakultät der Universität Heidelberg, 1896, 265; ders. Allgemeine Staatslehre, 3. Aufl. 1914, $394 \mathrm{ff}$.; s. auch N. MacCormick Questioning Sovereignty, Law, State, and Nation in the European Commonwealth, 1999, 17. Kritisch gegenüber einer weiteren Verwendung der Drei-Elemente-Lehre, weil die den Elementen von der traditionellen Staatstheorie zugemessene Bedeutung zunehmend verloren geht, $P$. Saladin (Fn. 4), 35f.

12 P. Kirchhof(Fn. 10), 951f. Zum normativen und faktischen Gehalt der Souveränität als Völkerrechtsbegriff $M$. Koskenniemi From Apology to Utopia, 1989, $192 \mathrm{ff}$. und allgemeiner ders. (Fn. 9), 249. Für eine strikte Trennung von Sein und Sollen hingegen C. Seiler (Fn. 6).

$13 \mathrm{Vgl}$. Erklärung zu den ,Richtlinien für die Anerkennung neuer Staaten in Osteuropa und in der Sowjetunion", Beschluss der EG-Außenminister im Rahmen der Europäischen Politischen Zusammenarbeit (EPZ) vom 16. Dezember 1991, Bulletin des Presseund Informationsamtes der Bundesregierung 1991, 1173; S. Oeter Selbstbestimmungsrecht im Wandel, Überlegungen zur Debatte um Selbstbestimmung, Sezessionsrecht und „vorzeitige“ Anerkennung, ZaöRV 1992, 741; J. Frowein The Contribution of the European Union to Public International Law, FS Ehlermann, 2002, 171. S. ferner auch Art. 49 und 6 EUV sowie Art. 3 Satzung des Europarates. 


\section{Staatsvolk}

Das Staatsvolk ${ }^{14}$ soll auch Kultur-, Gefahren- und Verantwortungsgemeinschaft ${ }^{15}$ und durch eine gewisse (nicht notwendigerweise ethnische) Homogenität zusammengehalten sein. Aufgrund von Massenmigration erhalten jedoch „die einzelnen Staatsvölker - ,Staatsvolk‘ hier verstanden als die in einem Staat wohnhafte Bevölkerung - eine Buntheit, wie sie Europa nie erlebt hat, wenn man bedenkt, dass praktisch alle Volksgruppen der Erde in jene Migrationsbewegungen einbezogen sind." 16 Mehrfache Staatsangehörigkeit, auch Wechsel der Staatsangehörigkeit, werden häufiger. Dies ergibt sich aus normativen Gründen - gesetzliche Hinnahme von mehrfacher Staatsangehörigkeit ${ }^{17}$ - und aus faktischen Gründen. Beispielsweise werden aufgrund gesteigerter Mobilität binationale Ehen häufiger; Ehefrauen können ihre Staatsangehörigkeit nach modernem Staatsangehörigkeitsrecht behalten, die Kinder werden regelmäßig Doppelstaatler. Die Migration beeinflusst letztlich auch das Staatsvolk als Gesamtheit der Staatsbürger. ${ }^{18}$

Darüber hinaus verliert das Institut der Staatsangehörigkeit an Bedeutung. Das Europäische Gemeinschaftsrecht und das internationale Wirtschaftsrecht verbieten Diskriminierung aufgrund der Staatsangehörigkeit. Das Institut der Unionsbürgerschaft leitet sich zwar aus der nationalen Staatsangehörigkeit her, nivelliert aber gleichwohl deren Bedeutung. ${ }^{19}$ Der internationale Menschenrechtsschutz knüpft, anders als der traditionelle diplomatische Schutz, gerade nicht an die Staatsangehörigkeit an. Auch das Internationale Privatrecht reagiert auf Mobilität und Migration, indem das Domizilprinzip gegenüber dem Staatsangehörigkeitsprinzip an

$14 \mathrm{Vgl}$. H. Maurer Staatsrecht, 3. Aufl. 2003, 190f. Zur Frage eines europäischen Volkes A. Augustin Das Volk der Europäischen Union, Zu Inhalt und Kritik eines normativen Begriffs, 2000.

15 P. Kirchhof Die Identität der Verfassung in ihren unabänderlichen Inhalten, in: Isensee/Kirchhof (Hrsg.) Handbuch des Staatsrechts, Bd. 1, 2. Aufl. 1995, § 19 Rn. 56 ff.; ders. (Fn. 8), 643.

16 P. Saladin (Fn. 4), 27.

17 Vgl. T. Franck Clan and Superclan: Loyalty, Identity and Community in Law and Practice, AJIL 1996, 359, $378 \mathrm{ff}$. mit rechtsvergleichenden Hinweisen.

${ }^{18}$ Das Bild der durch Sprache, Kultur und Tradition verbundenen Gefahren- und Schicksalsgemeinschaft trägt nicht. Zu diesem Bild vgl. etwa $R$. Grawert Staatsvolk und Staatsangehörigkeit in: Isensee/Kirchhof (Fn. 15), § 14 Rn. 8; J. Isensee Staat und Verfassung, ebd., \$ 13 Rn. 112f.; K. Stern Das Staatsrecht der Bundesrepublik Deutschland, Bd. 2, 1980, 6f. Zum Erfordernis einer gemeinsamen Identität $M$. Rosenfeld The European Convention and constitution making in Philadelphia, I-CON 2003, 373.

$19 \mathrm{Vgl}$. Art. $17 \mathrm{ff}$. EGV. 
Raum gewinnt. ${ }^{20}$ Das internationale Strafrecht schließlich lockert die Beziehung Heimatstaat-Individuum (und insbesondere deren Ausschließlichkeit) durch zunehmende Anerkennung und einen wachsenden Anwendungsbereich des Universalitätsprinzips und durch die erstarkende supranationale Strafgerichtsbarkeit.

Der Einzelne ist nicht mehr in dem Maße auf Schutz und Refugium seines Heimatstaates angewiesen, wie dies beim klassischen Nationalstaat noch der Fall war. ${ }^{21}$ Vielmehr kann sich das zum Völkerrechtssubjekt erstarkende Individuum oft selbst an Menschenrechtsschutzinstitutionen wenden und direkt internationale Streitbeilegungsmechanismen zum Schutz von Auslandsinvestitionen anrufen. ${ }^{22}$ Umgekehrt kann ein einzelner Staat seinen Bürgern heute ohnehin nur noch zum Teil ein zufrieden stellendes $\mathrm{Maß}$ an Sicherheit gewährleisten. ${ }^{23}$ Ein Fundamentalkriterium des diplomatischen Schutzes, das Institut der Staatsangehörigkeit, und damit auch das Staatsmerkmal „Volk“ sind in der Krise. ${ }^{24}$ Denn auf Hobbes zurückgreifend ließe sich ableiten, dass die Verpflichtung der Untertanen gegenüber dem Souverän nur solange dauert, wie er sie auf Grund seiner Macht schützen kann, und nicht länger. ${ }^{25}$

Der Bedeutungsverlust der Staatsangehörigkeit und die fehlende Schutzfähigkeit des einzelnen Staates mindert die Schutz- und Loyalitätbeziehung zwischen Staat und Staatsbürger (v.a. in Europa). ${ }^{26}$

${ }^{20}$ I. Schwander Einführung in das internationale Privatrecht, Bd. 1, 2000, 95 (Rn. 187): „Weltweit ist eine Tendenz zugunsten des Domizilprinzips feststellbar. Die zunehmende Migration hat die Vorteile territorialer Anknüpfungsbegriffe und gewisse Impraktikabilitäten der Anknüpfung an die Staatsangehörigkeit bestätigt.“

${ }^{21}$ D. Thürer Der Verfassungsstaat als Glied einer europäischen Gemeinschaft, VVDStRL 50 (1991), 97, 124f.

22 Vgl. J. Kokot Zum Spannungsverhältnis zwischen nationality rule und Menschenrechtsschutz bei der Ausübung diplomatischer Protektion, in: Ress/Stein (Hrsg.) Der diplomatische Schutz im Völkerrecht, Aktuelle Probleme und Entwicklungstendenzen, 1996, 45; dies. (Hrsg.) Interim Report on the Role of Diplomatic Protection in the Field of the Protection of Foreign Investment, The International Law Association, Report of the Seventieth Conference, New Dehli, 2002, 259.

${ }^{23}$ M. Zürn Regieren jenseits des Nationalstaates, 1998, 96.

${ }^{24} \mathrm{Vgl}$. Diskussion einzelner Angehöriger der International Law Commission mit der Völkerrechtskommission der Vereinten Nationen/ILC zu Fragen des diplomatischen Schutzes vom 29. Juli 2003 in Genf.

25 Th. Hobbes Leviathan: or the Matter, Forme and Power of a Commonwealth Ecclesiastical and Civil, herausgegeben von M. Oakeshott, 1962, 5. Druck 1978, 167: „The obligation of subjects to the sovereign, is understood to last as long, and no longer, than the power lasteth, by which he is able to protect them."

${ }_{26}$ Ähnlich T. Franck (Fn. 17), $376 \mathrm{mwN}$; vgl. auch Y. Hasebe Why We Should Not Take Sovereignty Too Seriously, in: Jyränki (Hrsg.) National Constitutions in the Era of Integration, 1998, 113, $121 \mathrm{f}$. 


\section{Staatsgebiet}

Das Staatsgebiet ist der räumliche Geltungsbereich staatlicher Herrschaftsmacht, insbesondere der staatlichen Rechtsordnung. ${ }^{27}$ Jeder, der sich im Staatsgebiet befindet, ist der Staatsgewalt unterworfen (positiver Aspekt der Gebietshoheit), und innerhalb des Staatsgebiets darf keine Hoheitsgewalt ausgeübt werden, die nicht von der staatlichen Regelungsgewalt abgeleitet ist (negativer Aspekt).

Die im Regelwerk der Welthandelsorganisation/WTO und den mittlerweile über 2000 Bilateralen Investitionsschutzverträgen ${ }^{28}$ verkörperten Prinzipien der Inländergleichbehandlung und Meistbegünstigung mindern auch die Bedeutung der Gebietsgrenzen. ${ }^{29}$ Sie gelten für den Warenund Dienstleistungs-, zunehmend aber auch für den Personenverkehr.

Die klassische Staatsaufgabe der Gewährleistung der Sicherheit nach außen mutiert von einer staatlichen zur internationalen Aufgabe. Das Grundgesetz trägt dem Rechnung, indem es Souveränitätsverzicht zugunsten kollektiver Verteidigungsbündnisse vorsieht, ${ }^{30}$ insbesondere die Teilnahme an Friedenssicherungseinsätzen der Vereinten Nationen. ${ }^{31}$ Der Militäreinsatz wird entterritorialisiert. Er erfolgt nicht mehr ausschließlich zur Landesverteidigung und erst recht nicht zum Zwecke des Erwerbs von Staatsterritorium. ${ }^{32}$ Auch die innerstaatliche Gefahrenabwehr in Form der Terrorismusbekämpfung ist völkerrechtlich überlagert und faktisch auf internationale Kooperation angewiesen.

Schließlich bedeutet Staat immer weniger impermeabler Herrschaftsbereich einer bestimmten Rechtsordnung. ${ }^{33}$ Diese Entwicklung betrifft sowohl das Staatsmerkmal Territorium als auch die Staatsgewalt. Die Staatsgrenzen werden $\mathrm{zu}$ relativen Jurisdiktionsgrenzen, ${ }^{34}$ die lediglich indizieren, dass eine spezifische Rechtsordnung anwendbar ist, vorbehaltlich supranationalen und internationalen Rechts. Zu völkerrechtlich begründeten Regelungen und supranationalem Recht kommt die grenzüberschreitende Anwendung nationalen und supranationalen Rechts

\footnotetext{
${ }^{27}$ Vgl. auch G. Teubner Globale Zivilverfassungen: Alternative zur staatszentrierten Verfassungstheorie, ZaöRV 2003, 1, 27.

28 J. Kokott Interim Report (Fn. 22), 259.

$29 \mathrm{Vgl}$. auch D. Grimm Ursprung und Wandel der Verfassung, in: Isensee/Kirchhof (Hrsg.) Handbuch des Staatsrechts, Bd. 1, 3. Aufl. 2003, § 1 Rn. 90; C. Tomuschat International Law: Ensuring the Survival of Mankind on the Eve of a New Century, General Course on Public International Law, 2001, 166.

30 Art. 24 GG.

$31 \mathrm{Vgl}$. BVerfGE 90, 286.

${ }^{32}$ Art. 26 GG.

$33 \mathrm{Vgl}$. auch D. Grimm (Fn. 29), \$ 1 Rn. 93f.

34 Vgl. P. Saladin (Fn. 4), 18.
} 
hinzu, besonders kraft des im Wettbewerbsrecht quasi universell anerkannten Auswirkungsprinzips. ${ }^{35}$ Udo Di Fabio spricht vom „Übergang vom territorial abgeschlossenen zum nur territorial radizierten Staat," ${ }^{\text {"36 }}$ an anderer Stelle sogar vom „Verlust der territorialen Radizierung des Staates." ${ }^{37}$

Am spürbarsten ist der Wandel innerhalb der Europäischen Union. Dort sind die Staatsgrenzen nicht mehr physisch erfahrbar. Weggefallen sind die Grenzposten, erst recht bewaffnete Grenzwächter und Zollbeamte. Die Grenzen innerhalb der Europäischen Union behalten lediglich - begrenzte - Bedeutung für die Frage, welches Recht anwendbar und wer durchsetzungsbefugt ist. ${ }^{38}$ Nach der Konzeption des Art. 23 GG ist der Staat nicht mehr Gebietsherr, sondern Wächter darüber, dass supranationale Aufgabenerfüllung in Übereinstimmung mit dem Demokratie-, Rechtsstaats-, Sozialstaats- und Bundesstaatsprinzip erfolgt. ${ }^{39} \mathrm{Ge}-$ rade in Art. 23 GG kommt die Aufgabe der Gebietsbezogenheit der Staatsgewalt klar zum Ausdruck.

Als abgegrenzter und ausschließlicher Geltungsbereich einer bestimmten Herrschafisordnung gehört das Staatsgebiet somit der Vergangenheit an. ${ }^{40}$

\section{Staatsgewalt}

\section{a) Einheit der Staatsgewalt}

Die Staatsgewalt soll einheitlich sein. ${ }^{41}$ „Rechtliche Einheit der Staatsgewalt bedeutet, daß es im Staatsgebiet keine hoheitlichen Regelungsbe-

\footnotetext{
${ }^{35}$ Vgl. M. Herdegen Internationales Wirtschaftsrecht, 3. Aufl. 2002, $35 \mathrm{ff}$.

${ }^{36}$ In Bezug auf Europa U. Di Fabio (Fn. 3), 5.

${ }_{37}$ U. Di Fabio (Fn. 3), 97 ff. P. Saladin (Fn. 4), 25 interpretiert diese Entwicklung so:
} „Das einzelne Staatsgebiet verliert solchermaßen immer mehr seine Bedeutung als geographischer ,Wirkungsplatz; an seine Stelle tritt zunächst das Gebiet einer internationalen oder supranationalen Gemeinschaft ..., später vielleicht - und hoffentlich, letztlich notwendig - das Gebiet der gesamten Erdoberfläche .....

${ }^{38}$ U. Di Fabio Der Verfassungsstaat in der Weltgesellschaft, 2001, 69.

${ }^{39} \mathrm{~S}$. auch $S$. Hobe Der offene Verfassungsstaat zwischen Souveränität und Interdependenz, Eine Studie zur Wandlung des Staatsbegriffs der deutschsprachigen Staatslehre im Kontext internationaler und institutionalisierter Kooperation, 1998, 164.

${ }^{40}$ Immerhin bleibt das Staatsgebiet vornehmlich außerhalb der Europäischen Union wichtig im Zusammenhang mit den Staatsaufgaben Wohlfahrt und Daseinsvorsorge, d.h. für das Aufenthaltsrecht von Personen. Die Nationalstaaten sind weiterhin befugt, Fremde auf ihrem Territorium zuzulassen oder nicht. Menschenrechte, Ausweisungsschutz und refoulement-Prinzip ziehen hier nur minimale völkerrechtliche Schranken.

${ }^{41}$ Vgl. z.B. D. Grimm (Fn. 29), Rn. 87. 
fugnisse gibt, die der Staatsgewalt gegenüber eigenständig wären." 42 „Kein Staat [kann] aus der einheitlichen und inhaltlich weder erschöpfend beschreibbaren noch aufspaltbaren Potenz seiner Staatsgewalt Teilbereiche mit absoluter Wirkung entlassen“.43 Er könne anderen hoheitlichen Einheiten die Ausübung öffentlicher Gewalt auf einem sachlichen Teilbereich seiner Staatssphäre lediglich gestatten. ${ }^{44}$ „Gäbe es im Staatsgebiet eigenständige hoheitliche Kompetenzen,“ so Zippelius, „über die kein Staatsorgan verfügen könnte, so würde der Staatsgewalt ex definitione die Kompetenzhoheit und damit die Souveränität fehlen." ${ }^{\text {"45 }}$

Besonders intensive Einbrüche in die Einheit der Staatsgewalt ergeben sich aufgrund des unmittelbar anwendbaren Gemeinschaftsrechts, selbst wenn man die Hoheitsgewalt der EG als abgeleitet versteht. ${ }^{46}$ Denn der unmittelbare, die Einheit der Staatsgewalt negierende Durchgriff des europäischen Gemeinschaftsrechts prägt den Alltag, die Nichtanwendung kompetenzwidrigen europäischen Gemeinschaftsrechts durch deutsche Behörden ist theoretischer Ausnahmefall. Gleiches gilt für das Szenario eines Austritts aus der EU, auch wenn der EU-Verfassungsvertrag den Austritt neuerdings explizit vorsieht. ${ }^{47}$

Das Gemeinschaftsrecht führt zu einer vielfältigen Verklammerung und Verbindung aller Staats- und Gemeinschaftsorgane. ${ }^{48}$ Mitgliedstaat-

42 R. Zippelius Allgemeine Staatslehre, 14. Aufl. 2003, 63.

43 F. Erler Das Grundgesetz und die öffentliche Gewalt internationaler Staatengemeinschaften, VVDStRL 18 (1960), 7, 19.

${ }^{4}$ F. Erler (Fn. 43), 19 f.

45 R. Zippelius (Fn. 42), 63.

$46 \mathrm{Vgl}$. auch R. Zippelius (Fn. 42), $67 \mathrm{ff}$. Wegen des aus autonomer Quelle fließenden, unmittelbar anwendbaren Gemeinschaftsrechts besteht entgegen C. Möllers (Fn. 7), $253 \mathrm{f}$. auch dann keine Einheit der Staatsgewalt, wenn man mit Kelsen Rechtsgeltung und Staatlichkeit gleichsetzt.

${ }^{47}$ Art. I-59 EU-Verfassungsvertrag, Entwurf i.d.F. von Thessaloniki, EuGRZ 2003, 357, 368. Zum bislang strittigen Fall eines EU-Austritts, BVerfGE 89, 155, 190 (Maastricht). Schärfstens gegen die Austrittsmöglichkeit aus der Gemeinschaft, die entgegen der nachfolgenden Entwicklung in Art. I-59 Verfassungsvertrag ein ,fundamentaler Bruch des Gemeinschaftsverfassungsrechts" sein soll, J. Frowein Kritische Bemerkungen zur Lage des deutschen Staatsrechts aus rechtsvergleichender Sicht, DÖV 1998, 806, 807. Das neue Austrittsrecht könnte als Reverenz an den klassischen Souveränitätsbegriff verstanden werden, erscheint aber wegen der einschneidenden tatsächlichen (vor allem wirtschaftlichen) Verflechtungen als Lippenbekenntnis. Allerdings könnte das Austrittrecht tatsächliche Bedeutung in einer erweiterten und durch verstärkten Rückgriff auf die Integration ,à géométrie variable“ veränderten Gemeinschaft erlangen.

48 D. Thürer (Fn. 21), 126; vgl. auch E. Schmidt-Aßmann Die Europäisierung des Verwaltungsverfahrensrechts, in: ders.u.a. (Hrsg.) Festgabe 50 Jahre Bundesverwaltungsgericht, 2003, 487, 504ff. 
liche Gerichte sind auch Gemeinschaftsgerichte. ${ }^{49}$ Das Staatsrecht der Mitgliedstaaten und das europäische Gemeinschaftsrecht bilden eine Einheit.

Weiter negiert der Durchgriff der Einzelnen durch ihren Staat, wenn sie sich an internationale Menschenrechtsgremien wenden, die Einheit der Staatsgewalt. Menschenrechtsschutzeinrichtungen mit ihrer staatskontrollierenden Funktion sind eine unabhängige, zusätzliche Gewalt mit beinahe supranationaler Kraft. ${ }^{50}$ Umgekehrt greift die internationale Strafgerichtsbarkeit unmittelbar auf die einzelnen zu.

Ulrich Scheuner interpretierte eine derartige offene Staatlichkeit ${ }^{51} 1964$ als Schwinden des alten Staatsbegriffs. ${ }^{52}$

\section{b) Souveränität}

Die Souveränität wird vielfach als Eigenschaft der Staatsgewalt erachtet. ${ }^{53}$ Was aber bedeutet der schillernde Begriff der "Souveränität"?

Nach Jean Bodin, Six livres de la république, bedeutet „Souveränität ... die absolute und ewige Gewalt einer Republik", 54 die das Volk dem Mo-

49 Vgl. I. Pernice Europäisches und nationales Verfassungsrecht, VVDStRL 60 (2001), 148, 172 u. 177 mwN; D. Grimm (Fn. 29), \$1 Rn. 97f.; G. Schuppert(Fn. 5), 81. Schuppert bezieht sich dabei auf Zürn. S. auch J. Isensee Gemeinnützigkeit und Europäisches Gemeinschaftsrecht, Veröffentlichungen der Deutschen Steuerjuristischen Gesellschaft e.V., Bd. 26 (2003), 93, 94 unter Berufung auf Richardi.

${ }^{50}$ F. Ermacora Die vierte Gewalt: Eine regional-supranationale Gewalt zum Schutze der Menschenrechte, FS Leibholz, Bd. 1, 1966, 673, 689f.; C. Grabenwarther Europäisches und nationales Verfassungsrecht, VVDStRL 60 (2001), 290, 344f.; S. Hobe (Fn. 39), 438f.; F. Hoffmeister Die Europäische Menschenrechtskonvention als Grundrechtsverfassung der Bürger, Der Staat 2001, 349.

51 Vgl. S. Hobe (Fn. 39); s. auch F. Erler (Fn. 43), 7f., der die „Grundfesten der Staatsrechtslehre" bereits 1964 bedroht sah.

52 U. Scheuner Diskussionsbeitrag zum Thema Bewahrung und Veränderung demokratischer und rechtsstaatlicher Verfassungsstruktur in den internationalen Gemeinschaften, VVDStRL 23 (1966), 106, 109. S. auch M. Stolleis Staatsrechtslehre und Politik, 1996, 20f.: „Dahinschwinden des Objekts“; P. Kirchhof(Fn. 8), 639: „Es gehört zur Geschichte des Staates, daß er totgesagt ... wird.“

${ }_{53}$ Vgl. M. Herdegen Völkerrecht, 2. Aufl. 2002, 199; A. Randelzhofer Staatsgewalt und Souveränität, in: Isensee/Kirchhof (Fn. 29), § 15 Rn. 3 f.; s. auch Art. 2 Ziff. 1 Charta der Vereinten Nationen. G. Jellinek Staatslehre (Fn. 11), $486 \mathrm{ff}$. trennte zwischen Staatsgewalt und Souveränität, dagegen $S$. Hobe (Fn. 39), 426 ff. Ein moderner Souveränitätsbegriff findet sich bei I. Pernice (Fn. 49), 162 und 190 (LS 7): „Souveränität ist nicht mehr die (monarchische) Voll-Macht des Staates oder die Urgewalt eines Mythos Volk, sondern bedeutet heute Selbstbestimmung des einzelnen als Element der Menschenwürde“.

54 J. Bodin Les six livres de la République I, chapitre VIII, (Corpus des oeuvres de philosophie en langue française) 179: „La souveraineté est la puissance absolue et perpetuelle d'une République". 
narchen übertragen hat. ${ }^{55}$ Wesentlich ist der Grundsatz, dass der Fürst weder an seine eigenen Gesetze noch an die seiner Vorgänger gebunden ist. ${ }^{56}$ Bodins Souveränität ist dennoch rechtlich gebunden, nämlich an $\mathrm{Na}-$ turrecht und Völkerrecht; 57 auch muss der Fürst von ihm geschlossene Verträge einhalten und darf Gesetze nicht willkürlich derogieren. ${ }^{58}$ In diesem nüchternen Sinne einer allgemeinen Geltung der lex posterior Regel bei Beachtung des Natur- und Völkerrechts ${ }^{59}$ ließe sich der Fortbestand der Souveränität auch heute noch bejahen. ${ }^{60}$ Doch nahm die Entwicklung des Souveränitätsbegriffs eine andere Richtung.

Im Völkerrecht könnte Souveränität verstanden werden als Handlungsfreiheit der Staaten, die nur durch freiwillig von den Staaten selbst eingegangene Verpflichtungen begrenzt wäre. ${ }^{61}$ Dies entspricht jedoch nicht dem gegenwärtigen Entwicklungsstand des Völkerrechts. ${ }^{62}$ Unbe-

55 J. Bodin (Fn. 54), 185f.: „... il est bien certain que celuy-là est souverain: car le peuple s'est dessaisi et despouillé de sa puissance souveraine, pour l'ensaisiner et investir: et à luy, et en luy transporté tout son pouvoir, auctorisés, prerogatives, et souveraineté ....".

56 J. Bodin (Fn. 54), 192.

57 J. Bodin (Fn. 54), 192ff.: „Mais quand aux lois divines et naturelles, tous les princes de la terre y sont subjects, et n'est pas en leur puissance d'y contrevenir, ... Et par ainsi la puissance absolue des Princes et seigneuries souveraines, ne s'entend aucunement aux lois de Dieu et de nature ... “. Missverständlich daher G. Roellecke Souveränität, Staatssouveränität, Volkssouveränität FS Quaritsch, 2000, 15, 19, wonach Bodin die ,radikale Positivität des Rechtes" ermöglicht habe.

58 J. Bodin (Fn. 54), 194: „Et par ainsi nostre maxime demeure, que le Prince n'est point subject à ses loix, ni aux loix de ses predecesseurs, mais bien à ses conventions justes et raisonables, et en l'observation desquelles les subjects en general ou en particuliers ont interest."

59 Die Völker- (und Naturrechts-)unmittelbarkeit als weiteres Souveränitätsmerkmal Bodins klingt an, wenn Bodin schreibt, das erste Souveränitätsmerkmal sei die Fähigkeit, allgemeine Gesetze zu machen, und zwar „sans le consentement de plus grand, ni de pareil, ni de moindre“, J. Bodin (Fn. 54), 306.

${ }^{60} \mathrm{Zu}$ Rolle des Naturrechts in neuerer Zeit vgl. W. Maihofer Naturrecht oder Rechtspositivismus, $1962 ;$ J. Kokott Naturrecht und Positivismus im Völkerrecht - sind wir auf dem Wege zu einer Weltverfassung?, in: Meier-Schatz/Schweizer (Hrsg.) Recht und Internationalisierung, 2000, 3; zum freiheitsschützenden Ursprung und zur freiheitsschützenden Funktion der Naturrechtsdoktrin H. Lauterpacht International Law and Human Rights, 1950, $108 \mathrm{ff}$.

$61 \mathrm{Vgl}$. N. Politis Les Nouvelles Tendances du Droit International, 1927, 18f.: „... pouvoir absolu et incontrôlable des États de se comporter, dans les relations extérieures, comme dans les affaires domestiques, selon leur bon plaisir, sans autres restrictions que celles qu'ils auraient volontairement acceptées."

$62 \mathrm{Vgl}$. J. Kokott Grund- und Menschenrechte als Inhalt eines internationalen ordre public, in: Coester-Waltjen/Kronke/Kokott (Hrsg.) Berichte der Deutschen Gesellschaft für Völkerrecht, Bd. 38, 1998, 71; dies. (Fn. 60), 3; jeweils mwN. 
stritten impliziert Souveränität heute noch Völkerrechtsunmittelbarkeit und volle Völkerrechtssubjektivität, ${ }^{63}$ Eigenschaften, die aber ohnehin jedem Staat im völkerrechtlichen Sinne zukommen. „Souveränität" wird regelmäßig in Anspruch genommen als Abwehrrecht gegen andere Souveränitätsprätendenten und als Recht zur Durchsetzung von Ansprüchen. ${ }^{64}$ Der Souveränitätsbegriff erfüllt im Wesentlichen rhetorische Funktionen. 65 Entsprechend kennt „die Wissenschaft vom öffentlichen Recht ... kaum eine vielschichtigere und umstrittenere Frage als die nach der Souveränität." 66

Im Staatsrecht soll Souveränität Kompetenz zur Letztentscheidung sowie die (verloren gegangene) Einheit, „Einzigkeit" der Staatsgewalt bedeuten. Wegen seiner charakteristischen Unbestimmtheit und wegen Missbrauchsgefahr haben Staats-, Völker- und Europarechtler schon früh und immer wieder die Aufgabe des Souveränitätsbegriffs gefordert. Der Staatsrechtler Hugo Preuss mag 1889 der erste gewesen sein, der die These vertrat, dass die Staatsrechtslehre „im Gespinnst des Souveränitätsbegriffs" verfangen sei, ,wie die Fliege im Gewebe der Spinne". ${ }^{67}$ Die „wahrhaft erdrückende Fülle höchst unterschiedlicher Definitionen des Souveränitätsbegriffs" gehe hervor „aus dem schier verzweifelten Streben, einem in der Wirklichkeit todten Begriffs ein künstliches Scheinleben einzuhauchen ... Jener Definitionenreichthum giebt einen deutlichen Fingerzeig zur Beseitigung nicht nur des Namens, sondern auch des Wesens der Souveränität."68 Hugo Preuss forderte die Eliminierung des Souveränitätsbegriffs aus der Dogmatik des Staatsrechts ${ }^{69}$ und seine Ersetzung durch den Begriff des Rechtsstaats. ${ }^{70}$

${ }^{63}$ Zum völkerrechtlichen Souveränitätsbegriff z.B. M. Koskenniemi (Fn. 12), 206ff.; S. Oeter Souveränität - ein überholtes Konzept?, FS Steinberger, 2002, 259, $275 \mathrm{ff}$.

${ }^{64}$ K. Doehring, Allgemeine Staatslehre, 2. Aufl. 2000, Rn. 258.

65 Ähnlich M. Koskenniemi (Fn. 9), 169.

${ }^{66}$ M. Baldus Zur Relevanz des Souveränitätsproblems für die Wissenschaft vom öffentlichen Recht, Der Staat 1997, 381.

${ }^{67}$ H. Preuss (Fn. 9), VI.

68 H. Preuss (Fn. 9), 101 mit einer „kleinen Blüthenlese von Souveränitätsdefinitionen“ zur Bestätigung.

69 H. Preuss (Fn. 9), 135.

70 H. Preuss (Fn. 9), 136 mit einer Herleitung des Begriffs der „souveraineté" aus obrigkeitsstaatlichem Denken auf $100 \mathrm{ff}$. (z.B. 115). S. auch $M$. Baldus (Fn. 66), 383. Nach von Bogdandy tritt der Begriff Identität an die Stelle von Souveränität, A. v. Bogdandy Europäische und nationale Identität: Integration durch Verfassungsrecht?, VVDStRL 62 (2003), 156, 190, LS 8 und 9. 
Der Völkerrechtler Nicolas Politis betrachtete bereits 1927 die Souveränität als unzulässiges, weil sinnloses und gefährliches Dogma, welches die internationale Anarchie begünstige..$^{71}$

In neuerer Zeit hat Dieter Grimm plastisch auf die "Doppelbedrohung“ staatlicher Souveränität hingewiesen: „Sowohl die externen Grenzen der Staatsgewalt, die mit den Landesgrenzen identisch waren, als auch die internen, die durch die Differenz zur Gesellschaft markiert wurden, [werden] durchlässig, und der für die neuzeitliche Staatsbildung zentrale Begriff der Souveränität verliert seine tatsächlichen Voraussetzungen ".72

Der Auffassung vom Zerfall der Souveränität ${ }^{73}$ skeptisch gegenüber steht Isensee. Unter Berufung auf Hegel und Rousseau hält er entgegen, die Staaten gäben durch inter- und supranationale Integration „die Souveränität als solche ... nicht preis“. Isensee ruft - ohne nähere Betrachtung der Charta der Vereinten Nationen - einen Weltstaat vor unser geistiges Auge, um diesen sodann, ebenso wie einen „Europastaat“, vehement abzulehnen. Konzeptionelle Alternative, auch im Rahmen der Europäischen Union, scheint die Bewahrung der Nationalstaaten zu sein. Die von Isensee ins Feld geführte und, wie er betont, mit neuen Dimensionen der Machtausübung verbundene, "gesteigerte Effizienz" ${ }^{\text {"74 }}$ der Nationalstaaten besteht jedoch zur gesamten Hand der Mitgliedstaaten. Zudem ist Souveränität kein nur abstrakter, philosophischer Begriff. Die politische Wirklichkeit, die dem klassischen Souveränitätsbegriff seine Maßgeblichkeit verlieh, gibt es nicht mehr. Evident ist daher, „dass die herkömmlichen konzeptionellen Instrumentarien der Beschreibung von Staaten

${ }^{71}$ N. Politis (Fn. 61), 23 f.; dazu M. Baldus (Fn. 66), 386.

Hans-Peter Ipsen stellte 1984 fest, dass der Begriff der Souveränität selbst verunsichere, wenn er nicht unhaltbar geworden sei, H.-P. Ipsen Europäisches Gemeinschaftsrecht in Einzelstudien, 1984, 100.

72 D. Grimm Vorwort, in: ders. (Hrsg.) Staatsaufgaben, 1994, 9. S. auch P. Saladin (Fn. 4), 32: „... äußere und innere Entsouveränisierung des Staates."

73 Vgl. z. B. H. Boldt Staat und Souveränität, in: Brunner (Hrsg.) Geschichtliche Grundbegriffe, historisches Lexikon zur politisch-sozialen Sprache in Deutschland, Bd. 6 (1990), 1, 152f.; J. Camilleri/J. Falk The End of Sovereignty, 1992, 256; E. Denninger Vom Ende nationalstaatlicher Souveränität in Europa, JZ 2000, 1121; L. Henkin (Fn. 9); H. Maurer(Fn. 14), 4; N. MacCormick(Fn. 11), 133; G. Roellecke(Fn. 57), 15; C. Schreuer The Waning of the Sovereign State: Towards a New Paradigm for International Law, EJIL 1993, 447; A.-M. Slaughter (Fn. 9), 537; H. Steiger Geht das Zeitalter des souveränen Staates zu Ende?, Der Staat 2002, 331.

74 J. Isensee Die vielen Staaten in der einen Welt - eine Apologie, ZSE 2003, 7; zur gewandelten Souveränitätsausübung im Wege der Mitarbeit in internationalen Organisationen vgl. auch A.-M. Slaughter (Fn. 9), $534 \mathrm{ff}$. („The Disaggregation of Sovereignty"). 
und ihrer Interaktion der Fortbildung bedürfen."75 Hermann Lübbe weist zutreffend darauf hin, dass das, was „Hegel seinerzeit in der ... Reichsverfassungsschrift zur Geltung brachte, ... inzwischen tiefe Vergangenheit" ist. ${ }^{76}$

Ich schließe mich dem Völkerrechtler Louis Henkin an, der als Präsident der amerikanischen Völkerrechtsgesellschaft eine klarere und dogmengeschichtlich weniger belastete Terminologie verlangte. ${ }^{77}$ Der Begriff der Souveränität passt nicht in die neue Struktur des konvergierenden Staats- und Völkerrechts.

\section{Abschied vom souveränen Staat}

Wegfall der Souveränität bedeutet, dass der einzelne Staat seine Ordnungsfunktion nur noch begrenzt wahrnehmen kann, ${ }^{78}$ aber Völker- und Europarecht treten als ergänzende Teilordnungen hinzu. ${ }^{79}$

Dualismus in Reinform, wie er von Triepel zur Hochzeit der Nationalstaaten entwickelt wurde, ist kaum noch anzutreffen. ${ }^{80} \mathrm{Im}$ Rahmen der an

75 H. Lübbe Geteilte Souveränität, Die Transformation des Staates in der europäischen Einigung, Information Philosophie, August 1994, 5, 12.

${ }^{76}$ H. Lübbe (Fn. 75), 12. S. auch G. Roellecke (Fn. 57), 22: „Der Realitätsbezug der Souveränität ist verblaßt.“

77 Vgl. L. Henkin (Fn. 9), Ziff. 5f.:,Surely, as applied to the modern secular state in relation to other secular states, it is not meaningful to speak of the state as sovereign. Sovereignty, I conclude, is not per se a normative conception in international law. There is a need for a clearer conception and a new vocabulary more accurate and with less ,baggage‘." Ähnlich schon H. Kelsen Das Problem der Souveränität und die Theorie des Völkerrechts, 1928, 320: „Die Souveränitätsvorstellung freilich muß radikal verdrängt werden. Diese Revolutionierung des Kulturbewußtseins tut vor allem not! “ Auch die neu definierte Souveränität der gegenwärtigen Präsidentin der amerikanischen Völkerrechtsgesellschaft, Anne Marie Slaughter, hat nichts mit dem herkömmlichen Souveränitätsbegriff zu tun: A.-M.Slaughter (Fn. 9), 537: „Sovereignty becomes the capacity to participate in an international regulatory process. The redefinition of sovereignty in a world of liberal states pushes this redefinition one step further, devolving it onto the component institutions of individual States and giving it substantive content with regard to the relationship between these institutions and individuals and groups in transnational society." AA jedoch $S$. Oeter (Fn. 63), 259.

${ }_{78} \mathrm{Vgl}$. S. Hobe(Fn. 39), 436. Nicht entgegen steht, dass die Staaten teilweise neue Aufgaben erwerben, so im Bereich der Daseinsvorsorge. A. Singer Nationalstaat und Souveränität, 1993, 174.

79 I. Pernice (Fn. 49), 148, $172 \mathrm{ff}$.

${ }^{80} \mathrm{Vgl}$. H. Triepel Völkerrecht und Landesrecht, Nachdruck von 1899, 1958; s. aber auch schon C. Schmitt Der Nomos der Erde im Völkerrecht des Jus Publicum Europaeum, 1950, 182: die dualistische Trennung von Völkerrecht und Staatsrecht nur als Fassa- 
Boden gewinnenden und auch in der Lehre vom Verfassungsverbund ${ }^{81}$ zum Ausdruck kommenden monistischen Sichtweise ${ }^{82}$ wird dem Staat ohnehin nicht die alleinige Letztverantwortung für das Wohl und Wehe seiner Bürger übertragen. Vielmehr gilt ganz selbstverständlich das Völkerrecht auch im Staate, so dass auch die Staatengemeinschaft Verantwortung trägt. 83

Hinsichtlich der Kompetenzverteilung zwischen den Staaten und den internationalen Organisationen evoziert Saladin gar das Bild eines Bundesstaates. ${ }^{84}$ Der Staat wird mehr und mehr zum Vollzieher supra- und international vorgegebener Normen. Solche internationalen Normen entstehen teils mit, teils ohne oder gar gegen den Willen betroffener Staaten. Das gilt für Völkergewohnheitsrecht, wenn der so gebundene Staat nicht „persistent objector“ war; 85 ius cogens führt ebenfalls zu einer Bindung des Staates jenseits des Konsensprinzips, vertraglich vorgesehene Mehrheitsentscheidungen erübrigen die staatliche Zustimmung im konkreten Fall. ${ }^{86}$

denangelegenheit. J. Kaiser Bewahrung und Veränderung demokratischer und rechtsstaatlicher Verfassungsstruktur in den internationalen Gemeinschaften, VVDStRL 23 (1966), 1, 15.

81 I. Pernice (Fn. 49), 148, $172 \mathrm{ff}$.

82 Gemeint ist Monismus mit Völkerrechtsprimat. Vgl. A. Verdross/B. Simma Universelles Völkerrecht, 1984, 53ff.; 1. Seidl-Hohenveldern/T. Stein Völkerrecht, 2000, 120 (Rn. 554f.). Oft wird lediglich von einer Annäherung der Theorien oder einem „gemäBigten Dualismus" gesprochen, vgl. z.B. O. Kimminich/S. Hobe Einführung in das Völkerrecht, 2000, 216. Die Verfassungs- und Gerichtspraxis der Staaten öffnet sich dem Völkerrecht jedoch zunehmend, so dass das innerstaatliche Recht mehr und mehr völkerrechtlich durchwirkt wird. Vgl. J. Kokott From Reception and Transplantation to Convergence of Constitutional Models in the Age of Globalization - with Special Reference to the German Basic Law, in: Starck (Hrsg.) Constitutionalism, Universalism and Democracy - a comparative analysis, 1999, 71, $129 \mathrm{ff}$. D.h. der Monismus mit Völkerrechtsprimat gewinnt, sowohl Dualismus - die Trennung von Völkerrecht und innerstaatlicher Rechtsordnung - als auch der überholte Monismus mit Staatsrechtsprimat verlieren. $\mathrm{Zu}$ einer Fortentwicklung des Monismus mit Völkerrechtsprimat $D$. Thürer Völkerrecht und Landesrecht, Thesen zu einer theoretischen Problemumschreibung, SZIER 1999, 217.

83 C. Vedder Diskussionsbeitrag zu den Berichten von Steinberger, Klein und Thürer zum Thema: Der Verfassungsstaat als Glied einer europäischen Gemeinschaft, VVDStRL 50 (1991), 183.

84 P. Saladin (Fn. 4), 238f;; ähnlich C. Schreuer (Fn. 73), 470.

${ }^{85}$ Zur eingeschränkten Bedeutung des Staatenkonsenses C. Tomuschat (Fn. 29), 50 sowie zum majoritären Element des Völkergewohnheitsrechts ebd. $325 \mathrm{ff}$.

${ }^{86}$ Anwendung des Mehrheitsprinzips z. B. bei Rechtsakten der Europäischen Gemeinschaften, im Rahmen des Weltwährungsfonds, bei Beschlüssen des Sicherheitsrates der Vereinten Nationen. 
Durch die Aufgabe der alleinigen Verantwortung für das geltende Recht wird die Souveränität nicht nur faktisch, sondern auch rechtlich beeinträchtigt.

Ein fundamentaler Wandel der Staatlichkeit in Europa, nämlich zum nicht mehr im früheren Sinne souveränen Staat, steht außer Zweifel. ${ }^{87}$ Dies war wesentliches ursprüngliches Ziel der Europäischen Einigung: Kriegsvermeidung durch Souveränitätsverlust. ${ }^{88}$ Bewusst wurden der Hohen Behörde nach dem Montanvertrag i.d.F. von 1958 ausdrücklich supranationale Befugnisse zuerkannt. Es hat keinen Sinn sich dieser Entwicklung entgegenzustellen. ${ }^{89}$ Der souveräne Staat ist kein Selbstzweck, ${ }^{90}$ wie extremer Nationalismus das vielleicht einmal annahm. Ebenso wenig sind Europäisierung und Internationalisierung Selbstzwecke.

Im Übrigen könnte und sollte auch eine europäische Verfassung oder ein europäischer Verfassungsvertrag die den Nationalstaaten durch die Globalisierung verloren gegangene Einheitlichkeit nicht wiederherstellen. ${ }^{91}$

Die Entsouveränisierung hat allerdings nur einen Funktionswandel des Staates, nicht dessen Untergang zur Folge..$^{92}$ Der ehemals souveräne Nationalstaat wird zum rechtlich und faktisch gebundenen Staat innerhalb

${ }^{87}$ Ebenso z.B. E. Denninger (Fn. 73), 1126. S. auch D. Thürer (Fn. 21), 123; P. Saladin (Fn. 4), 217. Ähnlich, aber aufgrund der parallelen innerstaatlichen Strukturveränderungen wies Ernst Forsthoff 1971 auf „den kontinuierlichen Abbau aller auf souveräne Eigenständigkeit hindeutenden Strukturen" hin. E. Forsthoff(Fn. 2), 165.

${ }^{88}$ Zur Friedensfunktion der Souveränitätsaufgabe in Westeuropa auch N. MacCormick (Fn. 11), 133.

89 Vgl. auch $M$. Nettesheim Das kommunitäre Völkerrecht, JZ 2002, 569, 578.

90 D. Grimm Braucht Europa eine Verfassung?, 1994, 47; s. aber G. W. F. Hegel Grundlinien der Philosophie des Rechts oder Naturrecht und Staatswissenschaft im Grundrisse, 1833, Akademie-Verlag-Berlin 1981, 284: Staat als „Gang Gottes in der Welt" und 313: „Man muß daher den Staat wie ein Irdisch-Göttliches verehren“. U. Haltern Völkerrecht und Liebe, in: Elm (Hrsg.) Politik und Kulturen im Globalisierungsprozess. Eine interdisziplinäre Zusammenführung, 1, 24 unter XX. (2003, im Erscheinen), wonach „das Politische den Bereich letzter Werte und letzter Bedeutungen betrifft", wobei politische Bedeutungen „keine moralischen Bedeutungen [sind]. Sie sind ihre eigenen letzten Werte." Ders. Gestalt und Finalität, in: v. Bogdandy (Hrsg.) Europäisches Verfassungsrecht, 2003, 803, 845 - auch zur Finalitätsdiskussion der EU, auf die hier nicht näher eingegangen werden kann.

91 Ähnlich D. Grimm (Fn. 29), Rn. 101; N. MacCormick (Fn. 11), 191f.; C. Walter Die Folgen der Globalisierung für die europäische Verfassungsdiskussion, DVB1 2000, 1.

$92 \mathrm{Vgl}$. J. A. Camilleri/J. Falk (Fn. 73), 256: „Though the state will continue to perform important administrative and other functions, the theory of sovereignty will seem strangely out of place ...". 
eines Systems multipler Rechtssetzung und Herrschaftsgewalt..$^{93}$ Souveränität ist also weder notwendiges, noch ein unter allen Umständen wünschenswertes Kriterium der Staatsgewalt. ${ }^{94}$

\section{Erfiillung der Staatsaufgaben im offenen Verfassungsstaat}

Staatsaufgaben lassen sich aus dem „Wesen“ des Staates und aus der Verfassung ableiten. Letztlich müssen sie zurückführbar sein auf die Bedürfnisse der Einzelnen, für die Staat und Recht bestehen. Herkömmlicherweise gehören zu den wesentlichen Staatsaufgaben ${ }^{95}$ : (1.) die Garantie von Freiheit und Sicherheit, (2.) die politische Definition des Gemeinwohls, (3.) Daseinsvorsorge und die Schaffung von Wohlfahrt, (4.) die Identitäts- und Integrationsfunktion und schließlich (5.) die Wahrung des Völkerrechts. ${ }^{96}$ Die genannten Staatsaufgaben werden heute weder autonom von den einzelnen Staaten definiert und ausgestaltet, diese müssen sich an die völker- und europarechtlichen Vorgaben halten, noch können die einzelnen Staaten die genannten Staatsaufgaben effektiv erfüllen.

\section{Garantie von Freiheit und Sicherheit}

Freiheit und Sicherheit nach innen und außen vermag der einzelne europäische Staat nur noch begrenzt zu garantieren. Man vergegenwärtige sich einmal die Diskrepanz zwischen dem bei Formulieren des Art. 87a Abs. 2 GG im Jahre 1968 noch vor Augen stehenden Konzept der Landesverteidigung ${ }^{97}$ und der realen Machtlosigkeit der Bundeswehr im Falle der Landesverteidigung. Sowohl äußere Bedrohungen als auch der

${ }_{93}$ C. Walter (Fn. 91), 12. Mit G. Jellinek Staatslehre (Fn. 11), 486ff., wird also hier von der Trennbarkeit des Staatsmerkmals Staatsgewalt und der Souveränität ausgegangen.

${ }^{94}$ Ebenso N. MacCormick (Fn. 11), 129.

95 Gemeint sind Aufgaben, die heute existierende, konkrete Staaten zu bewältigen haben. Auf alle Staatsaufgaben und die Intensität ihrer Dringlichkeit im Rahmen verschiedener Ansätze der politischen Philosophie kann hier nicht eingegangen werden. Zu den Staatsaufgaben vgl. C. Link Staatszwecke im Verfassungsstaat - nach 40 Jahren Grundgesetz, VVDStRL 48 (1989), 7, 51 ff. LS 5ff.; G. Ress Staatszwecke im Verfassungsstaat nach 40 Jahren Grundgesetz, ebd., 56, $114 \mathrm{ff}$. LS $13 \mathrm{ff}$.

96 Zur Staatszwecklehre H.-C. Link und G. Ress (Fn. 95), 7 und 56; zur nach Auffassung von Ress 1990 noch geringen Rolle des Völkerrechts, 113f., LS 7.

97 Vgl. M. Baldus in: v. Mangoldt/Klein/Starck (Hrsg.) Bonner Grundgesetz, Bd. 3, 4. Aufl. 2001, Rn. 37 zu Art. 87a Abs. 2. 
Kampf gegen im Staat operierende, international organisierte Terroristen erfordert internationale Zusammenarbeit.

Nur der Nationalstaat soll zwar nach teils vertretener Auffassung Opfer und Solidarität, etwa den persönlichen Einsatz im Krieg zur Verteidigung des Vaterlandes, verlangen können. ${ }^{98}$ Wenn aber der Nationalstaat zur Schutzgewährung nicht in der Lage ist, leidet konsequenterweise diese Einsatzbereitschaft.

\section{Definition des Gemeinwohls}

Einen eigenständigen Rahmen für die Bestimmung des Gemeinwohls setzt auch das Völkerrecht, ${ }^{99}$ jedenfalls seit Anerkennung zwingender Normen. Innerhalb dieses Rahmens bleibt den einzelnen Staaten aber Konkretisierungsspielraum. Teils sehen Kollegen sogar das Bedürfnis nach Stärkung der Staatsmacht, damit eine wirkungsvolle Selbstbestimmung trotz Globalisierung möglich sei. Der Staat sichere eine politische Definition des Gemeinwohls und damit den Primat des Politischen über Wirtschaft ${ }^{100}$ und Kultur.

Das Postulat einer Stärkung des Nationalstaates, um eine politische Bestimmung des Gemeinwohls zu ermöglichen, gilt, sofern die Grundannahme zutrifft, der Nationalstaat sei in der Politik beheimatet, während die Europäischen Gemeinschaften und die WTO von der Wirtschaft herkämen. ${ }^{101}$ Menschenrechte und Umweltschutz, nicht ausschließlich Handelsbeziehungen, sind aber Gegenstände supra- und internationaler Politikprozesse. Deshalb ist das Postulat: Stärkung des Nationalstaates zwecks politischer Bestimmung des Gemeinwohls nicht zwingend.

\footnotetext{
98 Vgl. K. Doehring Die Europäische Union aus der Sicht des Bürgers, ZeuS 2001, 395, 397f.; J. Isensee (Fn. 74), 24 und 30f. Zur "Einforderung letzter Opfer" durch den Staat s. auch U. Haltern Der europarechtliche Begriff des Politischen, Manuskript der Habilitationsschrift 2003, 73 (2. Kapitel, D, I. Souveränität, bei und um Fußnote 95); ders. Völkerrecht und Liebe (Fn. 90), unter VIII. und XIV.

$99 \mathrm{Vgl}$. z. B. B. Fassbender Der Schutz der Menschenrechte als zentraler Inhalt des völkerrechtlichen Gemeinwohls, EuGRZ 2003, 1.

100 U. Di Fabio (Fn. 38), 20.

101 P. Dagtoglou Diskussionsbeitrag zum Thema Bewahrung und Veränderung demokratischer und rechtsstaatlicher Verfassungsstruktur in den internationalen Gemeinschaften, VVDStRL 23 (1966), 126f.; F. Erler(Fn. 43), 18: Erler sprach 1959 „den so genannten supranationalen Gemeinschaften ... politische Eigenexistenz" ab. Sie seien echter politischer Grundentscheidung nicht fähig.
} 


\section{Daseinsvorsorge und die Schaffung von Wohlfahrt}

Angesichts der Aufgabe der Währungshoheit im Rahmen der Europäischen Union, der Verflechtung der Wirtschaften in der EU und unter dem Regime der Welthandelsorganisation/WTO mindert sich die Fähigkeit des Staates zur Daseinsvorsorge und Schaffung von Wohlfahrt. Bei Entwicklungs- und Schwellenländern kommt vielfach die Gestaltungskraft des Weltwährungsfonds im Wege von Auflagen hinzu.

Auch die Staatsaufgabe, die Wohlfahrt der Bürger zu gewährleisten, ist also teilweise internationalisiert, d.h. sie kann von den meisten Staaten nur in Zusammenarbeit mit anderen Staaten und im Rahmen internationaler Organisationen effektiv wahrgenommen werden.

\section{Identität, Integration}

Der Staat soll auch kulturell-soziale Heimstatt bieten. Er trägt so zur Identität des Einzelnen bei. ${ }^{102}$ Die Rechts- und Verfassungsordnung integriert darüber hinaus den Einzelnen in die Werteordnung des staatlichen Gemeinwesens. 103

Ebenso wenig wie die Staatsangehörigkeit jedoch primäre Loyalitätsbeziehung der Bürger und Einwohner eines Staatsgebiets sein dürfte, kommt dem Staat die primäre Funktion bei der Vermittlung von Identität zu. Besonders evident ist das Fehlen staatlicher Identifikations- und Integrationsfunktionen bei vielen künstlich geschaffenen afrikanischen Staaten. ${ }^{104}$ Doch auch im europäischen und amerikanischen Kontext gilt: „Die Bewohner territorialer Einheiten sind ... in vielfachen Loyalitätsbeziehungen, so etwa kirchlicher, dörflicher oder ethnischer Art, eingebunden. Multiple Zugehörigkeitsbindungen sind die Regel, was auch eine europäische neben einer nationalen Identität zuläßt. ${ }^{105}$ Umgekehrt ver-

102 Vgl. S. Hobe (Fn. 39), 405 ff.

103 P. Saladin (Fn. 4), $189 \mathrm{ff}$.

104 Vgl. R. Knieper Nationale Souveränität, Versuch über Ende und Anfang einer Weltordnung, 1991, 162.

105 Konkreter S. Hobe(Fn. 39), 408; I. Pernice(Fn. 49), 176ff. und 191, LS 16. AA Haltern: Nur im Nationalstaat, nicht in der Gemeinschaft, sei die für wichtig gehaltene „Sinnbefriedigung durch Transubstantation" möglich, in der Gemeinschaft bleibe der Mensch entwurzelter wesensmäßig Fremder. Vgl. U. Haltern Begriff des Politischen (Fn. 98), 474 (8. Kapitel, C V a.E.); ders. Pathos and Patina: The Failure and Promise of Constitutionalism in the European Imagination, EJIL 2003, 14, 18; ders. Völkerrecht und Liebe (Fn. 90), 17 unter XIV: „Der Staat, nicht die internationale Gemeinschaft, ist das erotische Liebesprojekt. Gerade die Abwesenheit einer erotischen Fundierung transnationaler Gemeinschaft erklärt das geringe Identitätspotential des Völkerrechts für den Bürger.“ 
mitteln auch substaatliche Regionen Bindung, Identität und Heimatgefühl“106 - der Staat als System von miteinander verwobenen Gemeinschaften. ${ }^{107}$ Auch ein im überkommenen Sinne nicht mehr souveräner Staat vermittelt immer noch Bindungen.

Weder vermag also der Nationalstaat fehlende Zugehörigkeit und Integration stets zuverlässig zu gewährleisten, noch ist der Einzelne ohne einen starken Nationalstaat notwendigerweise wurzellos, bindungslos und isoliert. Wie noch nie hat der Einzelne heute die Chance einer selbst bestimmten Identität, worunter Gemeinschaftswerte nicht leiden müssen. ${ }^{108}$

\section{Organ der Völkergemeinschaft}

Wenngleich „das große und kurze Zeitalter der territorial geschlossenen Verfassungsstaaten zu Ende" 109 ist, bleiben die offenen Nationalstaaten die entscheidenden Zurechnungspunkte des wichtiger werdenden Völkerrechts. ${ }^{110}$

Es geht jetzt im Wesentlichen darum, zu bestimmen, welche Aufgaben von ihrem Gehalt her auf substaatlicher, staatlicher oder supranationaler Ebene zu verrichten sind. Pernice spricht von einem „Mehrebenensystem öffentlicher Gewalt mit jeweils sachbezogenen begrenzten Kompetenzbereichen zur arbeitsteiligen Erfüllung der jeweils anvertrauten öffentlichen Aufgaben".111 Zweifelhaft ist dabei, ob es überhaupt noch Staatsaufgaben, die von ihrem Wesen her auf die nationale Ebene gehören, gibt..12

$\mathrm{Zu}$ einem ähnlichen romantisch-nationalen Ansatz bei Kaufmann vgl. M. Koskenniemi (Fn. 9), $252 \mathrm{ff}$.

106 Vgl. R. Knieper (Fn. 104), 162. Es bedarf allerdings einer besonderen Anstrengung der Theorie von der öffentlichen Gewalt, all diese Beziehungen unter den Gesichtspunkten demokratischer Teilhabe und Verantwortlichkeit (responsible government) zu verstehen und zu lenken. Vgl. J. A. Camilleri/J. Falk (Fn. 73), 25.

107 S. Hobe (Fn. 39), 407. S. auch J. A. Camilleri/J. Falk (Fn. 73), 251.

108 Vgl. T. Franck (Fn. 17), 382f.; s. auch das Plädoyer für doppelte Loyalitäten bei J. Weiler The State ,über alles“, Demos, Telos and the German Maastricht Decision, FS Everling, Bd. 2, 1995, 1651, $1687 \mathrm{f}$.

109 U. Di Fabio (Fn. 38), 50.

${ }^{110}$ U. Di Fabio (Fn. 38), 33; C, Tietje Die Staatsrechtslehre und die Veränderung ihres Gegenstandes: Konsequenzen von Europäisierung und Internationalisierung, DVBl 2003, 1081.

111 Vgl. I. Pernice in: Dreier (Hrsg.) Grundgesetz Kommentar, Bd. 2, 1998, Rn. 21 zu Art. 24; zum ursprünglich aus der Politikwissenschaft stammenden Konzept des Mehrebenensystems z.B. auch $R$. Wahl Verfassungsstaat, Europäisierung, Internationalisierung, 2003, $426 \mathrm{ff}$.

112 Das wäre nur der Fall, wenn es zwingende Grenzen der Übertragung von Hoheitsgewalt gäbe. Aber selbst staatliche Grundrechte können von supra- oder internationalen 
Supra- und internationalisierte Aufgaben verrichten die Staaten „zur gesamten Hand“ im Rahmen von internationalen Organisationen. Ohne fortbestehende und aktive Staaten können internationale Organisationen in ihrer gegenwärtigen Form gar nicht bestehen. Zudem fehlt es dem Völkerrecht an Vollzugsorganen. Nicht nur im europäischen Gemeinschaftsrecht, sondern auch im Völkerrecht gewinnt also die Vollzugsfunktion der Staaten ständig an Gewicht.

Die Erfüllung vieler Staatsaufgaben wird in Europa supra- und internationalisiert. ${ }^{113}$ Während insoweit der Einfluss einzelner Staaten schwindet, wird die Funktion des Staates als Mitgestalter und Vollzugsinstrument supra- und internationalen Rechts ständig wichtiger. $\mathrm{Ob}$ dies einen $\mathrm{Zu}$ wachs „... staatlicher Handlungsmittel bedeutet“,114 mag dahin stehen, jedenfalls handelt es sich um eine tief greifende Modifikation der Staatsaufgaben.

\section{Postnationale Demokratie?115}

Europäisierung und Internationalisierung mindern die Bedeutung der nationalen Parlamente. ${ }^{116}$ Diese Entparlamentarisierung erfolgt nicht nur zugunsten von Regierung und Ministerialbürokratie (Exekutive), sondern auch zugunsten nationaler und internationaler Gerichte. ${ }^{117}$ Europäisierung und Internationalisierung gefährden damit die parlamentarische Demokratie innerhalb der Nationalstaaten. In den Staaten und auf internationaler Ebene sind deshalb alle Möglichkeiten der Entschärfung der demokratischen Frage auszuschöpfen. Im folgenden konzentriere ich mich auf die internationale Ebene.

Wird es aber „den Ideen der Demokratie und des Rechtsstaats gelingen ..., das nationalstaatliche Gehäuse zu sprengen und sich in den nicht-

Grundrechten verdrängt werden. Vgl. P. Saladin (Fn. 4), 38ff.; S. Hobe (Fn. 39), 130; staatsspezifische Aufgaben ablehnend A. Peters Elemente einer Theorie der Verfassung Europas, 2001, 764.

113 Ähnlich R. Wahl Der Einzelne in der Welt jenseits des Staates, Der Staat 2001, 45; vgl. auch $P$. Kirchhof(Fn. 8), $646 \mathrm{ff}$.

114 So J. Isensee (Fn. 74), 7; ähnlich P. Kirchhof(Fn. 8), 649.

115 Zum Begriff „postnational“ I. Pernice (Fn. 49), 148, 154 ff. mit Nachweisen.

116 Vgl. auch H. Steinberger Der Verfassungsstaat als Glied einer europäischen Gemeinschaft, VVDStRL 50 (1991), 9, $39 \mathrm{ff}$.

${ }^{117}$ Dazu M. Jestaedt Verfassungsgerichtspositivismus, Die Ohnmacht des Verfassungsgesetzgebers im verfassungsgerichtlichen Jurisdiktionsstaat, FS Isensee, 2002, 183. 
staatlichen und nicht nationalen Erscheinungsformen öffentlicher Gewalt zu verwirklichen?"118

\section{Demokratiegebot}

Oder sind der Staat, Souveränität und Demokratie untrennbar verbunden, so dass der Abschied vom souveränen Staat auch eine Aufgabe der demokratischen Regierungsform implizieren würde? ${ }^{119}$ Dies wäre schon deshalb problematisch, weil Demokratie sich zur staats- und völkerrechtlich gebotenen Staatsform entwickelt. Moderne Verfassungstexte konvergieren, indem sie Grundrechte, Gewaltenteilung, Demokratie und Völkerrechtsfreundlichkeit vorsehen. ${ }^{120}$ Nach der modernen Völkerrechtslehre ist das Demokratiegebot (zumindest) eine Völkerrechtsnorm in statu nascendi. ${ }^{121}$

\section{Demokratiebegriff}

„Demokratie bedeutet staatliche Herrschaft durch das Volk."122 Paul Kirchhof präzisiert: „Wie jede Demokratie in einem vorgefundenen Staatsvolk ruht, so setzt das Entstehen und die Geltungskraft von Recht den Staat schon voraus." 123 Ist aber das amerikanische Staatsvolk in diesem Sinne „,vorgefunden“? 124 Und setzt die Geltung von Naturrecht, Gewohnheitsrecht, common law, notwendigerweise den Staat voraus?

Innerhalb des Nationalstaates ist Demokratie in erster Linie Herrschaft durch die Gesamtheit der Staatsbürger; im Grundsatz bedeutet Demo-

${ }^{118}$ P. Badura Mitbericht zum Thema Bewahrung und Veränderung demokratischer und rechtsstaatlicher Verfassungsstruktur in den internationalen Gemeinschaften, VVDStRL 23 (1966), 34, 38.

119 In diese Richtung wohl S. Oeter (Fn. 63), 259.

120 J. Kokott (Fn. 82), 71.

121 T. Franck The Emerging Right to Democratic Governance, AJIL 1992, 46; C. Tomuschat (Fn. 29), 67f.; M. HilfEin europäisches Grundrecht auf Demokratie?, FS Eitel, 2003, 745 .

122 J. Isensee Abschied der Demokratie vom Demos, Ausländerwahlrecht als Identitätsfrage für Volk, Demokratie und Verfassung, FS Mikat, 1989, 705.

123 P. Kirchhof(Fn. 10), 951.

124 Differenziert H. Steinberger (Fn. 116), 23: Volkssouveränität und Selbstbestimmung setzen ,nicht schlechthin voraus, daß die Einzelnen sich schon zuvor als Volk oder als Nation konstituiert haben müßten. Das Beispiel der amerikanischen Verfassungsgebung kann durchaus belegen, daß sich ein neuer selbständiger pouvoir constituant auch erst im Akt der Verfassungsgebung selbst begründen kann." 
kratie Herrschaft durch die Betroffenen. ${ }^{125}$ Das wird allerdings nur in Ausnahmefällen erheblich.

\section{Weltstaat, Europastaat}

Demokratie als Herrschaft durch die Staatsbürger aber kann nur in staatlichem Rahmen funktionieren. Ein staatsbürgerbezogenes Demokratieverständnis hilft folglich im Hinblick auf die Probleme der Europäisierung und Internationalisierung nur dann weiter, wenn man den Europaoder gar Weltstaat ${ }^{126}$ anstrebt. Ein „Europastaat ${ }^{\text {" } 127}$ wäre jedoch ebenfalls den Einflüssen und Wandlungen aufgrund der Globalisierung ausgesetzt, wie sie für die Staaten aufgezeigt wurden. „Wir stehen am Ende des neuzeitlichen Staatsparadigmas, und sollten die Europäische Integration nicht auf dieses so geradlinig scheinendes, aber wenig Zukunft verheißendes Gleis setzen." ${ }^{128}$ Also werde ich nicht auf den „Europastaat“ eingehen, sondern lediglich das Konzept eines Weltstaates streifen. Aber scheitert ein Konzept eines demokratischen Weltstaates nicht schon an der Größe?

Plato nahm an, dass bei 5040 Haushaltsvorständen die quantitative Grenze demokratischer Regierungsform liege; Sokrates ging davon aus, Demokratie sei durch die Reichweite der nicht künstlich verstärkten menschlichen Stimme territorial begrenzt. ${ }^{129}$ In Schweizer Landsgemeinden ist noch die direkte Demokratie lebendig. Wird derartiges Idyll ,inskünftig“ abgelöst durch eine virtuelle Demokratie mit Weltparlament, da immer mehr Fragen global zu lösen, die Bürger jedoch an der Entscheidungsfindung zu beteiligen sind? Wäre so ein demokratischer Weltstaat denkbar und wünschenswert?

125 BVerfGE 83, 37, 52: ,im Ausgangspunkt zutreffend“. Dagegen J. Isensee (Fn. 122), 729f. Ein Ausländerwahlrecht ergibt sich nicht notwendigerweise aus der Konzeption der Demokratie als Herrschaft der Betroffenen. Aber das wahlberechtigte Staatsvolk darf nicht willkürlich bestimmt werden.

${ }^{126}$ Dazu H. Steiger Brauchen wir eine Weltrepublik?, Zugleich Besprechung von Otfried Höffe Demokratie im Zeitalter der Globalisierung, Der Staat 2003, 249.

127 So die Terminologie von J. Isensee Integrationsziel Europastaat?, FS Everling, Bd. 1, $1995,567$.

128 U. Di Fabio (Fn. 38), 31; ähnlich schon H. Bülck Diskussionsbeitrag zum Thema Bewahrung und Veränderung demokratischer und rechtsstaatlicher Verfassungsstruktur in den internationalen Gemeinschaften, VVDStRL 23 (1966), 120.

129 Aristoteles Politik, Siebentes Buch, Viertes Kapitel, Übersetzung von E. Rolfes, 1981, $245 \mathrm{ff}$. Auch Isensee betont, dass die Demokratie idealerweise kleinräumig, innerhalb eines weitgehend autonomen Staatsgebildes zu verwirklichen ist. J. Isensee (Fn. 74), 17f. 
Leisner führt aus: „Der Entwicklungszug heutiger Demokratie geht nicht mehr zum ,großen Volk', zur einen unteilbaren Nation der französischen Revolution. Als deutliches Ziel erscheint immer mehr die kleine völkische Einheit, als Gemeinschaft selbst in großen Nationen lebendig in ihrer Autonomie ... In solchen Formen der Mikro-Demokratie findet heute die Volksherrschaft ihre Stärke, ihre tiefste Legitimation. "130 Lebendige Demokratie gedeiht besser in kleinen, überschaubaren Einheiten. ${ }^{131}$ Kleinere Einheiten fördern die „corporate identity“, die Europäische Union hat Mühe, den Eindruck der Bürgernähe zu vermitteln..$^{132}$

Circa zwei Jahrtausende ging man im Anschluss an die griechische Polis davon aus, Demokratie funktioniere am besten in kleinen Stadtstaaten; circa zwei Jahrhunderte herrscht nun das staatszentrierte Demokratieverständnis vor. Aber weder sind alle öffentlichen Aufgaben kleinräumig, noch auf Ebene des Nationalstaats erfüllbar. Von daher gibt es keine Idealgröße für politische Gemeinwesen. ${ }^{133}$ Das Selbstbestimmungs- und Demokratiegebot spricht für kleine politische Gemeinwesen, nicht zwingend für den Nationalstaat. Die Art der Aufgabe kann hingegen eine transnationale Regelung gebieten.

\section{Elemente postnationaler guter Herrschaft (,good governance") \\ a) Subsidiaritätsprinzip}

Die international anerkannten Prinzipien der Selbstbestimmung und Demokratie gebieten die Anwendung des Subsidiaritätsgrundsatzes auch auf internationaler Ebene. ${ }^{134}$ Nur die eine supranationale oder internationale Lösung wirklich erfordernden Probleme dürfen also supra- oder international geregelt werden. Das Subsidiaritätsprinzip steht demokratiefeindlicher, unnötiger Zentralisierung sowohl zugunsten supranationaler Organisationen als auch zugunsten des Nationalstaates entgegen. Es ist also eine Anpassung demokratischer Konzepte und Institutionen an die Gegebenheit erforderlich, dass unterschiedliche Probleme optimal durch Einheiten unterschiedlicher Größe gelöst werden können, substaatlich, staatlich, supra- oder international. ${ }^{135}$ Die meisten Staaten werden sich in

130 W. Leisner Der unsichtbare Staat, Machtabbau oder Machtverschleierung, 1994, 267.

131 Vgl. R. Dahl/E. Tufte Size and Democracy, 1973, 2 f.

132 K. Doehring (Fn. 98), 395; U. Haltern Pathos and Patina (Fn. 105), 18.

133 R. Dahl/E. Tufte (Fn. 131), 135; ähnlich A. Peters (Fn. 112), 779.

134 P. Carozza Subsidiarity as a Structural Principle of International Human Rights Law, AJIL 2003, 38.

135 R. Dahl/E. Tufte (Fn. 131), 135. 
beide Richtungen zu bewegen haben:136 Stärkung regionaler Untergliederungen einerseits und Übertragung von Hoheitsbefugnissen auf die Europäische Gemeinschaft und auf internationale Organisationen andererseits. Entsprechend geht die vertiefte europäische Integration in Italien und Frankreich gegenwärtig mit einer weitgehenden Dezentralisierung dieser Staaten einher. Insofern beinhaltet die Entsouveränisierung auch eine Chance für Bürgernähe, Volkssouveränität und Demokratie..137

\section{b) Demokratische Prinzipien}

Die Entwicklung dahingehend, dass wesentliche Entscheidungen auf universeller Ebene gefällt werden, ist nicht aufzuhalten. Darauf zu pochen, dass Demokratie notwendig den Staat voraussetze, kann in diesem Zusammenhang kontraproduktiv sein.

Staats- und Völkerrechtswissenschaft müssen sowohl an der richtigen Verteilung der Aufgaben auf die verschiedenen Ebenen ${ }^{138}$ als auch an der (möglichst) demokratischen Gestaltung supranationaler Entscheidungsprozesse arbeiten. ${ }^{139}$ Richtig führte Peter Badura bereits auf der Staatsrechtslehrertagung 1964 aus: „In dem Maße, wie die Ausübung öffentlicher Gewalt internationalisiert wird, nicht staatliche und nicht nationale Herrschaft an Raum gewinnt, internationalisiert sich auch die Verfassungsentwicklung und müssen die Ideen von Demokratie und Rechtsstaat ihren staatlichen und nationalen Entstehungsgrund überschreiten." 140

Demokratie jenseits des Staates wurde bislang in erster Linie hinsichtlich der Europäischen Gemeinschaften wissenschaftlich thematisiert. Die vorherrschende Auffassung kommt im Maastricht-Urteil zum Ausdruck: Die demokratische Legitimation der Europäischen Union erfolge zuvörderst „durch die Rückkoppelung ... an die Parlamente der Mitgliedstaaten"; hinzu tritt aber ,im Maße des Zusammenwachsens der europäischen Nationen zunehmend ... die Vermittlung demokratischer Legitimation durch das von den Bürgern der Mitgliedstaaten gewählte Europäische Parlament." "141

${ }_{136}$ R. Dahl/E. Tufte (Fn. 131), 136.

137 N. MacCormick (Fn. 11), 135.

138 Vgl. auch $S$. Hobe (Fn. 39), 448: „Tendenz zur aufgabenorientierten Erledigung auf der adäquaten Ebene“.

$139 \mathrm{Vgl}$. auch C. Tomuschat How the Classical Concept of Sovereignty has Evolved, FS Dimitrijevic, 2003, 21, 349.

140 P. Badura (Fn. 118), 34, 38.

141 BVerfGE 89, 155. 
Der parlamentszentrierte Ansatz ist im Rahmen der Europäischen Union wichtig. Im Rahmen der Internationalisierung ist er jedoch allenfalls beschränkt tauglich, da kein Weltstaat mit Weltparlament in Aussicht steht. ${ }^{142}$

\section{c) Kein internationaler Parlamentarismus}

Folglich „... muss man den zwar vertrauten, aber wenig erfolgversprechenden Weg der Parlamentszentriertheit verlassen" und einen Blick auf die maßgebenden „Entscheidungs- und Organisationsstrukturen werfen und sie auf die ihnen innewohnenden Legitimationspotentiale hin untersuchen; denn legitimationsvermittelnd wirken nicht nur Parlamentsakte, sondern z.B. auch Verfahren der öffentlichen Meinungsbildung, die durch Offenheits- und Transparenzregeln abgesichert werden ...".143 „Nur unter Inanspruchnahme aller Formen und Möglichkeiten demokratischer Legitimierung (nicht nur der parlamentarischen) kann unter den faktischen Gegebenheiten der Macht ... der demokratische Grundsatz optimal realisiert werden, dass alle öffentliche Gewalt, vom Volk' ausgeht". 144

\section{d) Optimierungsgebot, Transparenz, responsible government}

Dies führt zum Postulat von Peter Huber, wonach supra- und internationale Demokratie vor allem strukturadäquat sein muss. Das europarechtliche und das internationale Demokratiegebot enthält ein Optimierungsgebot, das auf Ausschöpfung der Partizipationsmöglichkeiten auf allen Ebenen zielt. ${ }^{145}$ Besondere Bedeutung kommt im Mehrebenensystem der Klarheit und Transparenz der Verantwortlichkeiten zu. Hinsichtlich der Verantwortlichkeiten darf es keine (vorgeschobenen) negativen Kompetenzkonflikte geben. Jede Ebene muss zu ihrer „ganze[n] harte[n]

\footnotetext{
142 Vielleicht war von manchen die Generalversammlung der Vereinten Nationen als eine solche Institution gedacht. S. auch C. Tomuschat (Fn. 29), 67: ,the world parliamentary body “. Die Generalversammlung ist jedoch demokratisch untauglich, da sie aus weisungsgebundenen Regierungsvertretern besteht und zumal noch nicht einmal alle dort vertretenen Staaten demokratisch sind.

143 G. Schuppert (Fn. 5), 72; vgl. auch D. Grimm Does Europe Need a Constitution?, European Law Journal 1995, 282, $293 \mathrm{ff}$.

144 J. Kaiser (Fn. 80), 33; s. auch P. Badura (Fn. 118), 34, 38.

145 P. Huber Demokratie ohne Volk oder Demokratie der Völker? - Zur Demokratiefähigkeit der Europäischen Union, in: Drexel u.a. (Hrsg.) Europäsche Demokratie, 1999, $29 \mathrm{ff}$., 55, zit. nach G. Schuppert (Fn. 5), 74.
} 
Verantwortung" stehen; wider die diffuse, unsichtbare Herrschaftsausübung, ins demokratische Licht der Öffentlichkeit. ${ }^{146}$

Subsidiaritäts- und Transparenzgebot sind je nach Konstellation durch direktdemokratische Entscheidungsverfahren und Klagemöglichkeiten der Einzelnen ${ }^{147} \mathrm{zu}$ ergänzen. ${ }^{148} \mathrm{Zu}$ beachten ist schließlich noch, dass Legitimation nicht ausschließlich verfahrensfokussiert zu betrachten ist ${ }^{149}$ (input-Legitimation); auch ein gutes, allgemein akzeptiertes Resultat, etwa expertengeleitete Normsetzung in Übereinstimmung mit allgemeinen Rechtsgrundsätzen [Modell der International Law Commission/ILC und des American Law Institute/ALI] ist legitim (output-Legitimation). Dies sind zumindest Ansätze zur Entschärfung des Demokratieproblems auf internationaler Ebene.

\section{Konvergenz von Staats- und Völkerrecht, ${ }^{150}$ Folgen für die Staatsrechtslehre}

Im Völkerrecht ist nicht mehr die Frage nach der Souveränität entscheidend, sondern die Frage, wem, in welchem Ausmaße und unter welchen Umständen (partielle) Völkerrechtssubjektivität zukommt. ${ }^{151}$ Das Völkerrecht nimmt mehr und mehr den Charakter eines Rechts an, welches nicht durch seinen zwischenstaatlichen Charakter, sondern dadurch gekennzeichnet ist, dass es unabhängig von seinen Quellen und seinen Adressaten auf staatsübergreifende Ordnung abzielt. ${ }^{152}$

\footnotetext{
146 W. Leisner (Fn. 130); B. Bauer Der völkerrechtliche Anspruch auf Demokratie, Zur Rolle internationaler Organisationen im weltweiten Demokratisierungsprozess, 1998, 261; E. Schmidt-ABmann Bericht über die Diskussion der Referate und die Podiumsdiskussion, in: Heyde/Schaber (Hrsg.) Demokratisches Regieren in Europa? Zur Legitimation einer europäischen Rechtsordnung, 2000, 65, 74.

147 Auf internationaler Ebene z.B. die Beschwerdemöglichkeiten der Einzelnen gegen umwelt- und menschenrechtsrelevante Weltbankprojekte vor dem ,inspection panel“.

148 G. Lübbe-WolffEuropäisches und nationales Verfassungsrecht, VVDStRL 60 (2001), 246, 289, LS 9.

$149 \mathrm{Vgl}$. auch H. Kelsen Vom Wesen und Wert der Demokratie, 2. Neudruck der 2. Aufl. 1929, 1981, 98; A. Jyränki Transferring Powers of a Nation-State to International Organisations: The Doctrine of Sovereignty Revisited, in: ders. (Hrsg.) National Constitutions in the Era of Integration, 1998, 61, 81.

$150 \mathrm{Vgl}$. bereits 1964 H. Bülck (Fn. 128), 120; B.-O. Bryde Konstitutionalisierung des Völkerrechts und Internationalisierung des Verfassungsrechts, Der Staat 2003, 61; s. auch P. Häberle Diskussionsbeitrag zum Thema: Der Verfassungsstaat als Glied einer europäischen Gemeinschaft, VVDStRL 50 (1991), 156, 157.

151 Ähnlich aus historischer Perspektive M. Koskenniemi (Fn. 9), 172.

152 A.-M. Slaughter (Fn. 9), 516.
} 
Der Gegenstand des Staatsrechts muss sich verlagern, weg vom souveränen Staat, hin zur einer Analyse der öffentlichen Gewalt. Der monistischen Herleitung allen Rechts aus der einen staatlichen Geltungsquelle steht die wachsende Vielzahl produktiver und nicht immer koordinierter Rechtssetzungsinstanzen entgegen, die das internationale Recht, aber auch private Körperschaften erzeugen. ${ }^{153}$ Das klassische Staats- und Verfassungsrecht muss sich auf diese neue Realität einstellen, nicht nur um den Anschluss zu wahren, sondern auch um die verfassungsrechtlichen Bindungen und Sicherungen, auf die die Bürger vertrauen, angemessen und systematisch zur Geltung zu bringen..$^{154}$

Die weitgehende Europäisierung und Internationalisierung des Staates muss mit anderen Worten unweigerlich zu einer weiteren Europäisierung und Internationalisierung der Staatsrechtslehre führen, das sollte auch Folgen für das Pflichtfachprogramm an den Universitäten haben. ${ }^{155}$ Staatsrechtslehre ohne Völkerrecht ist unvollständig, da Völker- und Europarecht den Rahmen für die insoweit nicht mehr ursprünglichen Verfassungsordnungen geben..$^{156}$

Die Staatsrechtslehre verliert dadurch nicht, im Gegenteil. Angesichts der Diversität der Rechtsquellen erwächst neuer Spielraum für die Judikative, aber auch für die Wissenschaft. Diversität der Rechtsquellen sowie geringere Regelungsdichte des Völkerrechts führen im Rahmen der Internationalisierung zu einer Relativierung des Positivismus. ${ }^{157}$ Das Recht muss selbst intensiver über Gerechtigkeit nachdenken, seine Legitimationsvoraussetzungen in der Gesellschaft ständig reproduzieren und nicht beides nur dem Gesetzgeber überlassen..$^{158}$

\section{Conclusio}

Ich habe versucht, die Realitäten einzufangen, ein Versuch, der sicherlich bei allem Bemühen um Objektivität auch subjektiv geprägt ist. Nie-

\footnotetext{
${ }^{153}$ C. Möllers (Fn. 7), $421 \mathrm{f}$.

154 U. Di Fabio (Fn. 38), 128.

155 S. auch P. Häberle (Fn. 150), 157; ders. Der europäische Jurist, Abschiedsvorlesung an der Universität St. Gallen, Gehalten am 28. Juni 2001, 2002.

${ }^{156} \mathrm{Vgl}$. J. Bridge The United Kingdom Constitution: Autochthonous or European?, FS Fleiner, 2003, $293 \mathrm{ff}$.

${ }^{157}$ Vgl. J. Kokott (Fn. 60), 3; zu naturrechtlichen Vorstellungen s. auch B. Fassbender (Fn. 99), 12; N. Politis (Fn. 61), $49 \mathrm{ff}$.

158 U. Di Fabio (Fn. 3), 148f., 128; vgl. auch C. Möllers/A. Voßkuhle Die Deutsche Staatsrechtswissenschaft im Zusammenhang der Internationalisierten Wissenschaften, Der Staat 2003, 321 .
} 
mandem ist es verwehrt zu versuchen, die Rückkehr zu einem mehr souveränitätsgebundenen Staats- und Völkerrecht anzustreben. Doch das ist eine rechtspolitische Entscheidung.

Maßstab für Staats-, Europa- und Völkerrecht ist der selbstbestimmte und doch gemeinschaftsgebundene Mensch, ${ }^{159}$ nicht der Staat. Folglich sind die dargestellten Veränderungen und Tendenzen aus der Perspektive des Einzelnen zu werten.

Zwar kann der Staat dem Bürger in einer globalisierten Welt weniger als früher Schutz und Wohlfahrt garantieren. Aber der Einzelne ist nicht notwendig der Verlierer im Prozess der Denationalisierung, nur muss die Schutzfunktion verlagert werden.

Der Bürger ist weniger auf seinen eigenen Heimatstaat angewiesen, er ist freier. Er kann sich selbst an internationale Instanzen zum Schutz der Menschenrechte oder auch seiner Auslandsinvestitionen wenden. Staatsgrenzen verlieren ihre hemmende Wirkung und erlauben mehr Mobilität. Weiter werden in einem durch Wegfall der Grenzen und Vermischung der Bevölkerung zusammenwachsenden Europa Kriege unwahrscheinlich. In alledem liegt ein Freiheits- und Sicherheitsgewinn, der allerdings nur durch Verfestigung und Durchsetzbarkeit des internationalen Rechts verbürgt werden kann. Deshalb möchte ich meinen Vortrag trotz des Unterganges des im alten Sinne souveränen Staates optimistisch beschließen.

159 Ähnlich schon N. Politis (Fn. 61), 69ff.; dazu M. Koskenniemi, (Fn. 9), 306 und allgemeiner 52, 177f.; H. Kelsen (Fn. 77), 128 und 143; s. auch P. Kirchhof(Fn. 8), 648; R.-U. Kunze Reconsidered: „Der Mensch ist nicht für den Staat, sondern der Staat für den Menschen da." Der Parlamentarische Rat und die Entstehung des Grundgesetzes, Der Staat 2003, 383, 394f. Kritisch U. Haltern Völkerrecht und Liebe (Fn. 90). AA G. W. F. Hegel (Fn. 90), 278: Indem der Staat „objektiver Geist ist, so hat das Individuum selbst nur Objektivität, Wahrheit und Sittlichkeit, als es ein Glied desselben ist." Dazu W. Pauly, Hegel und die Frage nach dem Staat, Der Staat 2000, 381. 
Leitsätze der 1. Berichterstatterin über:

\section{Die Staatsrechtslehre und die Veränderung ihres Gegenstandes: Konsequenzen von Europäisierung und Internationalisierung}

\section{Veränderungen des (europäischen) Staates}

1. Europäisierung und Internationalisierung beeinträchtigen die traditionellen drei Staatsmerkmale: Staatsvolk, Staatsgebiet, Staatsgewalt tief greifend.

2. Der Bedeutungsverlust der Staatsangehörigkeit und fehlende Schutzfähigkeit des einzelnen Staates vermindern die Schutz- und Loyalitätsbeziehung zwischen Staat und Staatsbürger vor allem in Europa.

3. Das Staatsgebiet als abgegrenzter und ausschließlicher Geltungsbereich einer bestimmten Herrschafisordnung gehört der Vergangenheit an.

4. Durch die Aufgabe der alleinigen Verantwortung für das geltende Recht wird die Souveränität nicht nur faktisch, sondern auch rechtlich beeinträchtigt.

5. Ein fundamentaler Wandel der Staatlichkeit in Europa, nämlich zum nicht souveränen Staat, steht außer Zweifel.

6. Der souveräne Staat ist kein Selbstzweck, wie extremer Nationalismus das vielleicht einmal annahm. Ebenso wenig sind Europäisierung und Internationalisierung Selbstzwecke.

7. Auch eine europäische Verfassung oder ein europäischer Verfassungsvertrag könnte und sollte die den Nationalstaaten durch die Globalisierung verloren gegangene Einheitlichkeit nicht wiederherstellen.

8. Die Entsouveränisierung hat nur einen Funktionswechsel des Staates, nicht dessen Untergang zur Folge. Der ehemals souveräne Nationalstaat wird zum rechtlich und faktisch gebundenen Staat innerhalb eines Systems multipler Rechtssetzung und Herrschafisgewalt.

\section{Erfüllung der Staatsaufgaben im offenen Verfassungsstaat}

9. Staatsaufgaben lassen sich aus dem „Wesen“ des Staates und aus der Verfassung ableiten. Letztlich müssen sie zurückführbar sein auf die Bedürfnisse der Einzelnen, für die Staat und Recht bestehen. 
10. Herkömmlicherweise gehören zu den wesentlichen Staatsaufgaben: (1.) die Garantie von Freiheit und Sicherheit, (2.) die politische Definition des Gemeinwohls, (3.) Daseinsvorsorge und die Schaffung von Wohlfahrt (4.), die Identitäts- und Integrationsfunktion und schließlich (5.) die Wahrung des Völkerrechts.

11. Die genannten Staatsaufgaben werden heute weder autonom von den einzelnen Staaten definiert und ausgestaltet, diese müssen sich an völker-und europarechtliche Vorgaben halten; noch können die einzelnen Staaten die genannten Staatsaufgaben effektiv erfüllen.

12. Nur der Nationalstaat soll Opfer und Solidarität, etwa den persönlichen Einsatz im Krieg zur Verteidigung des Vaterlandes, verlangen können. Wenn aber der Nationalstaat zur Schutzgewährung nicht in der Lage ist, leidet konsequenterweise diese Einsatzbereitschaft.

13. Weder vermag der Nationalstaat fehlende Zugehörigkeit und Integration stets zuverlässig zu gewährleisten, noch ist der Einzelne ohne einen starken Nationalstaat notwendigerweise wurzellos, bindungslos und isoliert. Wie noch nie hat der Einzelne heute die Chance einer selbst bestimmten Identität, worunter Gemeinschaftswerte nicht leiden müssen.

14. Die Erfüllung vieler Staatsaufgaben wird in Europa supra- und internationalisiert. Während insoweit der Einfluss einzelner Staaten schwindet, wird die Funktion des Staates als Mitgestalter und Vollzugsinstrument supra- und internationalen Rechts ständig wichtiger.

\section{Postnationale Demokratie?}

15. Europäisierung und Internationalisierung mindern die Bedeutung der nationalen Parlamente. Diese Entparlamentarisierung erfolgt nicht nur zugunsten von Regierung und Ministerialbürokratie (Exekutive), sondern auch zugunsten der nationalen und internationalen Gerichtsbarkeit. Europäisierung und Internationalisierung gefährden damit die parlamentarische Demokratie innerhalb der Nationalstaaten.

16. Das Demokratiegebot ist (zumindest) eine Völkerrechtsnorm in statu nascendi.

17. Innerhalb des Nationalstaates ist Demokratie in erster Linie Herrschaft durch die Gesamtheit der Staatsbürger; im Grundsatz bedeutet Demokratie Herrschaft durch die Betroffenen.

18. Die international anerkannten Prinzipien der Selbstbestimmung und Demokratie gebieten die Anwendung des Subsidiaritätsgrundsatzes auch auf internationaler Ebene.

19. Die meisten Staaten werden sich in beide Richtungen zu bewegen haben: Stärkung regionaler Untergliederungen einerseits und Übertragung 
von Hoheitsbefugnissen auf die Europäische Gemeinschaft und auf internationale Organisationen andererseits. Insofern beinhaltet die Entsouveränisierung auch eine Chance für Bürgernähe, Volkssouveränität und Demokratie.

20. Staats- und Völkerrechtswissenschaft müssen sowohl an der richtigen Verteilung der Aufgaben auf die verschiedenen Ebenen als auch an der (möglichst) demokratischen Gestaltung supranationaler Entscheidungsprozesse arbeiten.

21. Der parlamentszentrierte Ansatz ist im Rahmen der Europäischen Union wichtig. Im Rahmen der Internationalisierung ist er jedoch allenfalls beschränkt tauglich, da kein Weltstaat mit Weltparlament in Aussicht steht.

22. Das europarechtliche und das internationale Demokratiegebot enthält ein Optimierungsgebot, das auf Ausschöpfung der Partizipationsmöglichkeiten auf allen Ebenen zielt.

23. Besondere Bedeutung kommt im Mehrebenensystem der Klarheit und Transparenz der Verantwortlichkeiten zu. Jede Ebene muss zu ihrer ganzen, harten Verantwortung stehen. Hinsichtlich der Verantwortlichkeiten darf es keine (vorgeschobenen) negativen Kompetenzkonflikte geben.

\section{Konvergenz von Staats- und Völkerrecht, Folgen für die Staatsrechtslehre}

24. Im Völkerrecht ist nicht mehr die Frage nach der Souveränität entscheidend, sondern die Frage, wem, in welchem Ausmaße und unter welchen Umständen (partielle) Völkerrechtssubjektivität zukommt. Das Völkerrecht nimmt mehr und mehr den Charakter eines Rechts an, welches nicht durch seinen zwischenstaatlichen Charakter, sondern dadurch gekennzeichnet ist, dass es unabhängig von seinen Quellen und seinen Adressaten auf staatsübergreifende Ordnung abzielt.

25. Der Gegenstand des Staatsrechts muss sich verlagern, weg vom souveränen Staat, hin zur Analyse der öffentlichen Gewalt. Der monistischen Herleitung allen Rechts aus der einen staatlichen Geltungsquelle steht die wachsende Vielzahl produktiver und nicht immer koordinierter Rechtssetzungsinstanzen entgegen. Das klassische Staats- und Verfassungsrecht muss sich auf diese neue Realität einstellen, nicht nur um den Anschluss zu wahren, sondern auch um die verfassungsrechtlichen Bindungen und Sicherungen, auf die die Bürger vertrauen, angemessen und systematisch zur Geltung zu bringen.

26. Die weitgehende Europäisierung und Internationalisierung des Staates muss zu einer weiteren Europäisierung und Internationalisierung der Staatsrechtslehre führen. Staatsrechtslehre ohne Völkerrecht ist unvollständig, da Völker- und Europarecht den Rahmen für die insoweit nicht mehr ursprüng- 
lichen staatlichen Verfassungsordnungen geben. Das sollte auch Folgen für das Pflichtprogramm an den Universitäten haben.

27. Angesichts der Diversität der Rechtsquellen erwächst neuer Spielraum für die Judikative, aber auch für die Staatsrechtswissenschaft. Diversität der Rechtsquellen sowie geringere Regelungsdichte des Völkerrechts führen im Rahmen der Internationalisierung zu einer Relativierung des Positivismus. Das Recht muss selbst intensiver über Gerechtigkeit nachdenken, seine Legitimationsvoraussetzungen in der Gesellschaft ständig reproduzieren und nicht beides nur dem Gesetzgeber überlassen.

\section{Conclusio}

28. Maßstab für Staats-, Europa- und Völkerrecht ist der selbstbestimmte und doch gemeinschaftsgebundene Mensch, nicht der Staat.

29. Zwar kann der Staat dem Bürger in einer globalisierten Welt weniger als früher Schutz und Wohlfahrt garantieren. Aber der Einzelne ist nicht notwendig der Verlierer im Prozess der Denationalisierung, nur muss die Schutzfunktion verlagert werden.

30. Der Bürger ist weniger auf seinen eigenen Heimatstaat angewiesen, er ist freier. Er kann sich selbst an internationale Instanzen zum Schutz der Menschenrechte oder auch seiner Auslandsinvestitionen wenden. Staatsgrenzen verlieren ihre hemmende Wirkung und erlauben mehr Mobilität. Weiter werden in einem durch Wegfall der Grenzen und Vermischung der Bevölkerung zusammenwachsenden Europa Kriege unwahrscheinlich. In alledem liegt ein Freiheits- und Sicherheitsgewinn, der allerdings nur durch Verfestigung und Durchsetzbarkeit des internationalen Rechts verbürgt werden kann. 
Erster Beratungsgegenstand:

\section{Die Staatsrechtslehre und die Veränderung ihres Gegenstandes: Konsequenzen von Europäisierung und Internationalisierung}

2. Bericht von Prof. Dr. Thomas Vesting, Frankfurt a. M.*

Inhalt

I. Die Beziehung zwischen Öffentlichem Recht und Staat als Ausgangspunkt .................. 42

II. Der Rechtsstaat als Gegenstand und Resultat der Staatsrechtslehre ................. 43

1. Die Ablösung des Machtstaats durch den Rechtsstaat .. 43

2. Einheit und Autonomie des Öffentlichen Rechts . . . . . 45

3. Ambivalenzen der Rechtsstaatsformel . . . . . . . . 46

III. Die neuen Phänomene: Europäisierung und

Internationalisierung . . . . . . . . . . . . 47

1. Die Verselbstständigung des Europarechts gegenüber dem Staatsrecht und seine Rückwirkungen . . . . . . . 48

2. Vom Völkerrecht zum Menschheitsrecht ........ 52

a) Die staatsrechtliche Konzeption des Völkerrechts . . 52

b) Entwicklungen ihrer Auflösung ......... 53

3. Transnationale und internationale privat-öffentliche

Regulierungsnetzwerke .................. 56

4. Globales Recht ohne Staat . . . . . . . . . 58

IV. Die Suche nach Alternativen: Offener Staat,

Konstitutionalismus, Rechtspluralismus . . . . . . . . . 59

1. Der offene Staat . . . . . . . . . . . . . 61

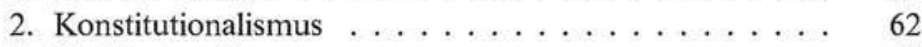

3. Rechtspluralismus .................. 64

V. Konsequenzen für das Staatsrecht und die Staatsrechtslehre 65

* Für Anregungen und konstruktive Kritik danke ich Karl-Heinz Ladeur, Günter Frankenberg, Martin Eifert und Carsten Kremer. 


\section{Die Beziehung zwischen Öffentlichem Recht und Staat als Ausgangspunkt}

Der Punkt, an dem die folgenden Überlegungen einsetzen, ist die $\mathrm{Be}$ ziehung zwischen Öffentlichem Recht und Staat. Wählt man als Ausgangspunkt den Staat als Element einer Beziehung, kann es nicht einfach um die Veränderung des Staates gehen. Damit werden zugleich bestimmte Fragestellungen ausgeschlossen. Fragen des Typs wie „Nähert sich die staatliche Souveränität angesichts der Globalisierung unaufhaltsam dem Nullpunkt? War die Souveränität des Nationalstaats nicht schon im 19. Jahrhundert eine ,Fiktion'?" sind dann eher in einem politik-wissenschaftlichen, nicht aber primär in einem staatsrechtlichen Referat zu beantworten.

Beginnt man also nicht mit dem Staat, sondern mit der Beziehung von Öffentlichem Recht und Staat, muss die Aufmerksamkeit auf die Veränderung einer Beziehung gelenkt werden. Die Beschreibung einer Veränderung setzt wiederum eine Grundlage voraus, gegen die die gegenwärtige Lage abgegrenzt und konturiert werden kann. Diese Grundlage kann in einem staatsrechtlichen Referat nur die Geschichte des eigenen Fachs selbst sein. Da die Staatsrechtslehre ihre Vollstufe aber nicht erst unter dem Grundgesetz erreicht hat, sondern schon im letzten Drittel des 19. Jahrhunderts, liegt es nahe, in einem ersten Schritt zu skizzieren, wie Öffentliches Recht und Staat im so genannten staatsrechtlichen Positivismus $^{1}$ miteinander in Beziehung gesetzt worden sind.

Es sollen daher zunächst einige der zentralen Voraussetzungen der Staatsrechtslehre des späten 19. Jahrhunderts herausgearbeitet werden. Die Grundlagen, die im staatsrechtlichen Positivismus gelegt worden sind, wirken bis heute nach; auch 1949 ist in der Geschichte des Öffentlichen Rechts in dieser Hinsicht kein grundlegender Einschnitt. ${ }^{2}$ Deshalb lassen sich die Veränderungen, die durch Prozesse der Europäisierung

\footnotetext{
1 Der Begriff soll hier in einem weiten Sinn verwendet werden und nicht nur Autoren wie C.F. Gerber und P. Laband, sondern auch $O$. Maver und G. Jellinek einschließen. Zu den Einzelheiten vgl. nur $M$. Stolleis Geschichte des öffentlichen Rechts in Deutschland, Bd. 2, 1992, $276 \mathrm{ff}$; W. Pauly Der Methodenwandel im deutschen Spätkonstitutionalismus, 1993, $92 \mathrm{ff}$.; M. Friedrich Geschichte der deutschen Staatsrechtswissenschaft, 1997, $222 \mathrm{ff} ., 235 \mathrm{ff}$.

${ }^{2}$ Etwa im Sinne eines Übergangs vom Staatsrecht zum Verfassungsrecht. Davon geht z.B. R. Wahl Verfassungsstaat, Europäisierung, Internationalisierung, 2003, aus. Wenn dieser Übergang hier relativiert wird, soll damit nicht behauptet werden, dass etwa die Vorstellung des „Vorrangs der Verfassung“ keinen Unterschied zum Staatsrecht des 19. Jahrhunderts oder der Weimarer Republik ausmachen würde. Der Unterschied ist aber m.E. nur gradueller Natur.
} 
und Internationalisierung ausgelöst werden (und bereits ausgelöst worden sind), ohne Rekurs auf die Anfänge des eigenen Fachs weder einordnen noch in ihrer Bedeutung für die Gegenwart richtig einschätzen.

\section{Der Rechtsstaat als Gegenstand und Resultat der Staatsrechtslehre}

\section{Die Ablösung des Machtstaats durch den Rechtsstaat}

Der Begriff, an dem sich der staatsrechtliche Positivismus orientierte, war der Begriff des Rechtsstaats. ${ }^{3}$ Mit dem Niedergang und Ende der altständischen Gesellschaft konnte das Öffentliche Recht nicht mehr in der Tradition eines jus publicum fundiert werden. Die liberale Gesellschaft zwang auch das Öffentliche Recht dazu, nach neuen Begriffen und Theorien zu suchen. Die Suche nach dem Neuen bedeutete freilich auch im 19. Jahrhundert nicht, das Neue einfach aus dem Nichts zu schaffen. Das Neue ist immer ein Neues zwischen der Identität der Tradition und dem Bruch mit dieser. Auch der Begriff des Rechtsstaats war das Produkt einer solchen Oszillation, einer Suchbewegung, in der sich die Staatsrechtslehre von den Konstruktionen der Vergangenheit absetzte.

Der Begriff des Rechtsstaats richtete sich vor allem gegen den neuzeitlichen (voluntaristischen) Souveränitätsbegriff, gegen den „Machtstaat“.4 Für den staatsrechtlichen Positivismus lag das entscheidende Merkmal dieser Tradition in der Schrankenlosigkeit des Herrscherwillens. ${ }^{5}$ Des-

\footnotetext{
${ }^{3}$ Stolleis (Fn. 1), 258ff., 276ff. Zum Rechtsstaatsbegriff vgl. einerseits E.-W. Böckenförde Entstehung und Wandel des Rechtsstaatsbegriffs, in: ders. (Hrsg.) Staat, Gesellschaft, Freiheit, 1976, 65ff. (,materieller Rechtsstaat ${ }^{\prime)}$ ) und andererseits I. Maus Entwicklung und Funktionswandel der Theorie des bürgerlichen Rechtsstaats, in: M. Tohidipur (Hrsg.) Der bürgerliche Rechtsstaat, Bd. 1, 1978, 13 ff. („formaler Rechtsstaat“).

${ }_{4}^{4}$ Der Machtstaat (bzw. Polizeistaat) strebte nach absoluter, unbeschränkter Gewalt und war daher für den Rechtspositivismus überhaupt kein möglicher Gegenstand eines systematischen Staatsrechts. Vgl. nur G. Jellinek Allgemeine Staatslehre (1928), unv. Nachdruck 1959, 325; O. Mayer Deutsches Verwaltungsrecht, Bd. 1 (1923), unv. Nachdruck 1969, 38, 39, spricht von der „schrankenlos gewordene(n) öffentliche(n) Gewalt“ des Polizeistaats, mit dem das Recht nichts zu tun hat. Noch $E$. Forsthoff Lehrbuch des Verwaltungsrechts, 1966, 40, pflichtet $O$. Mayer bei: „Die Verwaltung des Polizeistaates war kein möglicher Gegenstand einer systematischen Rechtswissenschaft.“

${ }_{5}^{5}$ Die Annahme, dass die absolutistischen Herrscher in einem rechtsfreien Raum (schrankenlos) hätten agieren können, entsprach selbstverständlich nicht den historischen Tatsachen, macht die Zielrichtung der Rechtsstaatsformel aber umso deutlicher. Das Recht war als lokales und interregionales Gewohnheitsrecht, als Königsrecht, Feudalrecht, Stadtrecht, kanonisches Recht, als lex mercatoria und nicht zuletzt als römisches Zivilrecht schon längst vorhanden, mit eigenen Gerichtsbarkeiten ausgestattet, ja teilweise sogar schon schriftlich fixiert, als der souveräne Staat sich als neue politische Ord-
} 
halb zielte der Rechtsstaat genau auf die Eliminierung jener Momente von Willkür, die aus der im Souveränitätsbegriff angelegten strikten Trennung von Recht (ius) und Gesetz (lex) resultierten. Die Unterscheidung von Recht und Gesetz ermöglichte es nämlich schon Bodin den Gesetzesbegriff aus der teleologischen Rechtsauffassung der altständischen $\mathrm{Ge}$ sellschaft zu lösen ${ }^{6}$ - und das Gesetz statt in einer notwendigen Wahrheit, dem Willen Gottes, in einer kontingenten Wahrheit, dem Willen des Königs, zu fundieren. ${ }^{7}$

Gegen diesen Bruch, den die Lehre vom souveränen Staat gegenüber der traditionalen Rechtsauffassung bewirkte, setzte der Rechtspositivismus aber nicht einfach auf Ethik und Moral. Vielmehr votierte der staatsrechtliche Positivismus für einen Rationalitätsanspruch, der in der Rechtsform selbst verankert wurde. Mit Hilfe der Verknüpfung von Öffentlichem Recht und Staat sollten alle, Staat und Verwaltung zurechenbaren Handlungen an ein von Moral und Religion emanzipiertes, aber regelhaftes, und systematisches und in diesem Sinne positives Staatsrecht gebunden werden.

Der Rechtsstaat war also weniger ein Prinzip des geltenden Rechts, ${ }^{8}$ sondern vor allem eine strategische Orientierungsformel. Das Ziel des Rechtsstaatsbegriffs bestand darin, sämtliche staatlichen Willensäußerungen in einem Rechtssystem zusammenzufassen und dieses System wie einen Automaten verlässlich und vorhersehbar zu programmieren. Das galt insbesondere für solche Handlungen, die in die Privatrechtsgesellschaft hineinwirkten und „Freiheit und Eigentum“ berührten. Anders ge-

nung zu konsolidieren begann; und gerade die Konsolidierung des souveränen Staates selbst basierte wiederum ganz maßgeblich auf rechtlichen Mitteln, nicht zuletzt auf einem neuartigen Verständnis des Öffentlichen Rechts, das sich an den Universitäten nach 1650 als jus publicum und Reichspublizistik zu etablieren begann. Zur Geschichte des modernen Rechts H.J. Berman Recht und Revolution, 1991; zur Reichspublizistik Stolleis(Fn. 1), $225 \mathrm{ff}$.

${ }^{6}$ Vgl. J. Bodin Sechs Bücher über den Staat (1583), Band I-III, 1981, 205; vgl. H. Quaritsch Staat und Souveränität, 1970, $39 \mathrm{ff}$., $243 \mathrm{ff}$.; $P$. Kondylis Konservatismus, 1986, $72 \mathrm{ff}$. Rechtlich! Politisch blieb der Fürst weiterhin an Konsens und Staatsräson gebunden. Jellinek (Fn. 4), 328, spricht in diesem Zusammenhang zu Recht vom ,potentiell schrankenlose(n) Staat der juristischen Theorie" (Hervorhebung von mir, T.V.).

${ }^{7}$ Daher voluntaristisch: nach der Einsicht Descartes', dass Gott die mathematischen Wahrheiten genauso konstituiert habe, wie ein König Gesetze gebe.

${ }^{8}$ Wie der Rechtsstaat heute normalerweise bezeichnet und in seinen dogmatischen Ausprägungen - als Gewaltenteilung, Vorrang und Vorbehalt des Gesetzes, Bestimmtheitsgebot usw. - in den Lehrbüchern zumeist unter Einschluss der Wiedergabe der Rechtsprechung des Bundesverfassungsgerichts dargestellt wird. Vgl. nur $C$. Degenhart Staatsrecht I, 18. Aufl., 2002, 233 ff.; J. Ipsen Staatsrecht I, 13. Aufl., 2001, 177 ff.; H. Maurer Staatsrecht I, 3. Aufl., 2003, $215 \mathrm{ff}$. 
wendet: Die Ordnungsleistung des positiven Staatsrechts sollte gegenüber den historisch gewachsenen Institutionen, der Verwaltung und Regierung als „Schranke“, d.h. zum Schutz der Privatrechtsgesellschaft, in Anschlag gebracht werden. Die Zielsetzung des staatsrechtlichen Positivismus bestand also darin, das im (voluntaristischen) Souveränitätsbegriff der frühen Neuzeit angelegte Willkürmoment in ein systemabhängiges Staatsrecht umzuleiten. ${ }^{9}$

\section{Einheit und Autonomie des Öffentlichen Rechts}

Deshalb lag der Akzent der Staatsrechtslehre ganz auf der Darstellung der Einheit und Autonomie des Öffentlichen Rechts. In der Unterstellung der Einheit der Rechtsordnung, die für Laband so lückenlos war wie die Ordnung der Natur, ${ }^{10}$ suchte der staatsrechtliche Positivismus Anschluss an die Tradition der Naturphilosophie und des Naturrechts. In dieser Tradition war die Systemabhängigkeit allen wissenschaftlichen Denkens seit Descartes selbstverständlich geworden. Hatte dort zunächst die Gründung und Durchsetzung eines einheitlichen Raums des Politisch-Rechtlichen im Vordergrund gestanden," ging es dem staatsrechtlichen Positivismus jedoch um die Trennung von Politik und Recht. Konstituierte das positive Recht vor allem bei Hobbes einen von aller Tradition befreiten souveränen Willen, der aber zugleich ein politischer Herrscherwille war und blieb, ${ }^{12}$ betont der staatsrechtliche Positivismus gerade die Unabhängigkeit des Öffentlichen Rechts von aller Politik. Das Öffentliche Recht sollte wie bei Hobbes unabhängig von der Natur und ihr inhärenter moralischer Prinzipien konstruiert werden. Aber im Unterschied zu Hobbes setzte der staatsrechtliche Positivismus sehr viel stärker auf das Recht im Unterschied zur Politik, wie sich etwa an der scharfen Kritik der „Genossenschaftslehre" zeigte.

Worauf beruhte die Autonomie des Staatsrechts nun aber genau? Die Antwort auf diese Frage lautet: Auf der Produktion rechtswissenschaft-

\footnotetext{
9 Also den „vorrechtlichen Machtstaat" zum „Rechtsstaat" zu formen, wie Stolleis (Fn. 1), 453 schreibt.

10 P. Laband Das Budgetrecht (1871), Nachdruck 1971, 75.

" $\mathrm{Zu}$ den Ambivalenzen des politischen Raumbegriffs vgl. H. Heller Staatslehre, in: Draht/Stammer/Niemeyer/Borinsky (Hrsg.) Gesammelte Schriften, Bd. 3, Staatslehre als politische Wissenschaft, Leiden 1971, $239 \mathrm{ff}$. und den Eintrag Raum, politischer in: J. Ritter/K. Gründer (Hrsg.) Historisches Wörterbuch der Philosophie, Bd. 8, 1992, 122 ff.

$12 \mathrm{Zu}$ dieser Ambivalenz im liberalen Denken von Hobbes, Locke und der schottischen Aufklärung vgl. K.-H. Ladeur Negative Freiheitsrechte und gesellschaftliche Selbstorganisation, 2000, $21 \mathrm{ff}$; ders. Das selbstreferenzielle Kamel: Die Emergenz des modernen autonomen Rechts, Zeitschrift für Rechtssoziologie 21 (2000), $177 \mathrm{ff.}, 178 \mathrm{f}$.
} 
licher Theorien und Begriffe in Form von geschriebener und gedruckter Literatur, also auf der Staatsrechtslehre selbst. Man könnte gerade am Beispiel der Diskussion über die juristische Person zeigen, wie sehr es dem staatsrechtlichen Positivismus um die Selbstbegründung des Öffentlichen Rechts ging. ${ }^{13}$ Im Vordergrund stand das Recht als symbolische Ordnung, das Recht als Zeichensystem, als ,geistiger" Kommunikationszusammenhang. ${ }^{14}$ Durch die Produktion rechtswissenschaftlicher Literatur und ihre allmähliche Verankerung in der sozialen Wirklichkeit sollte vor allem die Beziehung des Staates zu den "Gewaltunterworfenen“ als geschriebenes Rechtsverhältnis, als Beziehung von (juristischer) Person zu (juristischer) Person konstruiert werden - und darin das sprachlose Gewaltverhältnis der Vergangenheit ablösen. ${ }^{15}$ Die Wirklichkeit des Rechtsstaats lag mit anderen Worten in seiner medialen Realisierung; und die Themen dieses selbst tragenden Unternehmens hießen: Herrschaft des Gesetzes, Gesetzmäßigkeit der Verwaltung und (individueller) Rechtsschutz durch unabhängige Gerichte.

\section{Ambivalenzen der Rechtsstaatsformel}

Allerdings erfolgte die Akzentsetzung auf die Einheit und Autonomie des Öffentlichen Rechts im 19. Jahrhunderts unter der Voraussetzung eines sich formierenden Nationalstaats. Das hatte eine nicht auflösbare Ambiva-

\footnotetext{
${ }^{13}$ Wie Laband in der Auseinandersetzung um die Auffassung des Staates als einer juristischen Person des Öffentlichen Rechts im Staatsrecht von 1887 anmerkte, habe der Staat als juristische Person zwar keine reale physische Existenz, er existiere als „Rechtsvorstellung", aber er sei „wirklich“ und nicht lediglich eine „Fiktion“. So wie die Natur Menschen schaffe, aber keine natürlichen Personen, so gebe es auch in der sozialen Natur keine wirklich existierende Gesamtperson, kein Rechtssubjekt Staat. Aber so wie das Zivilrecht aus den Individuen Personen mache, d.h. Rechtssubjekte, so schaffe das Öffentliche Recht mittels der Konstruktion der juristischen Person einen rechtlich verselbstständigten Träger kollektiver Rechte und Pflichten. Vgl. nur P. Laband Das Staatsrecht des Deutschen Reiches, Bd. 1, 2. Aufl., Tübingen 1894, 94 (Fn. 1).

14 Laband bemüht einerseits die Sprache der Bewusstseinsphilosophie und nennt den Staat eine „Rechtsvorstellung“, ein Produkt aus „dem Reich der Gedanken“; zugleich soll der Staat als juristische Person etwas Wirkliches sein. Trotz dieser Inkonsistenzen kann es aber nicht zweifelhaft sein, dass Laband das Recht als wirkliche autonome Ordnung dachte. Laband fehlten allenfalls die theoretischen Mittel, den Sachverhalt, der ihm vor Augen stand, so zu formulieren, dass gedankliche Vorstellung und (sprachliche) Wirklichkeit keinen Widerspruch mehr bildeten, sondern eine Einheit. Hier wird diese Einheit als (Rechts-)Kommunikation bezeichnet.

${ }^{15}$ Zur Verschriftlichung des Rechts vgl. nur J. Goody Die Logik der Schrift und die Organisation von Gesellschaft, 1990, $211 \mathrm{ff}$; P. Goodrich Languages of Law, London 1990 (Common Law); M.-Th. Fögen Römische Rechtsgeschichten, 2002, $82 \mathrm{ff}$.
} 
lenz der Rechtsstaatsformel zur Folge: Der Rechtsstaat sollte den Machtstaat vereinnahmen. Die Kehrseite dieser Vereinnahmungsstrategie war jedoch, dass das Öffentliche Recht auf den Staat als Nationalstaat fixiert blieb. War der Rechtsstaat als symbolische Ordnung, als Rechtsordnung, „eine Einrichtung des Rechts“, ${ }^{16}$ fungierte er in seiner Zentrierung auf den Nationalstaat als Chiffre einer politischen Instrumentierung des Rechts.

Damit wurde der Rechtsstaat Bestandteil eines politisch-territorialen Ordnungsanspruchs. Er wurde zum Element einer politischen Raumordnung, in der die Ordnungsleistung des Öffentlichen Rechts letztlich aus einem räumlichen Substrat, dem auf einem fest umrissenen politischen Territorium vorhandenen "Gewaltmonopol“, abgeleitet wurde. Daraus resultiert eine bis heute nicht aufgelöste Paradoxie: Die Selbstbegründung des Staatswillens als Komponente eines rechtlichen Kommunikationszusammenhangs wurde mit einer politisch-staatlichen Fremdbegründung kurzgeschlossen. Politisch-territoriale Ordnung und Rechtsordnung bildeten in der Orientierungsformel Rechtsstaat eine Einheit, obwohl sie dies der Sache nach niemals waren.

Der Rückgriff auf den staatsrechtlichen Positivismus hat gezeigt: Der Klammerbegriff Rechtsstaat hatte im 19. Jahrhundert die Aufgabe, das Öffentliche Recht vom traditionellen Souveränitätsbegriff zu lösen, es als autonome Ordnung zu begründen und die Beziehung zwischen Staat und Untertan in eine rechtsförmige (vertextete) Beziehung zwischen juristischen Personen zu transformieren. Darin war die Staatsrechtslehre ganz Rechtslehre. ${ }^{17}$ Allerdings vollzog sich die Transformation des Machtstaates in den Rechtsstaat vor dem Hintergrund eines sich ausbildenden Nationalstaates. Beide Ebenen, Recht und Staat, zu verknüpfen, gelang deshalb nicht ohne innere Widersprüche, aber vor diesem Hintergrund war es zumindest schlüssig, das Öffentliche Recht auf den Staat zu zentrieren. Es war einleuchtend, Öffentliches Recht als Staatsrecht zu betreiben und die akademische Disziplin, unter der man dies tat, als Staatsrechtslehre zu bezeichnen.

\section{Die neuen Phänomene: Europäisierung und Internationalisierung}

Lässt sich diese Tradition angesichts der neuen Phänomene der Europäisierung und Internationalisierung fortsetzen? Inwiefern ist die stillschweigende Prämisse der Staatsrechtslehre des 19. Jahrhunderts, poli-

\footnotetext{
16 N. Luhmann Das Recht der Gesellschaft, 1993, 415.

17 Für Laband vgl. nur den Brief an Gerber vom 8. 3. 1880 - abgedruckt bei Pauly (Fn. 1), 160; für Jellinek vgl. nur ders. (Fn. 4), $367 \mathrm{ff}$.; für Mayer vgl. ders. (Fn. 4), 54ff.
} 
tisch-territoriale Ordnung und Rechtsordnung als Einheit denken zu können, heute hinfällig geworden? Die Klärung dieser Frage soll beispielhaft in vier Zusammenhängen erfolgen.

\section{Die Verselbstständigung des Europarechts gegenüber dem Staatsrecht und seine Rückwirkungen}

Durch das Europarecht wird eine Rechtsordnung jenseits der staatlichen Hoheitsgewalt geschaffen und begründet, die gleichwohl auf dem Territorium eines jeden Mitgliedstaates gilt und auf dessen jeweilige Rechtsordnung einwirkt. ${ }^{18}$ Zur Übertragung von Hoheitsrechten gem. Art. 23 Abs. 1 GG (wie zuvor Art. 24 Abs. 1 GG) gehört vor allem die Übertragung von Rechtserzeugungs- und Rechtsanwendungskompetenzen auf Gemeinschaftsorgane. Ganz gleich, wie man die Übertragung derartiger Kompetenzen konstruiert: ${ }^{19}$ Es lässt sich schwerlich bestreiten, dass das geltende Gemeinschaftsrecht nur noch in sehr eingeschränktem $\mathrm{Ma}$ auf die einzelstaatlichen Übertragungsakte (und den darin gespeicherten Willen) zurückgeführt werden kann. In der europarechtlichen Literatur wird die Verselbstständigung des EG-Rechts gegenüber den einzelstaatlichen Akten der Kompetenzübertragung sogar ausdrücklich akzentuiert, wenn das EG-Recht als neue oder eigene Rechtsordnung bezeichnet wird, ${ }^{20}$ der nach ständiger Rechtsprechung des EuGH sogar ein Anwendungsvorrang vor dem Recht der Mitgliedstaaten zukommen soll. ${ }^{21}$

\footnotetext{
${ }^{18}$ Vgl. allg. R. Wahl Die zweite Phase des öffentlichen Rechts in Deutschland - Die Europäisierung des öffentlichen Rechts, Der Staat 38 (1999), 495-518; ders. (Fn. 2), 22.

${ }^{19}$ Zwei Vorstellungen konkurrieren: die Übertragung im Sinne des (endgültigen) Verzichts auf die Ausschließlichkeit staatlicher Hoheitsgewalt und die (vorübergehende) Suspendierung staatlicher Rechte. Für eine echte Übertragung z.B. M. Zuleeg AK-GG, 3. Aufl. (2001), Art. 24 Rn. 4, Art. 23 Rn. 45; dagegen z.B. R. Scholz in: Maunz/Dürig/ Herzog (Hrsg.) Grundgesetz (Stand 2002), Art. 23, Rn. 51 und I. Seidl-Hohenveldern/ G. Loibl Das Recht der internationalen Organisationen einschließlich der supranationalen Gemeinschaften, 1996, 260f.; zum Meinungsstand vgl. auch D. König Die Übertragung von Hoheitsrechten im Rahmen des europäischen Integrationsprozesses - Anwendungsbereich und Schranken des Art. 23 des Grundgesetzes, 2000, 50ff.; Wahl (Fn. 2), $20 \mathrm{ff}$.

${ }^{20}$ In Rs. 26/62 (van Gend \& Loos, Slg. 1963, 1 ff., 25) nannte der EuGH die Gemeinschaft wohl erstmalig als ,eine neue Rechtsordnung des Völkerrechts“. Vgl. dazu nur $\mathrm{Zu}$ leeg (Fn. 19), Art. 23 Rn. 19; S. Kadelbach Allgemeines Verwaltungsrecht unter europäischem Einfluß, 1999, 54ff.; S. Hobe Der offene Verfassungsstaat zwischen Souveränität und Interdependenz, 1998, 348f. jeweils mwN aus der Rechtsprechung des EuGH.

${ }^{21} \mathrm{Vgl}$. nur I. Pernice Europäisches und nationales Verfassungsrecht, VVDStRL 60 (2001), 182f.; Zuleeg (Fn. 19), Art. 23 Rn. 34 mwN aus der Rechtsprechung des EuGH; ders. Deutsches und europäisches Verwaltungsrecht - Wechselseitige Einwirkungen,
} 
Die Verselbstständigung des EG-Rechts gegenüber dem Staatsrecht der Mitgliedstaaten tritt insbesondere dann klar und deutlich hervor, wenn europäisches Sekundärrecht in einer zirkelhaften Bewegung der Selbstbegründung von Kompetenzen durch Organe der EG selbst geschaffen wird. So wurden beispielsweise nicht unwesentliche Schritte auf dem Weg zur Marktöffnung im Telekommunikationsbereich vielfach auf den früheren Art. 90 Abs. 3 EGV gestützt.22 Diese Vorschrift, die die gemeinschaftsrechtliche Zulässigkeit öffentlicher Unternehmen regelt, gibt der EG-Kommission eine eigenständige Gestaltungskompetenz, die den Erlass von Richtlinien einschließt. Diese Richtlinienkompetenz ist als „Delegation" von Rechtsetzungsbefugnissen nur unzulänglich beschrieben. Sie wird lediglich durch eine Zweckformel, ein Finalprogramm begrenzt, nämlich das gemeinschaftsrechtliche Integrationsziel der Gewährleistung eines wirksamen, unverfälschten Wettbewerbs. ${ }^{23}$

Damit soll nicht behauptet werden, dass die Organe der Gemeinschaft in solchen Fällen tun und lassen könnten, was sie wollen. Sie sind natürlich an politischen Konsens gebunden. Rechtlich definieren sie ihre Handlungsmöglichkeiten jedoch weitgehend selbst, da sich Finalprogramme rechtlich nur schwer strukturieren und kontrollieren lassen. Das belegt auch die Geschichte der europäischen Rundfunkregulierung. ${ }^{24}$

VVDStRL 53, 154, $159 \mathrm{ff}$; aus dem neueren Schriftum vgl. nur $A$. Peters Elemente einer Theorie der Verfassung Europas, 2001, 309ff.; W. Schroeder Das Gemeinschaftsrechtssystem, Jus Publicum Bd. 86 (2002), $104 \mathrm{ff}$.

22 Jetzt: Art. 86 Abs. 3 EGV. Das betrifft beispielsweise die Richtlinie der Kommission über den Wettbewerb auf dem Markt für Telekommunikationsendgeräte 88/301/EWG und die Richtlinie über den Wettbewerb auf dem Markt für Telekommunikationsdienste 90/388/ EWG. Vgl. zu dieser Entwicklung in den 70er- und 80er-Jahren allg. H. v.d.Groeben Kommentar zum EWG-Vertrag, 4. Aufl. (1991), Art. 90, Rn. 83ff.; zur neueren Entwicklung vgl. nur W. Hoffmann-Riem Telekommunikationsrecht als europäisiertes Verwaltungsrecht, in: Schmidt-Aßmann/Hoffmann-Riem (Hrsg.) Strukturen des Europäischen Verwaltungsrechts, 1999, $191 \mathrm{ff}$.

${ }^{23}$ Vgl. 1. Pernice in: Grabitz (Hrsg.) Kommentar zum EWG-Vertrag, 1983, Art. 90 Rn. 2; v.d.Groeben (Fn. 22), Art. 90, Rn. 1.

${ }^{24}$ Die europäische Fernsehrichtlinie ist, nachdem sich die Kommission mit Hilfe des Grünbuchs „Fernsehen ohne Grenzen“ selbst für diesen Bereich zuständig erklärt hatte, durch eine äußerst großzügige Interpretation der Dienstleistungsfreiheit (Art. 59 EG) in mehreren Urteilen des EuGH möglich worden. Vgl. Kommission der Europäischen Gemeinschaften, KOM (84) 300 endg. Fernsehen ohne Grenzen, Brüssel 1984; dazu etwa M. Holznagel Rundfunkrecht in Europa. Auf dem Weg zu einem Gemeinrecht europäischer Rundfunkordnung, 1996, $123 \mathrm{ff}$; kritisch $M$. Stock Europäisches Medienrecht im Werden - Probleme und Chancen, RuF 37 (1989), 180 ff., $182 \mathrm{ff}$. Zur Rolle des EuGH vgl. nur N. Petersen Rundfunkfreiheit und EG-Vertrag, Die Einwirkung des europäischen Rechts auf die Ausgestaltung der nationalen Rundfunkordnung, 1994, 21 f.; Holznagel ebd., $123 \mathrm{ff}$.; T. Vesting Prozedurales Rundfunkrecht, 1997, 256ff., $269 \mathrm{ff}$;; aus dem neue- 
Bereits diese beiden Beispiele zeigen, wie sehr der EG-Vertrag im Laufe seiner Existenz eine Eigendynamik jenseits des mitgliedstaatlichen Ableitungszusammenhangs entwickelt hat. Diese Eigendynamik resultiert nicht zuletzt aus der Rechtsprechung des EuGH. ${ }^{25}$ Die Rechtsprechung des EuGH orientiert sich ganz an den funktionalen Erfordernissen einer transnationalen Rechtsordnung, aber gerade nicht an einem ,supranationalen“ Willen. Damit wird eine an sektoralen Funktionserfordernissen orientierte Differenz von Text und Interpretation freigesetzt, die in der Praxis zu einer laufenden „Rechtsfortbildung“ des Europarechts führt. Diese Rechtsfortbildung wirkt dann auf das nationalstaatliche Recht zurück und europäisiert dieses seinerseits. ${ }^{26}$

Die Beeinflussung und der Umbau des Staatsrechts durch Europarecht lassen sich etwa im Bereich der Grund- und Menschenrechte beobachten. Dafür steht nicht nur die Europäische Menschenrechtskonvention. Auch die Auslegung der Grundrechte des Grundgesetzes ist heute stark vom Europarecht geprägt, sowohl von den Grundfreiheiten des EG-Vertrages als auch von europäischen Grundrechten. Dieser Trend wird sich durch die Grundrechtscharta und die Entwicklung der Unionsrechte weiter fortsetzen. ${ }^{27}$

ren Schriftum C. Roider Perspektiven einer europäischen Rundfunkordnung, 2001. Telekommunikations- und Medienrecht sind zugleich Beispiele für eine Vorstrukturierung der Handlungsmöglichkeiten der Legislativorgane des Nationalstaats, entweder, wie im Fall der Telekommunikation, auf Bundesebene oder, wie im Fall des Rundfunks, auf Landesebene.

${ }^{25}$ Es geht nicht so sehr um eine „open-texture" Situation (im Sinne Harts), wie etwa Schroeder (Fn. 21), 49, glaubt, sondern eher um eine institutionell unvermeidbare „preference for Europe“, wenn man einmal ein europäisches Gericht gegründet hat.

${ }^{26}$ Dieser Prozess verläuft durchaus netzwerkartig, nicht aber, wie viele Europarechtler glauben, von „oben“ nach „unten“: Die authentische Interpretation des EG-Rechts obliegt zwar in erster Linie den EG-Organen, vor allem dem EuGH. Dennoch wird durch das Europarecht eine Verknüpfung unterschiedlicher „Rechtskreise“ notwendig, deren jeweilige Eigenlogik jetzt aufeinander abgestimmt werden muss. Das hängt nicht zuletzt damit zusammen, dass der mittelbare Vollzug, die Ausführung des EG-Rechts durch nationale Verwaltungsbehörden, in der Praxis den Großteil der Fälle ausmacht (vgl. auch Fn. 88).

${ }^{27}$ Vgl. nur B.-O. Bryde Konstitutionalisierung des Völkerrechts und Internationalisierung des Verfassungsrechts, Der Staat 42 (2003), 61 ff.; C. Tietje Die Staatsrechtslehre und die Veränderung ihres Gegenstandes: Konsequenzen von Europäisierung und Internationalisierung, DVBI 2003, 1081; H.-W. Rengeling Grundrechtsschutz in der Europäischen Gemeinschaft, 1993. Durch die Einwirkungen des Europarechts ist es auf dieser Ebene beispielsweise zu einer Ausdehnung des Kreises der Grundrechtsberechtigten gekommen (Lohngleichheit, Freizügigkeit), aber auch zur Erhöhung des mitgliedstaatlichen Grundrechtsschutzes (Umweltschutzvorschriften, PCP-Verbot). 
Dass man hinsichtlich der Europäisierung mit Fug und Recht von einem Umschlag von Quantität in Qualität sprechen kann, wird auf der Ebene des Verwaltungsrechts vielleicht noch deutlicher. ${ }^{28}$ Das Verwaltungsrecht, das bei Otto Mayer nicht zufällig den Namen „Deutsches Verwaltungsrecht" trug, ist heute in hohem Maße durch Europarecht geprägt. Im Besonderen Verwaltungsrecht gilt dies nicht nur für das Medien- und Telekommunikationsrecht. Die Konsequenzen der Europäisierung zeigen sich genauso deutlich im Umweltrecht, ${ }^{29}$ im Energierecht ${ }^{30}$ und im Wirtschaftsrecht, hier insbesondere im Bereich des Subventionsrechts und der Beihilfe. ${ }^{31}$

Darüber hinaus sind inzwischen sämtliche Kernbereiche des Allgemeinen Verwaltungsrechts in das „Gravitationsfeld“ des Europarechts geraten.32 Dafür stehen etwa die Einwirkungen des Europarechts auf die Rechtsquellenlehre, auf das Verwaltungshandeln, das Verwaltungsverfahren und den Verwaltungsrechtsschutz. Auch das Verwaltungsprozessrecht ${ }^{33}$ und das Staatshaftungsrecht ${ }^{34}$ haben sich unter dem Einfluss des Gemeinschaftsrechts verändert. Das nationale Verwaltungsrecht ist in-

$28 \mathrm{Vgl}$. allgemein nur $F$. Schoch Europäisierung des Allgemeinen Verwaltungsrechts und des Verwaltungsprozessrechts, NordÖR 2002, $1 \mathrm{ff}$; ders. Europäisierung der Verwaltungsrechtsordnung - einschließlich Verwaltungsverfahrensrecht und Rechtsschutz, VBIBW 1999, $241 \mathrm{ff}$; E. Schmidt-Aßmann Das allgemeine Verwaltungsrecht als Ordnungsidee, 1998, $29 \mathrm{ff} ., 307 \mathrm{ff}$; Kadelbach (Fn. 20); Th. v. Danwitz Verwaltungsrechtliches System und Europäische Integration, 1996.

${ }^{29} \mathrm{~F}$. Schoch Individualrechtsschutz im deutschen Umweltrecht unter dem Einfluß des Gemeinschaftsrechts, NVwZ 1999, $457 \mathrm{ff}$;; W. Köck Das Pflichten- und Kontrollsystem des Öko-Audit-Konzepts nach der Öko-Audit-Verordnung und dem Umweltauditgesetz, VerwArch 1996, 644ff.; R. Steinberg Probleme der Europäisierung des deutschen Umweltrechts, AöR 1995, $549 \mathrm{ff}$.

${ }^{30}$ H.-P. Schneider Liberalisierung der Stromwirtschaft durch regulative Marktorganisation, $1999,384 \mathrm{ff}$.

31 Zum Wirtschaftsrecht vgl. R. Schmidt Öffentliches Wirtschaftsrecht in einer offenen Staatlichkeit, FS Vogel, 2000, $21 \mathrm{ff}$.; zu Subventionsrecht und Beihilfe vgl. den Überblick bei $P$. Badura in: Schmidt-ABmann (Hrsg.) Besonderes Verwaltungsrecht, 12. Aufl., 2003, $245 \mathrm{ff}$., $313 \mathrm{ff}$., $317 \mathrm{ff}$; D.H. Scheuing Europäisierung des Verwaltungsrechts, Die Verwaltung 34 (2001), $107 \mathrm{ff}$.

32 V. Danwitz (Fn. 28), 190 ff., 334; vgl. auch allg. Kadelbach (Fn. 20), 296ff., SchmidtAßmann (Fn. 28), $31 \mathrm{f}$.

${ }_{33}$ P.M. Huber Die Europäisierung des verwaltungsgerichtlichen Rechtsschutzes, BayVBl 2001, $577 \mathrm{ff}$; $W$. Buck Die Europäisierung des verwaltungsgerichtlichen vorläufigen Rechtsschutzes, 2000; F. Schoch Die europäische Perspektive des Verwaltungsverfahrens- und Verwaltungsprozessrechts, in: Schmidt-Aßmann/Hoffmann-Riem (Hrsg.) Strukturen des Europäischen Verwaltungsrechts, 1999, $279 \mathrm{ff}$.; C.D. Classen Die Europäisierung der Verwaltungsgerichtsbarkeit, 1996.

${ }^{34}$ F. Schoch Europäisierung des Staatshaftungsrechts, FS Maurer, 2001, $759 \mathrm{ff}$. 
zwischen durchgehend mit Komponenten des Europarechts durchsetzt. Es ist jedenfalls nicht mehr möglich, das auf dem Territorium der Bundesrepublik geltende Verwaltungsrecht als deutsches Verwaltungsrecht zu bezeichnen: als das eigentümliche Recht der Beziehung zwischen verwaltendem Staat und seinem ihm dabei begegnendem Untertan. ${ }^{35}$ Das Zeitalter Otto Mayers ist endgültig verstrichen. In der Literatur wird in diesem Zusammenhang auch von einer „Ent-Territorialisierung“ des Verwaltungsrechts gesprochen. ${ }^{36}$

\section{Vom Völkerrecht zum Menschheitsrecht \\ a) Die staatsrechtliche Konzeption des Völkerrechts}

Nach herkömmlicher (und noch heute weit verbreiteter) Auffassung ist das Völkerrecht ein Derivat des Staatsrechts. Es ist Völkerrecht im Sinne eines „Verkehrsrechts“, das die Beziehungen zwischen souveränen Nationalstaaten normiert. ${ }^{37}$ Noch heute wird das Völkervertragsrecht entsprechend dieser Tradition als „Hauptrechtsquelle“ des Völkerrechts angesehen. ${ }^{38}$ Dazu passt, dass die Geltung des Völkergewohnheitsrechts (der zweiten allgemein akzeptierten Quelle des Völkerrechts) zumindest in der deutschen Staatsrechtslehre des 19. Jahrhunderts nie ganz unumstritten war. ${ }^{39}$

Bereits darin zeigt sich, dass das Völkerrecht durch die Grundaxiome des staatsrechtlichen Positivismus bestimmt worden ist und bis heute bestimmt wird. So wie die Unterscheidung von Staat und Gesellschaft auf der Innenseite des Staates in der Regel als Unterordnung des Individuums unter den Staat interpretiert wurde, als Subordination, war auch die begriffliche Opposition Innen/Außen in Form der Hierarchie gebaut.

${ }^{35}$ Mayer(Fn. 4), 14. Verwaltung ist für Mayer „Tätigkeit des Staates zur Verwirklichung seiner Zwecke unter seiner Rechtsordnung, außerhalb der Justiz."

${ }^{36} \mathrm{Vgl}$. C. Tietje Internationalisiertes Verwaltungshandeln, 2001, 174ff.; Vesting (Fn. 24), 254f.; von Danwitz (Fn. 28), 414f.; E. Schmidt-Aßmann Deutsches und Europäisches Verwaltungsrecht, DVBI 1993, 924, 936. In ähnlicher Weise wird in der politikwissenschaftlichen Literatur der „Inter-Relations" schon seit einiger Zeit vom Ende der Territorien gesprochen. Vgl. nur B. Badie La Fin de territoires, Paris, 1995.

37 A.W. Heffter Das europäische Völkerrecht der Gegenwart auf den bisherigen Grundlagen, 7. Aufl., Berlin 1882, 3; dazu B. Fassbender Der Schutz der Menschenrechte als zentraler Inhalt des völkerrechtlichen Gemeinwohls, EuGRZ 2003, 2.

$38 \mathrm{Vgl}$. nur K. Ipsen Völkerrecht, 1999, 92 ff.

$39 \mathrm{Vgl}$. nur H. Triepel Völkerrecht und Landesrecht, Leipzig 1899, 95ff., 99, für den Völkergewohnheitsrecht nur das ist, was „als Bestandtheil einer rechtsetzenden Vereinbarung " auftritt oder in eine solche Vereinbarung zwischen Staaten zurückgeführt werden kann. 
Staatsrecht und Völkerrecht wurden im späten 19. Jahrhundert zwar als zwei strikt verschiedene Rechtsordnungen gedacht. ${ }^{40}$ Der Unterschied von Völkerrecht und Staatsrecht fand seine Einheit jedoch im Staatsrecht. Der Staat war die Basis, auf dem das Völkerrecht ruhte. Die Geltung des Völkerrechts gründete in der Unabhängigkeit und Einheit einer Verträge schließenden und diese bestimmenden Staatsgewalt. ${ }^{41}$

\section{b) Entwicklungen ihrer Auflösung}

Der Trend einer Lösung des Öffentlichen Rechts vom Nationalstaat lässt sich auch im Völkerrecht nachweisen. ${ }^{42}$

Die Grenzen der traditionellen Zentrierung des Völkerrechts auf den Staat werden zunächst in der Einbindung der Staaten in ein dichtes Netz von Verträgen sichtbar. Obwohl die Staaten Urheber der Verträge sind, hat die zwischenstaatliche Kooperation mittlerweile eine solche Dichte erreicht, dass sich die Stellung der Staaten innerhalb dieses Netzwerks von Verträgen und den daraus hervorgegangenen Institutionen ${ }^{43}$ selbst verändert hat. Das hängt nicht zuletzt damit zusammen, dass die Kooperation zwischen den Staaten nicht mehr ausschließlich über die Staatsspitze bzw. die auswärtige Gewalt erfolgt, sondern sich in variablen Strukturen zwischen Ministerien, Verwaltungen, Regulierungsbehörden, Gerichten usw. festsetzt.

\footnotetext{
${ }^{40}$ Grundlegend Triepel (Fn. 39), 11 ff. (Völkerrecht und Landesrecht als Gegensätze); dazu aus jüngerer Zeit ausführlich Tietje (Fn. 36), 86ff., $94 \mathrm{ff}$.

${ }^{41}$ Triepel (Fn. 39), $27 \mathrm{ff}$., $63 \mathrm{ff}$. (Völkerrecht entsteht durch „Vereinbarung“ zwischen Staaten); ähnlich bereits Heffler (Fn. 37), 5, 23 (,Völkerverträge" der "Staatsgewalten“); eine Ausnahme ist hier Jellinek (Fn. 4), 378f., der davon ausgeht, dass das Völkerrecht nur formell im Willen der vertragsschließenden Einzelstaaten gründet, materiell aber einem „Etwas“ entspricht, „das über den Einzelstaat hinausgeht"; dazu Tietje (Fn. 36), 71 ff.; zur Lage des Völkerrechts um 1900 vgl. auch F. Herrmann Das Standardwerk, 2001, insb. $175 \mathrm{ff}$. Der h.M. entsprach es, dass das Völkerrecht auch als akademisch-universitäre Disziplin um 1900 kaum mehr als ein Supplement des Staatsrechts war. Vgl. dazu M. Stolleis Geschichte des öffentlichen Rechts in Deutschland, Bd. 3, 1999, 88f.

42 Dazu allg. J. Delbrück Das Staatsbild im Zeitalter wirtschaftsrechtlicher Globalisierung, in: Tietje/Kraft (Hrsg.) Arbeitspapiere aus dem Institut für Wirtschaftsrecht, Heft 3; ders. Structural Changes in the International System and its Legal Order: International Law in the Era of Globalization, Schweizerische Zeitschrift für internationales und europäisches Recht 2001, 1 ff., $26 \mathrm{ff}$.; D. Thürer Modernes Völkerrecht, ZaöRV 2000, $557 \mathrm{ff}$;; P. Zumbansen Die vergangene Zukunft des Völkerrechts, KJ 34 (2001), 46ff.; Hobe (Fn. 20).

${ }^{43}$ Die vielen internationalen Organisationen, die aus den völkerrechtlichen Verträgen hervorgegangen sind, man denke nur an den Sicherheitsrat der Vereinten Nationen (UN) oder die verschiedenen Organisationen zur gerichtlichen Beilegung von Streitigkeiten (wie z.B. den ständigen Haager Gerichtshof), legen davon Zeugnis ab. Ihre Zahl betrug 1998: 48350. Vgl. dazu Tietje (Fn. 36), 116ff.
} 
Diese Dynamik treibt das Völkerrecht über ein Staatenkooperationsrecht hinaus zu einem autonomen Staatengemeinschaftsrecht, das seinerseits in die staatlichen Territorien hineinwirkt. ${ }^{44}$ In diesem Staatengemeinschaftsrecht sind die Staaten nicht mehr nur "Herren der Verträge“, sondern - um im Bild zu bleiben - zugleich ihre „Knechte“.

Ein Beispiel dafür ist das Recht der Welthandelsorganisation (WTO). Wurde der grenzüberschreitende Freihandel zu Zeiten des staatsrechtlichen Positivismus noch als von der Erlaubnis des Nationalstaates abhängig gedacht, ${ }^{45}$ bringt das WTO-Recht jetzt genau umgekehrt die Nichtdiskriminierung freier Märkte als zentralen Rechtsgrundsatz gegen die Staaten in Anschlag. ${ }^{46}$ Der Grundsatz der Nichtdiskriminierung wirkt sich zumindest auch mittelbar in den Mitgliedstaaten aus. Zwar verfügt die WTO über keine explizit eingeräumten Rechtsetzungskompetenzen. Die Verselbstständigung des WTO-Rechts zeigt sich aber deutlich im Streitbeilegungsverfahren (Dispute Settlement Understanding, Art. III Abs. 3 WTO). Vor allem das Berufungsgremium, der Appellate Body, verfügt über eine eigenständige Kompetenz der ,adjudication“..47 Damit setzt auch das WTO-Recht eine Dynamik funktionsorientierter Rechtsfortbildung frei, ähnlich wie sich die Rechtsprechung des EuGH nicht in reiner Rechtsanwendung, der Deduktion aus Regeln, erschöpft. ${ }^{48}$

${ }^{44}$ In diese Richtung denkend etwa Thürer (Fn. 42), $557 \mathrm{ff}$., $595 \mathrm{ff}$.; B. Simma From Bilateralism to Community Interest in International Law, Recueil des Cours 281 (1999), 221 (233); Tietje (Fn. 36), 180; zusammenführend B. Fassbender UN Security Council Reformand the Right of Veto, The Hague/London/Boston 1998, $50 \mathrm{ff}$. Kritisch dazu aus demokratietheoretischer Perspektive $S$. Oeter Internationale Organisation oder Weltföderation? Die organisierte Staatengemeinschaft und das Verlangen nach einer Verfassung der Freiheit, in: Brunkhorst/Kettner (Hrsg.) Globalisierung und Demokratie - Wirtschaft, Recht, Medien, 2000, $208 \mathrm{ff}$;; ders. Souveränität - ein überholtes Konzept?, FS Steinberger, 2002, $259 \mathrm{ff}$., 298.

${ }^{45} \mathrm{Zu}$ dieser Abhängigkeit und ihren Ambivalenzen Delbrück (Fn. 42 - Staatsbild), 8.

46 Das Gebot der Nichtdiskriminierung wird u.a. in der Form von Meistbegünstigung und Inländerbehandlung gegen die Staaten geltend gemacht.

47 J.P. Trachtmann The Domain of WTO Dispute Resolution, Harvard International Law Journal 40 (1999), $333 \mathrm{ff}$. Der im deutschen Schrifttum vielfach anzutreffende Vergleich des Streitbeilegungsverfahrens mit einem Gericht trifft die Funktion des Appellate Body nur teilweise.

$48 \mathrm{Vgl}$. Trachtman (Fn. 47), 338. Auch wenn Panel und Appellate Body an die herkömmlichen Regeln der Auslegung des Völkerrechts und damit an die Interpretationsregeln der Wiener Konvention gebunden sind (Art. 3 Abs. 2 DSU), ist diese Unterscheidung in der Praxis des Appellate Body fließend geworden. Gründe sind u.a.: die unvermeidbare Lückenhaftigkeit der WTO-Verträge selbst und andere „Unschärferelationen“ des WTORechts, insbesondere das Verhältnis von WTO-Recht zu sonstigem (Völker-)Recht. Zum WTO-Recht vgl. nur A. v.Bogdandy Verfassungsrechtliche Dimensionen der Welthandels- 
Auch im humanitären Völkerrecht lassen sich Tendenzen einer Lösung des Völkerrechts vom Staat und seiner Rückwirkung auf das Staatsrecht feststellen.

Auslöser für diese Verselbstständigungstendenzen ist einmal die unterschiedliche wirtschaftliche Entwicklung der Weltregionen. Darauf hat das humanitäre Völkerrecht mit der Ausarbeitung sozialer Menschenrechte in Form der Anerkennung sozialer Mindeststandards und einem Recht auf Entwicklung reagiert. ${ }^{49}$ Daneben haben die schon seit längerem sichtbare Veränderung des Krieges, die Veränderung der weltpolitischen Lage seit 1989 sowie der Umgang mit Diktatoren und „Schurkenstaaten“ dem humanitären Völkerrecht zu wachsender Bedeutung verholfen. Dies hat in Rechtsprechung und Literatur u.a. zur Anerkennung bestimmter Verpflichtungen eines Staates gegenüber allen anderen Staaten geführt (sog. erga omnes-Pflichten), beispielsweise in Form des Verbots des Angriffskrieges, des Völkermordes, der Sklaverei oder der Rassendiskriminierung. ${ }^{50}$ Eine andere Fallgruppe ist die Anerkennung zwingenden Völkerrechts (jus cogens) vor allem in Form des Folterverbots, ${ }^{51}$ des Rechts auf Leben ${ }^{52}$ oder einer sich abzeichnenden Beschränkung des staatlichen Immunitätsschutzes bei schweren Menschenrechtsverletzungen..$^{53}$

Neben der Forderung nach weltwirtschaftlicher „Gerechtigkeit“ entwickelt sich im Völkerrecht also offensichtlich ein weiterer globaler rechtlicher Kode der „Humanität“, der die staatliche Mediatisierung des

organisation, 1. Teil: Entkopplung von Recht und Politik, KJ 2001, 267; R. Uerpmann Internationales Verfassungsrecht, JZ 2001, 565, 569; Delbrïck (Fn. 42 - Staatsbild), $13 \mathrm{ff}$.; M. Herdegen Internationales Wirtschaftsrecht, 2002, $120 \mathrm{ff}$. Um die Autonomie und Eigendynamik des WTO-Rechts rechtswissenschaftlich besser abbilden zu können, erscheint es durchaus plausibel, den Begriff des Völkerrechts in diesen Zusammenhängen aufzugeben und durch den Begriff des transnationalen (Wirtschafts-)Rechts zu ersetzen. In diese Richtung etwa $C$. Tietje Transnationales Wirtschaftsrecht aus öffentlich-rechtlicher Perspektive, Zeitschrift für Vergleichende Rechtswissenschaft - Archiv für Internationales Wirtschaftsrecht 4 (2002), $404 \mathrm{ff}$.; kritisch z.B. Herdegen ebd., 26.

49 E. Riedel Menschenrechte der dritten Dimension, EuGRZ 1989, $9 \mathrm{ff}$.

50 Ausgangspunkt ist hier der Barcelona Traction, ICJ Reports 1970; weitere Nachweise bei Fassbender (Fn. 37), 6 f.

51 Vgl. International Criminal Tribunal for the former Yugoslavia (ICTY), Prosecutor v. Furundžija, Judgment of 10 Dec. 1998, case no. IT-95-17/I-T, paras. 153, 154, in: ILM 38 (1999), 317 (349).

52 C. Tietje/S. Hobe Schießbefehl an der DDR-Grenze und ius cogens, Archiv des Völkerrechts 32 (1994), $130 \mathrm{ff}$.

53 EGMR, Urteil vom 21. 11. 2001 - Al Adsani, EuGRZ 29 (2002), 403 ff.; C. Maierhöfer Der EGMR als „Modernisierer“ des Völkerrechts? - Staatenimmunität und ius cogens auf dem Prüfstand, EuGRZ 29 (2002), 391-398. 
Völkerrechts mehr und mehr durchbricht und selbst das Staatsrecht beeinflusst. ${ }^{54}$ Stellt man höhere Ansprüche an sprachliche Genauigkeit geht es im humanitären Völkerrecht gar nicht mehr um Völkerrecht, sondern um Menschheitsrecht, um das humanitäre Recht der Weltgesellschaft. 55

\section{Transnationale und internationale privat-öffentliche Regulierungsnetzwerke}

Der Eindruck einer Aufweichung der Exklusivität der Staatszentrierung des Völkerrechts verstärkt sich weiter, wenn man die Zunahme der Bedeutung solcher Regulierungsnetzwerke in die Betrachtung einbezieht, an deren Norm- und Regelbildung neben staatlichen auch nicht-staatliche Akteure wie Nichtregierungsorganisationen (NGOs), Verbände, Sachverständige, agencies usw. beteiligt sind. Gerade NGOs sind heute vielfach in transnationalen Rechtsbildungsprozessen involviert und übernehmen dort funktional die Rolle, die im Nationalstaat politischen Parteien und Verbänden zukommt (ja teilweise nehmen NGOs selbst die Rolle von Staaten ein). ${ }^{56}$ Das zeigt etwa der Einfluss von Greenpeace bei der Entwicklung solcher umweltrechtlicher Institutionen wie der Verschmutzungszertifikate. Ein anderes Beispiel ist der Einfluss von amnesty inter-

\footnotetext{
${ }^{54}$ Im Ergebnis löst sich damit die seit der Französischen Revolution sichtbare Paradoxie der Zwillingsexistenz von Menschenrechtsidee und Nationalstaatsprinzip zugunsten der Menschenrechte auf. In diese Richtung etwa A. Paulus Die internationale Gemeinschaft im Völkerrecht - Eine Untersuchung zur Entwicklung des Völkerrechts im Zeitalter der Globalisierung, 2001, 358; C. Tomuschat International Law: Ensuring the Survival of Mankind on the Eve of a new Century, Receuil des Cours 281 (1991), 9-438; Fassbender (Fn. 37), 6f.; in der Tendenz ähnlich S. Kadelbach Zwingendes Völkerrecht, 1992, 320 - „Positionen“ für die „Rechtssubjekte Staat, Gruppe, Einzelner“.

55 Vor allem die Verselbstständigungstendenzen im humanitären Völkerrecht werden in der Literatur als Beleg für eine grundsätzlichere Umstellung des Völkerrechts von zwischenstaatlichem Koordinationsrecht auf Staatengemeinschaftsrecht oder das Recht der internationalen Gemeinschaft angesehen. Vgl. z.B. Paulus(Fn. 54), 285 ff. Diese Richtung als gemeinwohlorientierte Normkategorien generalisierend z.B. Fassbender (Fn. 37), 16 mwN, der von einer ,zeitgemäßen Rechtsordnung interdependenter Völker einer Menschheit" spricht. Zu den Menschenrechten als Faktoren des Rechts der Weltgesellschaft Luhmann (Fn. 16), $574 \mathrm{ff}$.

${ }_{56}$ Dazu Tietje(Fn. 36); Hobe (Fn. 20), 309ff.; Wahl(Fn. 2), 43; K. Günther/S. Randeria Recht, Kultur und Gesellschaft im Prozeß der Globalisierung, in: Werner Reimers Stiftung (Hrsg.) Suchprozesse für innovative Fragestellungen in der Wissenschaft, Heft 4 (2001), $63 \mathrm{ff}$;; aus der neueren politikwissenschaftlichen Literatur vgl. nur R.A. Higgott (ed.), Non-State Actors and Authority in the Global System, London/New York 2000.
} 
national auf die Standards von Menschenrechten, z.B. im Bereich der Folterung mit Wissen oder unter dem Schutz staatlicher Organe. ${ }^{57}$

Vergleichbare Entwicklungen lassen sich im internationalisierten Verwaltungshandeln beobachten. Hier zeichnet sich ab, wie durch Prozesse der Internationalisierung nicht nur die territorialen Staatsgrenzen destabilisiert werden, sondern zugleich die für das liberale Staatsrecht konstitutive Grenzziehung zwischen dem Öffentlichen und dem Privaten unterlaufen wird.

Das Muster lässt sich folgendermaßen beschreiben: Ausgangspunkt des internationalisierten Verwaltungshandelns sind Kooperationen zwischen internationalen und nationalen Verwaltungsbehörden. Dabei entsteht regelmäßig ein ausgeprägtes Kommissionswesen, dessen Arbeit die Einbeziehung technisch-wissenschaftlichen Sachverstands erforderlich macht. Da die Normen und Standards, die in diesen transnationalen Regulierungsnetzwerken entstehen - ähnlich wie in der „Komitologie“ auf europäischer Ebene ${ }^{58}$ - einem starken Einfluss privater Regelbildung ausgesetzt sind, wird die Grenze zwischen dem Privaten und dem Öffentlichen undicht.

Ein Beispiel für die Produktion von Standards, die in privat-öffentlichen Netzwerken eines internationalen Kommissionswesens geschaffen und von hier aus auf Völkerrecht, WTO-Recht, Gemeinschaftsrecht und nationales Verwaltungsrecht einwirken, liefert die Standardisierung des Lebensmittelrechts durch die Codex Alimentarius-Kommission. ${ }^{59}$ Diese Standards entfalten zwar keine unmittelbare völkerrechtliche Wirksamkeit, gleichwohl ist in der einschlägigen Literatur aber die faktische normative Wirkkraft der Codex Alimentarius-Standards unbestritten. ${ }^{60}$ So

${ }^{57}$ Hobe (Fn. 20), 322ff.; vgl. allg. auch A. Bianchi Globalization of Human Rights: The role of Non-state Actors, in: G. Teubner (Hrsg.) Global Law Without a State, Aldershot u.a. $1997,179 \mathrm{ff}$.

58 Gemeint sind die technisch-wissenschaftlichen Ausschüsse und Agenturen innerhalb der Europäischen Gemeinschaft. Vgl. G. Lübbe-Wolf Europäisches und nationales Verfassungsrecht, VVDStRL 60 (2001), 246ff., 268ff.; C. Joerges/J. Falke (Hrsg.) Das Ausschußwesen der Europäischen Union, 2000, $17 \mathrm{ff}$.; C. Joerges Bureaucratic Nightmare, Technocratic Regime and the Dream of Good Tansnational Governance, in: ders./E. Vos (Hrsg.) EU Committees: Social Regulation, Law and Politics, Oxford, 1999, $3 \mathrm{ff}$.

59 Die Codex Alimentarius-Kommission befasst sich mit der Standardisierung des Lebensmittelrechts und hat bis heute etwa 200 Lebensmittelstandards verabschiedet sowie mehr als 3000 Standards für maximale Pestizidrückstände - vgl. nur Tietje (Fn. 36), $301 \mathrm{ff}$.

60 Tietje(Fn. 36), 313 mwN; C. Joerges „Gutes Regieren“ im Binnenmarkt, in: Joerges/ Falke (Fn. 58), 349, $373 \mathrm{ff}$. 
reflektieren z.B. zahlreiche Rechtsinstrumente der EG, an die die Mitgliedstaaten viele ihrer Kompetenzen im Lebensmittelbereich abgegeben haben, eben jene Codex-Standards.

\section{Globales Recht ohne Staat}

Das Schlagwort vom globalen Recht ohne Staat referiert auf Rechtsbildungsprozesse, in denen die Norm- und Regelbildung in ähnlicher Weise auf Netzwerke verlagert wird, wie im Fall der privat-öffentlichen Regulierungsnetzwerke. Im Gegensatz zu diesen nimmt die Bedeutung der Beteiligung öffentlicher Organisationen (Regulierungsbehörden, Gerichte, Gesetzgebung) hier aber weiter ab. ${ }^{61}$ Als Beispiel dafür könnte man die Regulierung globaler Finanzmärkte nennen, etwa die Entwicklung von Standards der Transparenz und Rechnungsauslegung. ${ }^{62}$

Reiches Anschauungsmaterial für die These des globalen Rechts ohne Staat liefert darüber hinaus die Regulierung des Internets. Dabei kann man einmal auf die Verwaltung der Domain Names durch die ICANN verweisen. ${ }^{63}$ Wie sehr sich die materielle Regelbildung im Internet dabei vor allem vom staatlichen Gesetzgebungsakt löst, ${ }^{64}$ zeigt der Fall der technischen Standards. Die Netzwerkstandards gewinnen im Internet eine neuartige Bedeutung, weil sie, ähnlich wie früher die grammatischen Regeln der Sprache, in der operativen Basis digitaler Kommunikation selbst verankert sind. Die Folgen treten etwa im Datenschutzrecht hervor. Das Datenschutzrecht verwandelt sich weitgehend in ein technisches Recht, und das heißt: in ein Recht der Software Standards. ${ }^{65}$

${ }^{61}$ Grundlegend: G. Teubner,Global Bukowina': Legal Pluralism in the World Society, in: ders. (Fn. 57), $3 \mathrm{ff}$; K.-H. Ladeur Die Rechtswissenschaftliche Methodendiskussion und die Bewältigung des gesellschaftlichen Wandels, Rabels Zeitschrift für ausländisches und internationales Privatrecht 64 (2000), 60, $98 \mathrm{ff}$.; dazu auch $S$. Oeter International Law and General Systems Theory, German Yearbook of International Law, 2001, $72 \mathrm{ff}$.

62 Tietje (Fn. 48).

${ }^{63}$ Teubner (Fn. 61); G. Teubner/V. Karavas http://www.CompanyNameSucks.com: Drittwirkung der Grundrechte gegenüber „Privaten“ im autonomen Recht des Internet?, in: W. Hoffmann-Riem/K.-H. Ladeur (Hrsg.) Innovationsoffene Regulierung des Internet, 2003 (i.E.); J. v. Bernstorff ICANN as a Global Governance Network: The Rise and Fall of a Governance Experiment, in: C. Joerges/I.-J. Sand/G. Teubner (Hrsg.) Transnational Governance and Constitutionalism, Oxford, 2003 (i.E.).

${ }^{64} \mathrm{Vgl}$. dazu allg. V. Géczy-Sparwasser Die Gesetzgebungsgeschichte des Internet, 2003, insb. $253 \mathrm{f}$.

65 Das hat in der rechtswissenschaftlichen Literatur sogar zu der Vermutung geführt, dass die Netzwerkstandards die Ordnungsfunktion des Rechts selbst ersetzen. Die Internetregulierung liefe dann in essenziellen Bereichen nicht nur auf Lösungen ohne Staat, sondern sogar auf „Lösungen ohne Recht" hinaus. Vgl. nur C. Engel Das Internet und 


\section{Die Suche nach Alternativen: Offener Staat, Konstitutionalismus, Rechtspluralismus}

Die Skizze einiger Prozesse der Europäisierung und Internationalisierung hat deutlich gemacht: Wenn man den Akzent auf die Beschreibung der Veränderung der Beziehung von Öffentlichem Recht und Staat legt, liegt die entscheidende Neuerung im Unterschied zur Situation um 1900 nicht in einer wie auch immer einzuschätzenden Veränderung staatlicher Macht, sondern in der sich abzeichnenden Abkopplung des Öffentlichen Rechts vom Staat. Die im Staatsrecht des 19. Jahrhunderts und auch nach 1949 noch als selbstverständlich unterstellte Identität von Rechtsordnung und politischer Raumordnung hat sich zumindest teilweise aufgelöst.

Die Staatsrechtslehre sieht sich heute mit einem „Mehrebenensystem“ konfrontiert, in dem nationales Recht, Europarecht, Völkerrecht, transnationales und globales Recht variabel und flexibel miteinander verknüpft werden. Diese Verknüpfungen folgen keiner territorialen Logik mehr. Über die alten Differenzen des raumbezogenen Staats- und Völkerrechts hat sich eine funktionale Logik der Regulierung und Sicherung unterschiedlichster Sektoren, Interessen, Güter und Werte gelegt: 66 von der europäischen Regulierung der Telekommunikation und der Medien über die Gewährleistung freier weltweiter Handelsströme im Rahmen der WTO, dem universellen Menschenrechtsschutz des Völkerrechts bis hin zur Sicherung globaler Lebensmittel- und Internetstandards in internationalen und transnationalen Regulierungsnetzwerken.

Diese Entwicklung schlägt auch auf die Rechtsquellenlehre durch. So wie schon Bodin das Gesetz als Setzungsprodukt gegen das Recht als Phänomen der sozialen Selbstorganisation auszuspielen versuchte, schuf der staatsrechtliche Positivismus ein hierarchisch aufgebautes Rangfolgesystem von Rechtsnormen, in dem Rechtsbildung im Wesentlichen mit staatlicher Rechtsetzung identifiziert wurde. Obwohl die Verankerung des liberalen Rechts in Prozessen der gesellschaftlichen Selbstorganisation im 19. Jahrhundert insbesondere in Form von Eigentum und Freiheit anerkannt wurde, wurde die Rechtsbildung im staatsrechtlichen Positivismus

der Nationalstaat, in: Deutsche Gesellschaft für Völkerrecht (Hrsg.) Völkerrecht und Internationales Privatrecht in einem sich globalisierenden internationalen System - Auswirkungen der Entstaatlichung transnationaler Rechtsbeziehungen, 2000, $411 \mathrm{f}$; t tonangebend ist hier L. Lessig Kode and other Laws of Cyberspace, New York 2000.

66 Tietje (Fn. 36), 416, spricht von einem „komplexen Geflecht an territorialen und entterritorialisierten Strukturen des Rechts“; die „funktionale Dezentralisation“ und ihre weitreichenden, die jahrhundertelange „Essenz des Politischen“ sprengenden Folgen betont auch Wahl(Fn. 2), 37; vgl. auch G. Teubner Globale Zivilverfassungen: Alternativen zur staatszentrierten Verfassungstheorie, ZaöRV 63 (2003), 1-28. 
doch gleichsam als durch den Staat „aufgesogen “ dargestellt. ${ }^{67}$ Die Geltung der transnationalen Normen und Regeln kann aber nicht mehr abschließend in eine staatszentrierte Rechtsquellenhierarchie zurückgeführt werden. 68 Im Gegenteil, das verselbstständigte europäische, internationale, transnationale und globale Recht beeinflusst und bestimmt nun das Staatsrecht und seine Quellen selbst. ${ }^{69}$ Damit weicht die Trennung von staatlichem und nicht-staatlichem Recht einer Interdependenz und Kooperation zwischen verschiedenen Rechtsordnungen.

Der Ausgangspunkt der Staatsrechtslehre des 19. Jahrhunderts, das Öffentliche Recht als Staatsrecht, als Recht einer geschlossenen territorialen politischen Einheit denken und betreiben zu können, lässt sich vor dem Hintergrund der skizzierten Entwicklungen nicht mehr halten. ${ }^{70}$

${ }^{67}$ Jellinek (Fn. 4), 366. Jellinek spricht von „Aufsaugung“, bezieht dies aber zu Recht nur auf den staatlich geordneten Rechtschutz, also die staatliche Gerichtsbarkeit, nicht aber die darunter liegenden Infrastrukturen des Rechts. In die Richtung einer „Aufsaugung" denkend vgl. aus neuerer Zeit nur W. Reinhard Geschichte der Staatsgewalt, 1999, $291 \mathrm{ff}$.

68 Man denke als Beispiel nur noch einmal an das humanitäre Völkerrecht: Die Geltung der Menschenrechte liegt weder im staatlichen Gewaltmonopol begründet noch macht sie vor der territorialen Souveränität der Staaten halt. Wenn der Rechtscode der Humanität überhaupt einer Außenabstützung bedarf, dann dürfte er im moralisierenden Kommunikationsmodus der globalen Fernsehdemokratie zu suchen sein. Vgl. dazu nur K. Röhl Das Recht nach der visuellen Zeitenwende, JZ 2003, $339 \mathrm{ff} ., 344 \mathrm{f}$.

${ }^{69} \mathrm{Vgl}$. dazu auch C. Tietje, Recht ohne Rechtsquellen? Entstehung und Wandel von Völkerrechtsnormen im Interesse des Schutzes globaler Rechtsgüter im Spannungsverhältnis von Rechtssicherheit und Rechtsdynamik, Zeitschrift für Rechtssoziologie, 24 (2003), $27 \mathrm{ff}$.

${ }^{70}$ Das ist natürlich keine neue Erkenntnis, sondern bereits der berechtigte Kern der Bemerkung Carl Schmitts, dass die Epoche der Staatlichkeit zu Ende gehe. Die Zentrierung des Öffentlichen Rechts auf den Staat ist also nicht erst heute, im Zeitalter der Globalisierung, problematisch geworden. Ein Rückblick könnte zeigen, dass spätestens mit dem Ersten Weltkrieg eine Entwicklung eingeleitet wurde, durch die das Staatsrecht auf der Innenseite bereits in ähnlicher Weise unter Druck gesetzt worden ist, wie heute durch die Globalisierung auf der Außenseite. Vgl. nur Peters (Fn. 21), 130ff., 134f. Es ist daher kein Zufall, dass die Staatsrechtslehre im Bereich der wissenschaftlich systematischen Monographie schon während der Weimarer Republik in die Minderheitenposition gerät. Dass Kelsen, Smend und Schmitt kein Staatsrecht mehr geschrieben haben, kann als deutliches Indiz dafür angesehen werden, dass die komplementären Komposita von Rechtsstaat und Staatsrecht schon am Ende der Weimarer Republik ihre synthetisierende Kraft verloren hatten. Insbesondere Carl Schmitts „Begriff des Politischen“ (1932) könnte als ein früher Beleg für die Suche nach neuen Haltepunkten des Öffentlichen Rechts jenseits des Staates interpretiert werden. Aber so beeindruckend die Suchbewegungen der 20erund 30er-Jahre immer noch scheinen mögen, die Diskussion hat gezeigt, dass die Erklärungskraft von Integrationslehre, Wirklichkeitswissenschaft und Reiner Rechtslehre heute erschöpft ist. Gerade Carl Schmitt konnte und wollte die Suche nach neuen Hal- 
Entgegen früherer Szenarien, die in der Europäisierung und Internationalisierung nur einen Zerfall des Staates erkennen konnten (und wollten), hat die Staatsrechtslehre inzwischen begonnen, produktiv auf diese Prozesse zu reagieren. Drei Suchbewegungen, die neuen Phänomene zu verarbeiten, zeichnen sich ab.

\section{Der offene Staat}

Eine Richtung reagiert auf die neuartigen Herausforderungen mit dem Begriff des offenen Staates. ${ }^{71}$ Ausgangspunkt ist die Einsicht, dass sich das Öffentliche Recht gegenüber dem Staat verselbstständigt habe und eine rein staatszentrierte Betrachtungsweise den Anforderungen an ein wirklichkeitsnahes Öffentliches Recht nicht mehr gerecht werde. Deshalb wird eine "transmoderne Staatstheorie“ vorgeschlagen, die einerseits über den modernen Staat hinausweisen soll, aber andererseits nicht die „kraftvoll fortbestehenden öffentlichen Gewalten“ leugnet. ${ }^{72}$ Eine Variante dieses Konzepts setzt den „offenen Staat“ dem „souveränen Staat“ entgegen. ${ }^{73}$

Was die Offenheit des offenen Staates und damit den Begriff ausmacht, ist in beiden Konzeptionen nicht leicht ersichtlich. Seine Besonderheit besteht aber anscheinend darin, dass der Staat trotz aller Verflechtungen nach außen nicht aufgehört hat, ,Staat zu sein“ “ ${ }^{74}$

Der Haupteinwand, den die Theorie des offenen Staates entkräften muss, lautet: Es ist nicht möglich, in einem dichten Netzwerk staatlicher Kooperation von Eigenschaften des Staates auszugehen, die von diesem Netzwerk unabhängig sind und den Verbindungen zwischen den Staaten vorgegeben sein könnten. Ein nach außen vielfach eingebundener und in diesem Sinne „offener Staat“ ist eben kein Staat mehr. ${ }^{75}$ Diese Einsicht

tepunkten des Öffentlichen Rechts nicht mehr konstruktiv wenden, sondern hat das Öffentliche Recht direkt in die Nebelbänke der politischen Theologie geführt bzw. in die nicht weniger trüben Gewässer einer Theorie des konkreten Großraums.

71 U. di Fabio Das Recht offener Staaten, 1998, 122ff.; ders. Der Verfassungsstaat in der Weltgesellschaft, in: Walter Eucken Institut (Hrsg.) Beiträge zur Ordnungstheorie und Ordnungspolitik 166 (2001), $120 \mathrm{ff}$., 130 - „System offener, miteinander kooperierender und konkurrierender Staaten".

72 Di Fabio (Fn. 71), 133.

73 Wahl (Fn. 2), 17 ff., 49 (der „offene Staat“ als bleibender „ausschließlicher Kristallisationskern von politischen Prozessen“"); vgl. auch Hobe (Fn. 20), 380ff.; K. Vogel Der räumliche Anwendungsbereich der Verwaltungsrechtsnorm, 1965, $89 \mathrm{ff}$. („Verfall des Territorialprinzips").

$74 \mathrm{Wahl}$ (Fn. 2), 52.

$75 \mathrm{Vgl}$. auch Tietje (Fn. 27), 1164. 
wirft aber unweigerlich die Frage auf, warum man, um die neuen Phänomene begrifflich erfassen zu können, weiterhin am Staatsbegriff festhalten sollte. ${ }^{76}$

\section{Konstitutionalismus}

Der Konstitutionalismus favorisiert eine Höherlegung des politischen und administrativen Niveaus und sucht nach neuen Haltepunkten jenseits des Staates. Der Kern dieser Suchbewegung besteht darin, Vorstellungen von europäischer und internationaler Demokratie in den Vordergrund zu stellen und diese mit dem Verfassungsbegriff zu verknüpfen. So nimmt seit geraumer Zeit die Zahl der Publikationen zu, die, Analyse und Empfehlung verbindend, Europarecht, Völkerrecht, transnationales und globales Recht in einer Phase der Konstitutionalisierung sehen. ${ }^{77}$ Der Ver-

\footnotetext{
${ }^{76}$ Der Einwand ließe sich in der hier eingenommenen Perspektive etwa so formulieren: Der Staatsbegriff der Neuzeit referiert auf die flächenhafte Vorstellung eines Staatsgebiets. Ein Staatsgebiet setzt wiederum eine Grenze (von slawisch: granica) voraus, deren Integrität von anderen Staaten geachtet wird. Ein Territorium mit einer offenen Grenze ist aber kein Territorium mehr. Es wird vielmehr zu einem Transitraum, so wie auch die anderen staatlichen Territorien zu Transiträumen werden. Wenn das ausschlaggebende Moment des Raumes nicht mehr die Innenseite der Grenze ist, sondern das dauernde Kreuzen der Grenze (z.B. zwischen Düsseldorf und Palma de Mallorca), dann werden zwar nicht alle Unterschiede zwischen den Staaten beseitigt, durch das dauernde Kreuzen wird aber unweigerlich eine Dynamik freigesetzt, in der die „Umschlußfunktion des Raumes" (H. Heller) immer weniger einen Unterschied macht. Damit geraten zugleich die weiteren Voraussetzungen des Staatsbegriffs (im Sinne Jellineks) unter Druck, das Staatsvolk, d.h. die Lokalisierung einer Menge von Körpern auf diesem und keinem anderen Staatsgebiet und ihre „Unterwerfung" unter diese und keine andere Hoheitsgewalt. Hellers zutreffender Vermutung (Fn. 11), 242, dass auf einer Schicksalsgemeinschaft des Bodens das Wesen des Staates als einer gebietsuniversalen Entscheidungs- und Wirkungseinheit wesentlich beruht, werden dann auch ,sozio-kulturell“ die Voraussetzungen entzogen.

$\pi$ Allgemein z.B. G. Frankenberg Autorität und Integration, 2003, $171 \mathrm{ff}$.; für das globale Recht z.B. Teubner (Fn. 66); diese Perspektive leicht abschwächend A. FischerLescano Globalverfassung: Los desaparecidos und das Paradox der Menschenrechte, Zeitschrift für Rechtssoziologie 23 (2002), $217 \mathrm{ff}$;; für das Völkerrecht J.A. Frowein Konstitutionalisierung des Völkerrechts, in: K. Dicke u.a. (Hrsg.) Völkerrecht und internationales Privatrecht in einem sich globalisierenden System - Auswirkungen der Entstaatlichung transnationaler Beziehungen, Berichte der Deutschen Gesellschaft für Völkerecht, Bd. 39, $427 \mathrm{ff}$; für das WTO-Recht E.-U. Petersmann Constitutional Functions and Constitutional Problems of International Economic Law, Fribourg 1991, insb. $210 \mathrm{ff}$.; Uerpmann (Fn. 48); für das Gemeinschaftsrecht vgl. nur I. Pernice(Fn. 21), $148 \mathrm{ff}$., 153, mit der These, dass es eine europäische Verfassung schon gibt; J.H.H. Weiler European Neo-constitutionalism - In Search of Foundations for the European Constitutional
} 
fassungsbegriff dient dabei auch häufig als Chiffre für eine allerdings eher unklar bleibende Vorstellung des Schutzes Drittbetroffener vor den negativen Auswirkungen globaler wirtschaftlicher Macht.

Bei diesem Unternehmen fragt sich vor allem, was ein Verfassungsbegriff leisten kann, der vom Staatsbegriff abgelöst wird. Verfassung im spezifisch modernen Sinn, d.h. als geschriebene und gedruckte Verfassung, ${ }^{78}$ meint die Verpflichtung einer einheitlich organisierten Staatsmacht auf einen einzigen Rechtstext, auf ein schriftliches Dokument. ${ }^{79}$ Sicher kann man den Verfassungsbegriff von diesen Voraussetzungen befreien und Verfassung auf alle möglichen transnationalen Institutionen und Netzwerke beziehen, von denen man glaubt, sie übten rechtlich nicht gehegte Macht aus. Dann kann man etwa die „Macht“ der WTO konstitutionalisieren. Aber dann muss man auch zeigen, welchen spezifischen Sinn der Verfassungsbegriff bei solchen Operationen haben könnte. ${ }^{80}$ Es genügt jedenfalls nicht, den Verfassungsbegriff mal als Synonym für den Schutz vor wirtschaftlicher Macht zu verwenden, mal als Ausdruck für die Autonomie des konstitutionalisierten Rechts und mal über den Verfassungsbegriff den Vorrang des einen „Rechtskreises“ gegenüber anderen begründen zu wollen. ${ }^{81}$ Diese Begriffsstrategie ist umso unbefriedigender, solange nicht klar wird, warum man meint genau diese Dinge noch einmal mit dem Verfassungsbegriff ausdrücken zu müssen. Gerade die Vorstellung des „Vorrangs der Verfassung“ wird in den neuen Phänomenbereichen des Öffentlichen Rechts entwertet. Es fehlt eben der eine staatliche „Gesetzgeber", der an höherrangige Verfassungsprinzipien und Grundrechte gebunden werden könnte.

Order, Political Studies 44 (1996), 517-533; Frankenberg ebd., 73 ff., 93 (,KontraktVerfassung“); Joerges (Fn. 58 - Bureaucratic Nightmare), 15ff.; ders. „Good Governance" Through Comitology?, in: ders./Vos (Fn. 58), $311 \mathrm{ff} ., 322 \mathrm{ff}$. (,deliberative supranationalism").

78 Zum Verhältnis von Verfassung und Druckpresse am Beispiel der amerikanischen Verfassung vgl. E. Katsh The Electronic Media and the Transformation of Law, Oxford 1989, 266f.; vgl. auch C. Vismann Kommentierung Art. 79, in: AK GG, 3. Aufl. 2001, Rn. 12.

79 Vgl. nur Heller (Fn. 76), 385 ff.; Fögen (Fn. 25), 30; Peters (Fn. 21), 55.

${ }^{80}$ Kritisch $R$. Wahl Konstitutionalisierung - Leitbegriff oder Allerweltsbegriff, FS Brohm, 2002, 191ff.; vgl. auch meine Überlegungen in Constitutionalism or Legal Theory: Comments on Gunter Teubner, in: Joerges/Sand/Teubner (Fn. 63).

${ }^{81}$ Es scheint jedenfalls kein Zufall zu sein, dass noch der ambitionierteste Versuch aus neuerer Zeit, die Vorstellung einer europäischen Verfassung zu begründen, sich selbst als „Elemente einer Theorie der Verfassung Europas“ (Peters Fn. 21) beschreibt. Denn genau das ist zu vermuten: Dass es mit Hilfe des Verfassungsbegriffs nicht gelingen wird, über Elemente einer Theorie hinauszukommen. 


\section{Rechtspluralismus}

Diese Überlegungen werfen die Frage auf, ob das Öffentliche Recht nicht gut beraten wäre, stärker auf begriffliche Diskontinuität zu setzen, anstatt die neuen Phänomene in bewährten Begriffen wie Staat und Verfassung bewältigen $\mathrm{zu}$ wollen. In der Literatur wird an dieser Stelle das Angebot einer Netzwerktheorie des Rechts gemacht. Diese Suchbewegung knüpft vor allem an die Erfahrungen mit privat-öffentlichen Regulierungsnetzwerken an. Sie antwortet auf die neuartigen Phänomene transnationaler Rechtsstrukturen mit der Anerkennung einer paradoxen Selbstbegründung des Rechts. ${ }^{82}$ Daraus resultiert u.a. die Idee eines Pluralismus von Rechtsordnungen, dessen Normenreichtum nicht auf staatliche und politische Setzungsakte reduziert werden dürfe. Die rechtswissenschaftliche Aufmerksamkeit würde sich dann auf die spontanen und inkrementellen Prozesse der Verknüpfung und wechselseitigen Durchdringung verschiedener, teils raumbezogener, teils funktionsbezogener Rechtsordnungen richten.

Die Grundannahme dieser Suchbewegung lautet, dass es in einem weltweiten Netzwerk von Rechtskommunikationen kein Oben und kein Unten, kein Zentrum und keine Peripherie, keinen Ursprung und keinen letzten Grund mehr geben kann. Die neuen Phänomene des Öffentlichen Rechts jenseits des Staates ließen sich dann nicht mehr vom Staat aus entwickeln, in einem Schichtenmodell abbilden und z.B. als „Mehrebenensystem“ beschreiben. Es ginge vielmehr um „Netzwerke“, um prinzipiell gleich geordnete Rechtsordnungen mit eigenen Traditionen und Infrastrukturen, die wie die Olympischen Ringe ineinander hängen und sich partiell überlappen.

Die Theorie des Rechtspluralismus führt das Öffentliche Recht freilich auch an eine Grenze. Der Rechtspluralismus wirft vor allem die Frage auf, ob es nicht gewagt ist, das ehemalige Staatsrecht in einen Begriff (Öffentliches Recht) umzuleiten, den es nur im Gegensatz zum Privatrecht geben kann. Öffentliches Recht setzt eine stabile Grenze zwischen dem Privaten und dem Öffentlichen voraus. Genau davon kann in den neuartigen privat-öffentlichen Regulierungsnetzwerken jedoch nicht mehr aus-

82 Ladeur (Fn. 12 - Das selbstreferenzielle Kamel), $177 \mathrm{ff} ., 182$ : „Das autonome, von den Bindungen an Moral und Religion emanzipierte Recht hat einen emergenten Charakter, es ist ein Phänomen der Selbstorganisation, das ein Akzeptieren der sich herausbildenden Verknüpfungsmuster von Bindungen zu Netzwerken voraussetzt ". Zu den theoretischen Grundlagen vgl. auch die weiteren Beiträge von N. Luhmann in: G. Teubner (Hrsg.) Die Rückgabe des zwölften Kamels: Niklas Luhmann in der Diskussion über Gerechtigkeit, 2000; vgl. dazu auch die Arbeiten von G. Teubner u.a. in Fn. 61 und 66. 
gegangen werden. Damit wird aber zugleich die Unterscheidung von Öffentlichem Recht und Privatrecht selbst auf eine harte Probe gestellt, ja es fragt sich, wie das Öffentliche Recht unter dieser Voraussetzung als eigenständige Disziplin stabilisiert werden kann. Dazu werden in der Literatur bislang nur funktionale Überlegungen angeboten, etwa im Sinne der Konturierung eines Rechts der Gemeinschaftsgüter.

\section{Konsequenzen für das Staatsrecht und die Staatsrechtslehre}

Rufen wir uns abschließend noch einmal in Erinnerung: Der staatsrechtliche Positivismus beruhte nicht auf der überhistorischen Prämisse, das Öffentliche Recht ein für alle Mal als Staatsrecht zu begründen. Vielmehr vertrat der staatsrechtliche Positivismus den Standpunkt des Rechtssystems unter den Bedingungen eines sich formierenden $\mathrm{Na}$ tionalstaats.

Das ist etwas anderes als Etatismus. Der staatsrechtliche Positivismus des 19. Jahrhunderts hat nicht in konkreten Raumordnungen gedacht, sondern in abstrakten Relationen. Laband, Jellinek oder Otto Mayer, sie alle haben das Staatsgebiet im Gefolge der mathematischen Naturwissenschaft des 17. Jahrhunderts als geschlossene geometrische Fläche, also als Produkt einer symbolischen Ordnung, konzipiert. Die geometrische Fläche war kein Teil der Substanz des Rechts, sondern eine Voraussetzung seiner raumbezogenen Geltung. ${ }^{83}$ Gibt man die Staatszentrierung des Öffentlichen Rechts heute, im Zeitalter der Globalisierung, auf und stellt auf raumindifferente, normative Strukturen um, ist das folglich kein Bruch mit der liberalen Tradition, sondern ihre konsequente Weiterentwicklung. Zwischen Territorium, Staatsgewalt und Öffentlichem Recht mag es in der Vergangenheit eine enge historische Verknüpfung gegeben haben.

\footnotetext{
${ }^{83}$ Das erkennt man nicht zuletzt daran, dass die territoriale Grenze im staatsrechtlichen Positivismus als „Grenzlinie“ erscheint, also als gedachte (geometrische) Grenze, als Vorstellung, die sich räumlich formt; nicht aber umgekehrt repräsentiert der Begriff der Staatsgrenze ein Grenzland oder eine natürliche Grenze wie z.B. die Nordsee. Das kommt deutlich zwar erst in der um 1900 entwickelten Auffassung des Staatsgebiets als „Kompetenzsphäre“ zum Ausdruck, vgl. E. Radnitzky Die rechtliche Natur des Staatsgebiets, Archiv für öffentliches Recht 1906, $313 \mathrm{ff}$.; H. Kelsen Staatslehre, 1925, $137 \mathrm{ff}$; Heller (Fn. 11), 243f. Die Vorstellung des Territoriums als Kompetenzsphäre entspricht aber durchaus den Intentionen etwa Labands - vgl. nur ders. Das Staatsrecht des Deutschen Reiches, Bd. 1, 5. Aufl., 1911, Nachdruck 1964, 192: „Das Gebiet ist also nicht Teil der rechtlichen Organisation des Volkes, sondern eine Voraussetzung seiner Seßhaftigkeit."
} 
Aber es gibt keine rechtslogische Abhängigkeit zwischen diesen Komponenten.

Die Diskussion, wie der Nachfolgebegriff für den Rechtsstaat lauten und wie er theoretisch konturiert werden könnte, hat, wie eben gezeigt, gerade erst begonnen. Deshalb verbietet sich jede abschließende Einschätzung. Zweierlei dürfte aber deutlich geworden sein:

Ein neues Öffentliches Recht jenseits des Staates kann der funktionalen Dynamik der Europäisierung und Internationalisierung in einem ersten Schritt durchaus folgen. Insofern wäre es weiterhin ein Recht öffentlicher Güter oder Interessen, wenn auch nicht mehr im nationalstaatlichen Rahmen. ${ }^{84}$ Ein solches Recht darf sich aber nicht in einer Abbildung des Trends zur Herausbildung funktionaler Regulierungsnetzwerke samt ihrer sektoralen Engführung erschöpfen. Statt einfach auf Funktionalisierung, Materialisierung und Politisierung des Öffentlichen Rechts zu setzen, muss ein neues Öffentliches Recht jenseits des Staates nach einem Substitut für den Systembegriff des staatsrechtlichen Positivismus suchen.

Ein zentraler Bestandteil dieser Suchbewegung hätte ein Kollisionsrecht konfligierender Rechtsordnungen zu sein. Darin würde das Öffentliche Recht auf neuartige Abstimmungsprobleme reagieren, wie sie etwa im Bananenmarktfall sichtbar geworden sind. ${ }^{85}$ Natürlich enthielte dieses Kollisionsrecht sowohl Komponenten des „einfachen“ wie auch des „,konstitutionalisierten“ Rechts. In der neuen Ordnung des Rechtspluralismus würde es aber keinen pauschalen Anwendungsvorrang der einen Rechtsordnung mehr vor der anderen geben. Gefordert wäre vielmehr die Ausarbeitung einer "Meta-Dogmatik des Rechtspluralismus" , ${ }^{86}$ die Abstimmungsregeln zwischen den raum- und funktionsbezogenen „Rechtskreisen“ schafft. Ansätze eines solchen Kollisionsrechts finden sich z.B. auf der Ebene des transnationalen Wirtschaftsrechts, etwa im Verhältnis von Handelsfreiheit und Umweltschutz. ${ }^{87}$ Auch im Verhältnis von Europarecht und (Allgemeinem) Verwaltungsrecht hat in den letzten

84 Als Fallstudie vgl. T. Vesting The Network Economy as a Challenge to create New Public Law (beyond the State), in: K.-H. Ladeur (Hrsg.) Globalization and Public Governance, Ashgate, Cambridge 2003 (i.E.); Überlegungen in diese Richtung auch bei Oeter (Fn. 44), 208ff., 222 und Tietje (Fn. 48).

85 Vgl. C. Schmidt Ein enttäuschender Rückzug, NVwZ 2001, $249 \mathrm{ff}$.

86 Ladeur (Fn. 61), 101.

${ }^{87} \mathrm{Vgl}$. dazu etwa R. Schmidt/W. Kahl Umweltschutz und Handel, in: H.-W. Rengeling (Hrsg.) Handbuch zum europäischen und deutschen Umweltrecht, Bd. 2, 1998, § 90; Wahl (Fn. 2), $40 \mathrm{ff}$. 
Jahren die Bereitschaft zugenommen, die Haltbarkeit eines Kollisionsrechts zu testen..$^{88}$

Damit wäre zugleich das Ende der Möglichkeit eingeleitet, die Einheit des Öffentlichen Rechts als Staatsrecht bezeichnen zu können. Unstrittig sollte jedenfalls sein: Der Anspruch der Staatsrechtslehre, das Ganze einer Disziplin zu repräsentieren, muss aufgegeben werden. Staatsrecht muss heute als Differenz begriffen werden, als Unterscheidung im Unterschied zum Europarecht, als Unterscheidung im Unterschied zum Völ-

\footnotetext{
${ }^{88}$ Die Konsequenzen ließen sich etwa so entwickeln: Die Europäisierung des Öffentlichen Rechts bedeutet auch in verwaltungsrechtlicher Perspektive nicht das Ende der Unterscheidung von nationalem Verwaltungsrecht und europäischem Recht. Die Krise der Grenzziehung ist zugleich eine Krise der Hierarchie. Das nationale Verwaltungsrecht wird also nicht einfach durch ein europäisches oder gar gemeineuropäisches Verwaltungsrecht verdrängt und ersetzt. Entgegen der h.M. wird auch keine Hierarchie bzw. kein pauschaler Anwendungsvorrang des Gemeinschaftsrechts vor dem nationalen Recht begründet. Vielmehr tritt das europäische Verwaltungsrecht mit dem nationalen Verwaltungsrecht und seinen Infrastrukturen, insbesondere dem Allgemeinen Verwaltungsrecht der Mitgliedstaaten, in einen laufenden Kontakt und setzt Letzteres voraus. Beide Seiten tauschen sich auf dieser Grundlage aus und irritieren sich wechselseitig. Dabei ist es keineswegs so, dass Rat, Kommission und EuGH in diesem Netzwerk von Entscheidungen immer das letzte (EuGH) oder erste Wort (Rat/Kommission) hätten. In einem Netzwerk von Netzwerken gibt es weder letzte noch erste Worte und auch keine „letzten, ursprünglichen“ Entscheidungen mehr. Wenn die wechselseitige Irritation zwischen Europarecht und nationalem Verwaltungsrecht dauerhaft erfolgreich verlaufen soll, muss das Europarecht eine hohe Variabilität und Flexibilität der nationalen Verwaltungsrechte zulassen, die genügend Raum für variierende Prozesse der nationalstaatlichen Umsetzung und Anpassung lässt. Umgekehrt verlangt das auf der Seite der Mitgliedstaaten, die jeweils unterschiedlich gewachsenen Strukturen des Verwaltungsrechts, die Geschichte seiner Institutionen und dogmatischen Regeln einschließlich ihrer institutionell-organisatorischen Besonderheiten auf die Europäisierung einzustellen. Vgl. zu einer solchen Perspektive $K .-H$. Ladeur Introduction: Conflict and Cooperation between European Law and the General Administrative Law of the Member States, in: ders. (Hrsg.) Europeanisation of Administrative Law, Aldershot u.a., 2002, $1 \mathrm{ff}$.; ders. Flexibility and „Co-operative Law": The Co-ordination of European Member States' Law - The Example of Environmental Law, in: G. de Burca/J. Scott (Hrsg.) Constitutional Change in the EU, Oxford 2000. Weitere Überlegungen in diese Richtung u.a. bei Schmidt-AßMmann (Fn. 28), 29ff., 36, $307 \mathrm{ff}$; 334 („diskursive Aufgabe“); v. Danwitz (Fn. 28), 394ff., 482 (Umstellung von „harmonisierungsrechtlicher Orientierung“ auf eine „kollisionsrechtliche Ausrichtung“); Kadelbach (Fn. 20), 114ff., $276 \mathrm{ff}$. (betont die Autonomie der nationalstaatlichen Dogmatik gegenüber dem EG-Recht); $F$. Schoch Die Europäisierung des verwaltungsgerichtlichen vorläufigen Rechtsschutzes, DVBI 1997, 289, 296f.; ähnlich wohl auch P.M. Huber Europäisches und nationales Verfassungsrecht, VVDStRL 60 (2001), 194ff., 209ff.; für das Zivilrecht C. Joerges The Europeanisation of Private Law as a Rationalisation Process and as a Contest of Disciplines, European Review of Private Law (1995), $178 \mathrm{ff}$.
} 
kerrecht und als Unterscheidung im Unterschied zum transnationalen und globalen Recht. Das bedeutet nicht, dass die Staatsrechtslehre in nächster Zeit eingestellt werden sollte. Staatsrechtslehre und ihr Substrat, der Staat, verschwinden nicht. Aber in Zukunft ist Staatsrechtslehre nicht länger das Zentrum, sondern ein Teilgebiet des Öffentlichen Rechts (Public Law), ein Knoten in den neuartigen Netzwerken einer prinzipiell weltweiten Rechtskommunikation. 
Leitsätze des 2. Berichterstatters über

\title{
Die Staatsrechtslehre und die Veränderung ihres Gegenstandes: Konsequenzen von Europäisierung und Internationalisierung
}

\author{
„Es geht nicht um Recht oder Unrecht, \\ es geht um Macht und Gewalt!“ \\ Alessandro Manzoni Die Brautleute \\ (I Promessi Sposi), 1827
}

1. Der staatsrechtliche Positivismus des 19. Jahrhunderts hat nicht einfach introvertiert-etatistisch gedacht. Im Vordergrund stand vielmehr die Ablösung des neuzeitlichen Souveränitätsbegriffs (Machtstaat) durch ein autonomes, systemabhängiges und darin positives Staatsrecht. Die Orientierungsformel für dieses Modell hieß „Rechtsstaat“. Seine Themen hießen: Herrschaft des Gesetzes, Gesetzmäßigkeit der Verwaltung und (individueller) Rechtsschutz durch unabhängige Gerichte. Allerdings hat der staatsrechtliche Positivismus das Rechtssystem, seine Geltung und Institutionen, an eine politische Raumordnung, den Staat, gekoppelt. Für diese Verknüpfung von Öffentlichem Recht und politischem Staat steht der Klammerbegriff „Rechts-Staat“.

2. Die Verankerung des Öffentlichen Rechts in einer politischen Raumordnung ist eine von Anfang an paradoxe Konstruktion, die sich angesichts der Prozesse der Europäisierung und Internationalisierung nicht mehr halten lässt. Letztere finden ihren gemeinsamen Nenner darin, dass sich das Öffentliche Recht mehr und mehr in eigenständige, funktionsorientierte Rechtsordnungen jenseits des Staates pluralisiert. Als europäisches, internationales, transnationales und globales Recht wirken diese Rechtsordnungen dann in die nationalstaatliche Rechtsordnung zurück, die dadurch ihrerseits europäisiert, internationalisiert, transnationalisiert und globalisiert wird.

3. Die Folge dieser Bewegung ist eine Auflösung von Unterscheidungen, die bislang als stabil vorausgesetzt werden konnten. Dazu gehören vor allem die Unterscheidungen Europarecht/Staatsrecht und Völkerrecht/Staatsrecht. Das Staatsrecht wird aber nicht einfach durch ein angeblich „supranationales “ Europarecht oder ein "höheres" Staatengemeinschaftsrecht verdrängt. Die hierarchischen Konstruktionen des 19. Jahrhunderts, wie sie vor allem das Verhältnis von Staatsrecht und Völkerrecht bestimmt haben, werden im 
21. Jahrhundert nicht einfach umgekehrt. Die Krise der Grenzziehung ist zugleich eine Krise der Hierarchie. Die Trennung von Rechtsordnungen weicht einer Interdependenz und Kooperation zwischen ihnen.

4. In welchem Rahmen die Staatsrechtslehre auf diese Lage reagieren und sich selbst neu orientieren kann, wird inzwischen offen, aber auch sehr kontrovers unter Themen wie "offener Staat", „Konstitutionalismus“ oder „Rechtspluralismus“ diskutiert. Eine abschließende Einschätzung dieser Diskussion ist zurzeit noch nicht möglich. Es hat jedoch den Anschein, dass der mit der Theorie des Rechtspluralismus verbundene Netzwerkbegriff die neue Form der laufenden Grenzziehung und gleichzeitigen Kontaktverdichtung zwischen Rechtsordnungen am besten abzubilden in der Lage ist.

5. Entscheidend für die zukünftige Diskussion ist, dass sich das Öffentliche Recht - wie der staatsrechtliche Positivismus des 19. Jahrhunderts - als Suchbewegung versteht und die Notwendigkeit zu theoretischem Experimentieren anerkennt.

6. Die Suchbewegung nach einem Substitut für den „Rechtsstaat“ sollte sich nicht in der Abbildung des Trends zur Herausbildung funktionaler Regulierungsnetzwerke samt ihrer sektoralen Engführung erschöpfen (Steuerungstheorie). Ein neues Öffentliches Recht jenseits des Staates muss ein Substitut für den Systembegriff des staatsrechtlichen Positivismus und die darin angelegte Ordnungsleistung entwerfen. Die Vorstellungen eines „Kollisionsrechts“ und einer "Meta-Dogmatik des Rechtspluralismus " weisen in diese Richtung.

7. Der Anspruch der Staatsrechtslehre, das Ganze einer Disziplin zu repräsentieren oder doch zumindest ihr Zentrum, muss angesichts der Prozesse der Europäisierung und Internationalisierung aufgegeben werden. Staatsrechtslehre und ihr Substrat, der Staat, verschwinden nicht. Aber in Zukunft ist Staatsrechtslehre nur noch ein Teilgebiet des Öffentlichen Rechts (Public Law), ein Knoten in den neuartigen Netzwerken einer prinzipiell weltweiten Rechtskommunikation. 


\section{Aussprache und Schlussworte}

\section{Die Staatsrechtslehre und die Veränderung ihres Gegenstandes: Konsequenzen von Europäisierung und Internationalisierung}

Vorsitzender (Schulze-Fielitz): Meine Damen und Herren, es haben sich für die Diskussion von anderthalb Stunden Dauer bislang $34 \mathrm{Kol}-$ legen gemeldet. Nach Adam Riese und empirischen Erfahrungen, die manchmal zum gleichen Ergebnis kommen, können aber maximal 22 bis 23 Kollegen sprechen, es sei denn, die ersten sind so diszipliniert, dass sie für die nachfolgenden, die wir ja auch registriert haben, noch Platz lassen. Insofern: Ein Appell an alle, diese Vierminutenregel dadurch zu optimieren, dass man noch kürzer spricht! Die $23 \mathrm{mir}$ vorliegenden Wortmeldungen habe ich in vier Themengruppen gegliedert. Die erste thematische Bündelung ergibt sich aus der Frage - das ist offenbar ein provozierendes Stichwort gewesen - nach der „Entsouveränisierung“ und der Einheit des Staates. Die zweite Themengruppe bezieht sich darauf, wie der Prozess der Europäisierung und Internationalisierung die Staatsaufgaben verändert und auch das Staatsinnere. Die dritte Themengruppe befasst sich mit dem Thema „Demokratie - Parlamentarismus: Stellung des Staatsbürgers unter internationalisiertem Einfluss", und die vierte Themengruppe mit „Konsequenzen für die Theoriebildung und für die Lehre an den Universitäten“. In dieser Reihenfolge möchte ich vorgehen und die Redner aufrufen. In der ersten Gruppe zur Frage der Einheit des Staates und dem Problem der Entsouveränisierung habe ich fünf Teilnehmer. Zunächst Herr Di Fabio.

Di Fabio: Ich darf mich bedanken für die Referate. Wir haben, glaube ich, zwei zur Diskussion auffordernde, sie gut vorbereitende Referate gehört. Frau Kokott hat über das ganze Feld eine „Tour d'horizon“ vorgeführt. So wurde uns die Problematik in kurzer Form noch einmal bewusst gemacht, und ich bin sehr dankbar dafür. Es war aber nicht nur eine Bestandsaufnahme, sondern Frau Kokott hat auch - durchaus provokant das Staatsrecht zu der Frage genötigt: „Wie halten wir es mit der Souveränität?“ Und dazu möchte gleich ich eine kleine Randbemerkung machen. Herr Vesting hat etwas anderes gemacht, und damit, meine ich, eine ideale Ergänzung geleistet. Er hat die Metaebene des Rechts betre- 
ten, das Recht aus einer systemtheoretischen Perspektive betrachtet, um das Recht zu sich selbst zu führen. Die Selbstreflexion des Staatsrechts hat begonnen, spätestens mit dieser Tagung begonnen, und wir werden jetzt stärker daran arbeiten müssen, die Konsequenzen für das Recht, für Rechtsaussagen, zu bedenken.

Zwei Bemerkungen zu den beiden Referaten, zwei Fragen: Ich habe nicht ganz verstanden, Frau Kokott, wo genau die Souveränität nun verloren gegangen ist. Sie haben zwar gute Gründe angeführt, warum man Souveränität der Staaten nicht „mögen“ sollte. Sie ist ja auch eine scharfe Setzung. Souveränität - da graust einem ja schon etwas vor, weil sich die Willkür, die Dezision an den Anfang stellt. Es handelt sich um eine Setzung, eine bewusste, fast provokante Setzung. Und dann haben Sie aber, Herr Vesting, gesagt, der Rechtsstaat sei die Idee, das zu mediatisieren, und das wieder einzufangen, die Willkür der Setzung in die Systematik und in die Formen des Rechts zu führen. Ist das nicht eigentlich eine unglaublich intelligente und fruchtbringende Idee gewesen? Und wenn man dann sagt, „es gibt keine Souveränität und es gibt keinen Staat mehr“, verlieren wir dann nicht eigentlich das Plateau, auf dem wir alle stehen und das uns zu solch intelligenten Einsichten überhaupt geführt hat? Bei der Souveränität würde ich sagen, es gibt ebenso gute Gründe, an ihr festzuhalten wie sie abzulehnen. Vielleicht sollte man als Jurist in einem entwickelten Rechtssystem an Ableitungszusammenhängen doch noch einen Augenblick festhalten. Auch der Europäische Verfassungsvertrag ist ja keine souveräne Verfassungsgebung, sondern ist betätigte Souveränität der sich bindenden Mitgliedstaaten. Sie scheint mir noch nicht über Bord geworfen zu sein. Meine zusätzliche Frage an Frau Kokott: Wieso ist es mit dem Begriff der Souveränität unvereinbar, dass der "Souverän“, der ja eigentlich nur deshalb so heißt, um ein Synonym für die Freiheit der Menschen in der Welt der Staaten zu finden - warum soll man sich nicht binden können in Freiheit und ohne Aufgabe der Freiheit? Warum soll man sich nicht immer stärker binden können? Warum verliert man seine Freiheit durch Bindung? Das ist eine, meine ich, interessante Frage, die man auch auf der Ebene des Völkerrechts weiterverfolgen sollte. Herrn Vesting möchte ich etwas anderes fragen: Herr Vesting, Sie haben ja den Staat im Grunde genommen für entbehrlich erklärt und durch Netzwerke zu ersetzen gesucht. Das war natürlich als Beschreibung gedacht, wenn Sie sagen, der Staat stehe nicht mehr im Mittelpunkt, er sei nicht mehr letztverantwortlich. Nur, ich frage mich: Wir sind ja Juristen, wir könnten ihn ja für letztverantwortlich erklären, normativ. Und wenn wir das täten: Hätten wir nicht dem Recht, das ja auf Durchsetzung, auf den Erzwingungsstab angewiesen ist, einen großen Gefallen getan? Denn die Netzwerke, die ohne selbstlegitimierende Ordnung, ohne den legi- 
timen Einsatz von Gewaltmonopolen, die Welt überspannen, wären die denkbar ohne die Ordnungsfunktion der Staaten, die diese Netzwerke zusammenhalten?

Doehring: Die Analyse und Diagnose von Frau Kokott zur Souveränität international ist vollkommen richtig und auch unwiderlegbar. Herr Di Fabio hat gerade gefragt, woran denn der Verlust der internationalen Souveränität liegt; das werde ich Ihnen gleich sagen, aber vielleicht ein bisschen stark gezeichnet. Die traditionellen Völkerrechtler, die ich gerade in Brügge im Institut de droit international getroffen habe, halten sehr stark noch an der völkerrechtlichen Souveränität fest. Nun, Souveränität ist ein terminologisches Problem und hat sich gewandelt. Ausgangspunkt war die Auffassung von Erich Kaufmann, der siegreiche Krieg entscheide auch über die Inhaberschaft des Rechts. Dann haben wir gesagt, Ordnungsabhängigkeit besteht, aber dennoch Befehlsunabhängigkeit. Das waren die beiden Thesen. Die Ordnungsabhängigkeit der Staaten ist erheblich stärker geworden. Frau Kokott hat richtig darauf hingewiesen: In erster Linie durch Erfindung ständig zunehmender zwingender Normen. Sie beschränken den Staat bis zu den Menschenrechten, und das nimmt immer stärker zu. Die Befehlsunabhängigkeit ist geringer geworden, auch wenn die UN nicht funktioniert; der Artikel 25 der Charta macht jedenfalls de lege die Staaten abhängig von sehr konkreten Beschlüssen des Sicherheitsrats. Dass in Europa die Souveränität kein Diskussionsthema mehr ist, ist mir völlig klar - es hat gar keinen Sinn mehr, über diesen Verlust zu sprechen, hat schon Ipsen gesagt. Nun aber so optimistisch wie Frau Kokott dann war, bin ich doch nicht, und ich hab ein wenig Bedenken, und etwas Trauer packt mich auch. Herr Di Fabio hat eben auch darauf hingewiesen: Hat der Einzelmensch durch den Verlust der staatlichen Souveränität eigentlich gewonnen oder verloren? Steht der Freiheitsgewinn, den wir feststellen, in angemessenem Verhältnis zum Schutzverlust? „Freiheit alleine konstituiert nichts", hat schon Vico gesagt. Wer vermittelt nun sinnvoll, wozu sich die Gemeinschaft entschließen soll? Oder wollen die Menschen überhaut so frei sein, wie man sie zwangsweise macht? Beim Sozialstaat, habe ich den Eindruck, ist es gar nicht so sehr die soziale Freiheit, die gewünscht wird, sondern die Sicherung. Und die geht hier etwas verloren. Ich möchte auch nicht bei Carl Schmitts und Forsthoffs Resignation stehen bleiben, wonach der Staat nun eigentlich aufgegeben wird, aber ich muss die Frage stellen: Streicht man den Staat, womit ersetzt man ihn? Denn seine Vorteile, die kennen wir alle. Aber wir wissen nicht, ob der Mensch nun in ein Loch fällt, in ein bodenloses, wenn wir alle diese Bindungen so aufheben, wie sie radikal auf- 
gehoben würden, wenn man dieser Entwicklung weiter völlig freien Lauf lässt.

Oppermann: Ich bedanke mich bei beiden Referenten für die ungemein interessanten und bereichernden Referate. Nach diesen Eindrücken können wir die weitere Entwicklung der europäischen Rechtsprechung mit Interesse beobachten, wenn Frau Kokott ab Montag als Generalanwältin das Portal des Europäischen Gerichtshofes durchschreitet.

Meinerseits hätte ich ebenfalls eine Frage zur Souveränität. Ebensowenig wie andere bin ich nicht überzeugt, dass sich der Staat auf EUEbene in dem Ausmaß auf dem Rückzug befindet, wie es Frau Kokott und wohl auch Herr Vesting dargestellt haben. Er kommt mir vor wie der Riese Gulliver, der von den Zwergen mit mehr oder weniger dicken Stricken gefesselt ist, sich aber, wenn er es wirklich will, immer noch befreien kann.

Ich darf die Frage wie folgt zuspitzen: Sie, Herr Vesting, haben von den Mitgliedstaaten der Europäischen Union als den „Knechten der Verträge " gesprochen. Ich frage umgekehrt: Ist denn die bekannte Lehre von den Staaten als den „Herren“ der Verträge falsch geworden? Ich würde sagen: Keineswegs! Wenn Sie sich die gegenwärtige europäische Verfassungsgebung ansehen, sind es dort weiterhin die Mitgliedstaaten, die den Weg bestimmen. Manche sagen, dass der Europäische Rat der Staatsund Regierungschefs im Verfassungsentwurf des Konvents zum eigentlichen „Herrn der EU“ gemacht wird. Die Entwicklung geht in eine Richtung, die alles andere als einen Abbau von Staatlichkeit bedeutet. Meine Frage also: Wie bringen Sie die Lehre von den „Herren der Verträge“ in Ihrer beider Gedankengebäude unter?

Eckart Klein: Dass wir Zeugen dramatischer Veränderungen im Staatsrecht und Völkerrecht sind, ist ja völlig unbestritten, und beide Referenten haben das auch in vorzüglicher Weise dargelegt. Ich hatte etwas das Gefühl, dass Sie sich beide im Überschwang dieser Diagnose etwas haben hinreißen lassen und dass Sie auch beide etwas zu stark ausgegangen sind von dem europäischen Integrationsstaat. Nun haben wir ja 191 Staaten in den Vereinten Nationen, minus 15 oder demnächst minus 25 , das gibt immer noch eine erkleckliche Zahl von Staaten, die ja nicht diesen Bindungen unterliegen. Ich glaube, wir müssen stärker und das vermisste ich etwas in den Referaten - den Blick auf diese anderen im Weltmaßstab eher typischen Hoheitsgewalten werfen und vielleicht von dort wieder auf unser Thema zurückkommen. Was die EU betrifft, ist ja nun glücklicherweise zu konstatieren, dass sie demokratisch - oder das demokratische Defizit wird zunehmend geschlossen - 
also weitgehend demokratisch und auch rechtsstaatlich konzipiert ist, auch gerade im Hinblick auf den Grundrechtschutz. Das sieht doch schon ganz anders aus, wenn wir auf die internationale Ebene gehen. Auch die von Ihnen, Frau Kokott, angesprochenen internationalen Menschenrechtsinstanzen sind ja nur dem Einzelnen eröffnet, wenn die Staaten die entsprechenden Verträge schließen, also diese Schneise ja doch auch wieder selbst eröffnen. Und ihre Durchschlagskraft - ich kann das nun aus eigener Erfahrung sagen aus dem Menschenrechtsausschuss ist ja begrenzt. Also allein darauf zu vertrauen, ist etwas schwierig. Und noch schlimmer wird's, wenn wir den Sicherheitsrat ansehen. Der Sicherheitsrat hat kürzlich eine Proskriptionsliste erstellt. Es sind Leute da daraufgenommen worden, die als Terroristen gelten - vielleicht auch durchaus zu Recht -, aber da stellt sich doch die Frage, wie dagegen der Rechtsschutz bestellt ist. Ich meine eben, dass wir die Staaten doch noch einstweilen auch als Kontrolleure der internationalen Gemeinschaft gegenüber brauchen. Es ist eine Verbindung von Internationalität und Nationalität, und das Ganze muss in ein richtiges Zuordnungsverhältnis gebracht werden. Übrigens nur noch zum Schluss ein Wort zur Europäischen Union: Solange sich Kommissionspräsidenten nicht zu schade sind, im Gegenteil sogar es anstreben, von ihrem europäischen Amt aus doch wieder in ihrem eigenen Land die Position des Staatspräsidenten oder des Ministerpräsidenten zu übernehmen, kann es so schlecht selbst im europäischen Integrationsstaat nicht mit der Position der Mitgliedstaaten bestellt sein.

Streinz: Vielen Dank für das zugleich aktuelle wie grundsätzliche Thema und vor allem für die Behandlung durch die Referenten, die, wie die Diskussion jetzt schon zeigt, kontroverse Thesen geboten haben, wenngleich ich selbst im Grundsatz zustimme, nicht nur wegen dem von Herrn Vesting gewählten Referenzgebiet des Lebensmittelsrechts für die WTO. Einige Anmerkungen dazu: In These 8 weist Frau Kokott auf den Funktionswandel des Staates, nicht sein Absterben, hin - meines Erachtens völlig zu Recht und vor allem auch mit entsprechenden Folgen für die Europäische Union im Weltmaßstab, soweit sie die Staatsfunktionen übernommen hat, wie die These 7 auch zeigt. Was sind aber die Folgen für das universelle Völkerrecht, für die Satzung der Vereinten Nationen, die selbst auf der souveränen Gleichheit der Staaten beruhen? Die prinzipiell unstreitigen Vorgaben des Völkerrechts werden genannt, aber selbst bei mehr oder weniger anerkanntem ius cogens wie dem Gewaltverbot stellen sich Fragen nach den Ausnahmen - nicht nur „preemptive action", gerade nach dem Irakkrieg - Fragen, die zum Teil aus verständlichen Gründen nicht vertieft behandelt wurden, zum Beispiel hinsicht- 
lich der Folgen für Art. 26 Grundgesetz. Anknüpfend an die These 16 vom Demokratiegebot im Völkerrecht: Dies gilt unstreitig regional für EU und Europarat, aber gilt dies auch universell? Und was sind die Folgen? Die Wertneutralität des Völkerrechts kommt in berechtigte Kritik, was die Diskussion über die so genannte humanitäre Intervention ausgelöst oder wiederbelebt hat. Aber: Haben oder bekommen wir den Wandel vom Völkerrecht der Koexistenz über das Völkerrecht der Kooperation zum Völkerrecht der Intervention? Und wie begegnen wir den damit offensichtlich verbundenen Gefahren, den Fragen nach objektiven Wertmaßstäben, der Einheitlichkeit der Rechtsdurchsetzung und nach rechtlichen und faktischen Vetomächten? Kurz zur Gestaltungsmöglichkeit für die Einzelnen, die in These 30 angesprochen wurde: Eine ist der „Zug nach Zug“, das heißt die Flucht vor deutschen Finanzämtern - vielleicht zeigt nichts mehr als dies den Souveränitätsverlust des Nationalstaates. Abschließend zu These 26: In der Juristenausbildung in Deutschland ist Europarecht endgültig Pflichtstoff als Bestandteil der in Deutschland geltenden Rechtsordnung geworden - dies hat ja auch lange genug gedauert. Aber dies muss auch für die völkerrechtlichen Bezüge zum Staatsrecht gelten, gerade jetzt bei der Reform des Pflichtstoffes, die notwendig zu Kürzungen führt wegen der Ausweitung der Wahlfachfächer. In Bayern ist es bezüglich der neuen JAPO mit Mühe gelungen, darauf aufmerksam zu machen und dies durchzubekommen.

Vorsitzender: Wir haben jetzt den nächsten Block, der die Rückwirkung von Europäisierung und Internationalisierung auf den inneren Bereich betrifft, wenn ich die Stichworte richtig interpretiert habe. Vielleicht kommt auch noch einmal der Souveränitätsgedanke zum Vorschein.

Vogel: Nur eine Bemerkung zu dem schönen Referat von Frau Kokott: Sie haben den „Dualismus in Reinform“, so habe ich wohl hoffentlich zutreffend mitgeschrieben, wie er von Triepel begründet wurde, als „kaum noch anzutreffend" bezeichnet. Ich würde Ihnen empfehlen, einmal einige Entscheidungen des Bundesfinanzhofs zu der Frage zu lesen, wie völkerrechtliche Verträge sich zu später erlassenen innerstaatlichen Gesetzen verhalten. Das ist reiner Triepel, einschließlich seiner Begründung durch eine petitio principii. Die Tatsache, dass von 43 europäischen Verfassungen 19 ausdrücklich den völkerrechtlichen Verträgen Vorrang vor allen (auch späteren) innerstaatlichen Gesetzen zuweisen, dass dasselbe in fünf europäischen Staaten anerkanntes ungeschriebenes Verfassungsrecht ist, in weiteren fün Staaten jedenfalls für menschenrechtliche Verträge gilt, ist dem BFH nicht bekannt (und die Höhe dieser Zahlen hat übrigens auch mich überrascht, als ich sie nachgezählt habe). Es lässt 
nämlich nur 14 Staaten übrig, in denen für einen echten Dualismus noch Platz wäre. Ich werde das bei Gelegenheit dem Bundesfinanzhof zur Kenntnis bringen.

Häberle: Werte Kolleginnen und Kollegen. Erlauben Sie mir eine themengeschichtliche Vorbemerkung und eine Hauptbemerkung zum von Herrn Vesting aufgegriffenen (These III 2) Verständnis des Völkerrechts als werdendem „Menschheitsrecht“, wir brauchen ja eine „neue Schule von Salamanca“, zu welcher heute trotz des internationalen Theoriedefizits nicht nur einige Fußnoten geschrieben worden sind.

Erstens: Unsere Vereinigung hat recht oft das Thema „Europa“, „Europäisierung", behandelt, etwa in Kiel, in Gießen, Leipzig sowie St. Gallen. Sie hat seltener das Thema „Internationale Beziehungen“ erörtert, Stichwort: Auswärtige Gewalt (Dresden) oder zuvor in Basel und Zürich (Stichwort: Verfassungsstaat im Geflecht internationaler Beziehungen). Dank der unendlichen Weisheit unseres Vorstandes werden heute beide Themenbereiche erstmals zusammen diskutiert. Meine Frage an die Referenten: Welches ist das Verhältnis von „Europäisierung “ und „Internationalisierung"? Vermutlich ist jene eine besonders dichte „Internationalisierung“, bezogen auf unseren Kontinent, wobei wir aber auch an andere denken müssen: Von Mexiko aus wurde jüngst die Idee des „Gemeinamerikanischen Verfassungsrechts“ entwickelt. -

Zweitens: Der alle Menschen, Völker und Kulturen verbindende Begriff „Menschheitsrecht“ leistet viel: Er zieht die Konsequenzen aus der Öffnung und Relativierung des (Verfassungs-)Staates bzw. der Souveränität, des Außen- und Innen, der Schaffung von Internationalen Gerichtshöfen, aus der Verstärkung der Subjektstellung des Menschen im von vielen fortgeschriebenen „Völkerrecht“, das nicht mehr einfach „Staatenrecht" ist. Vieles können wir an den Wachstumsvorgängen zum Thema "Internationale Beziehungen“ in neueren Verfassungstexten ablesen: die Bezugnahme auf Menschenrechte, das Bekenntnis zu weltweiter Solidarität (nicht nur im Umweltschutz, Kulturgüterschutz) und zum Humanitären (etwa in der Schweiz), die allgemeine Völkerrechtsfreundlichkeit, die NGOs sind praktisch hinzugekommen. Frau Kokott hat eindrucksvoll die Herrenchiemsee-Formel von 1947 (Art. 1: „Der Staat ist um des Menschen willen da“) sozusagen ins Völkerrecht gewendet, insbesondere den Staat in den Dienst des Menschen gestellt (These 28). Neue Textstufen zeigen sich in einem besonderen Vorgang: neben dem alten bekannten Verbot von Angriffkriegen und der positiven Friedensklausel sowie dem Begriff der „Entwicklung“ des Völkerrechts hat eine Verfassungsänderung in Argentinien (2003), zuvor wie in Äthiopien, etwas Neues gebracht: das Verbot jeder Amnestie für Kriegsverbrechen und Verbrechen 
gegen die Menschlichkeit, ihre Unverjährbarkeit, Konsequenz der dortigen leidvollen Geschichte. All dies zeigt, wie Prinzipien des Völkerrechts verfassungsstaatliches Innenrecht werden, das „Staatsbild“ hat sich ebenso verändert wie das Weltbild des Völkerrechts. Im Grunde lernen wir in Sachen „Menschheitsrecht" von Kant, der „Mensch" und „Menschheit" optimistisch zusammendenkt.

Rauschning: Zunächst darf ich an ein Wort von Joseph H. Kaiser auf der Staatsrechtslehrertagung 1964 erinnern, der sagte: „Der Staat, eine im Sterben begriffene Kategorie“. Wir beschäftigen uns sinnvollerweise weiterhin damit. Ich bin den Referenten äußerst dankbar, wie wir alle, für das Aufzeigen der neuen Entwicklungen.

Das soll uns die Augen nicht davor verschließen, dass wir noch ganz erhebliche Aufgaben in der Durchsetzung überhaupt des Staates in der Welt haben. Der Staat ist, wie wir früher gesagt haben, die effektivste politische Organisationsform, die sich in den letzten beiden Jahrhunderten über die ganze Welt verbreitet hat, aber noch nicht überall hin. Wir wären dankbar und froh, wenn wir überall mit geordneten staatlichen Verhältnissen zu tun hätten, bis hin zur Unverbrüchlichkeit der Rechtsordnung, dass man überhaupt im Laufe von zehn Jahren ein Urteil aus einem einfachen Verkehrsunfall erstreiten könnte, und ähnliches mehr, selbst in Europa. Das heißt, die Verwirklichung des Staates und auch seine Domestizierung in Gestalt des Rechtsstaates ist selbst im Inneren Europas noch nicht überall gelungen.

Wir sollten uns eben auch - und das ist in den ersten Diskussionsbeiträgen deutlich gesagt worden - davor hüten, eine zu innergemeinschaftliche Sicht überhand nehmen zu lassen. Wir sollten wissen, dass wir vielleicht über lange Jahre die Kraft der Völker und die Kraft des Nationalen unterschätzt haben. Sonst wäre es nicht zum Aufbrechen der Sowjetunion gekommen, und nach acht Jahre in Bosnien weiß ich, wie sehr um die Nationenbildung auch im kleinen Bereich gerungen wird. Wenn in diesen Tagen die baltischen Staaten dieses Europa jetzt bereichern, dann wissen wir auch, dass dieses aufgrund der nationalen Staatlichkeit geschieht. Wenn wir morgen den Tag der Wiedervereinigung feiern, dann wissen wir, dass auch die Wiedervereinigung selbstverständlich eben ein nationales Erlebnis war. Die Realisierung des Staatlichen ist auch im engeren Europa nicht abgeschlossen - denken wir an Griechenland und sein Betonen seiner Interessen in der EU, oder an Frankreich ..., denken wir an die jüngste Entscheidung Schwedens, die gemeinsame Währung abzulehnen. Wir denken an das Verhalten der USA, die sich nicht in ihrer Souveränität relativiert sehen, wir denken an Indien oder China. Die allgemeine Staatsrechtslehre sollte auch dies im Auge behalten. 
Die Aufgabe, den Staat als Garantie des menschlichen Lebens in der Welt durchzusetzen und ihn im Rechtsstaat zu domestizieren, erfordert weiterhin viel Kraft und Einsatz, was nicht hindert, dass die so eindrucksvoll erörterten neuen Entwicklungstendenzen von uns voll getragen werden.

Lege: Erlauben Sie, dass ich angesichts der Kürze der Zeit etwas zuspitze und provoziere. Mir ist in beiden Referaten ein Begriff etwas zu kurz gekommen, nämlich der Begriff des Gemeinwohls oder des öffentlichen Interesses. Meine Frage richtet sich deshalb vor allem an Herrn Vesting: Wenn Sie den Staat aus dem Zentrum des öffentlichen Rechts herausnehmen, wer definiert dann das Gemeinwohl und wer setzt es durch? Das scheint mir doch die Kernfrage zu sein. Und deshalb vielleicht noch etwas zugespitzter: Wo findet in Ihrer Konzeption das öffentliche Interesse überhaupt seinen Platz? Müssen Sie vielleicht nicht nur das Staatsrecht, sondern das öffentliche Recht insgesamt marginalisieren oder gar in den Dienst nicht-öffentlicher Interessen stellen?

Vorsitzender: Wir kommen jetzt zu diesem größeren Themenblock, der sich mit den Folgen für die Demokratie und die Stellung des Einzelnen in diesem internationalisierten Zusammenhang verbinden, wenn ich die Wortmeldungsstichworte richtig interpretiert habe. Ich darf mit Herrn Hobe beginnen.

Hobe: Meine Bemerkung bezieht sich auf den von Frau Kokott angesprochenen Art. 23 des Grundgesetzes und der darin meines Erachtens deutlich werdenden Funktionswandlung des offenen Verfassungsstaats zwischen Souveränität und Interdependenz. In diesem Art. 23 kommt ja zunächst die Befugnisübertragung von Hoheitsrechten auf die Europäische Union zum Ausdruck. Allerdings wird dem Staat in dieser Bestimmung aufgegeben, bestimmte zentrale Rechtssubstrate wie Rechtsstaatlichkeit, Demokratie, Sozialstaatlichkeit, in geminderter Form auch Bundesstaatlichkeit, zwar nicht unbedingt auf der staatlichen Ebene, aber doch jedenfalls im Rahmen und nach Maßgabe der Übertragung von Hoheitsrechten auch auf anderen Ebenen zu bewahren. Darin liegt meines Erachtens ziemlich deutlich jedenfalls nicht eine Form von Abschaffung von Staatlichkeit, sondern deren Relativierung und vor allem Neubeschreibung, die Frau Kokott auch umrissen hat. Diese Neubeschreibung der Rolle des Staates umfasst diejenige eines Wächters über die Wahrung dieses zentralen konstitutionellen Substrats als eines Garanten für die Wahrung dieses Substrats und als eines Kontrolleurs des entsprechenden Übertragungsprozesses auf andere Ebenen der Ausübung von Hoheitsrechten. 
Was sind nun - und das fehlte mir ein bisschen in beiden Referaten die Konsequenzen für die Staatsrechtslehre? Meines Erachtens müsste noch viel deutlicher als bisher eingegangen werden auf diese Funktionswandlung des Staates und die sich daraus ableitenden definitorischen und materiellrechtlichen Probleme, die wir ja haben, wenn wir etwa über den Verfassungsbegriff diskutieren, der angeblich auf europäischer Ebene nicht passen soll, obwohl selbst die Mitgliedstaaten hier von einer Verfassung oder einem Verfassungsvertrag sprechen. Es geht also - und da würde ich deutlich nicht so weit gehen wie Sie, Herr Vesting - nicht darum, hier Staatlichkeit sozusagen ins Abseits zu stellen. Herr Rauschning hat ja auch sehr deutlich gezeigt, welche zentrale Funktion der Staat auch im heutigen internationalen System noch ausübt. Deutlicher als es vielleicht uns allen bisher gelungen ist, sollten die Interdependenzen der verschiedenen Rechtsordnungen (auf nationaler, europäischer und universeller Ebene) und die daran deutlich werdende Funktionswandlung moderner Staatlichkeit kenntlich gemacht werden.

Walter Leisner: Demokratie als Staatselement - das ist bekanntlich eine alte Forderung der US-Außenpolitik. Und dabei ist die Demokratie selbst in den USA durchaus von außen gesehen nicht völlig problemfrei. Man denke an manche Menschenrechtsverletzungen oder an einen gewissen Wahlzirkus. Weit mehr als die Hälfte der Menschheit lebt in Regimen, die wir aus unserer deutschen Sicht gewiss nicht als demokratisch ansehen würden, von China beginnend. Es gibt doch so viele Demokratiebegriffe, wie es Staatsordnungen gibt, und wenn das, Frau Kollegin Ko$k o t t$, was Sie nun anbieten, juristisch umsetzbar sein sollte, dann müssten wir jedenfalls von einer Minimaltheorie der Demokratie ausgehen können. Es würde mich freuen, wenn Sie dazu einige Worte sagen könnten. Ich sehe eine solche nicht. Sicher ist aber, dass bisher jedenfalls die herrschende Völkerrechtslehre Demokratizität nicht als ein Staatselement ansieht, und was Ihr ,in statu nascendi“ bedeuten soll, ist mir nicht klar. Noch zwei Worte zur „Ablösung der Souveränität": Wir sollten hier etwas vorsichtiger und auch bescheidener sein, historisch gesehen vor allem. Staatsrechtlich bedeutsame Vereinheitlichungstendenzen, Zusammenschlüsse, kennen wir seit vielen Jahrhunderten, auch in organisatorischer Form. Vom Römischen Reich bis zum Heiligen Deutschen Reich, von der Internationalisierung des Rechts im Mittelalter über die Kirche bis zu den Fürstenbünden des 17. und 18. Jahrhunderts und einem danach zumindest tatsächlichen Kulturverbund. Sind wirklich wir es, die hier nun den Stein der Weisen gefunden haben, oder haben wir nicht nur längst bekannte Formen wieder entdeckt? Und: Ist dieser Prozess denn wirklich irreversibel? Wir haben lernen müssen, dass ein verhältnismäs- 
sig kleiner Anlass, wie der Irakkonflikt, genügt, um alle unsere Blütenträume von einer europäischen Einigung zu gefährden. Die Öffnung nach dem Osten - könnte sie nicht dazu führen, dass die bestehenden Staaten sich erst recht jetzt zusammenschließen und dagegen Front machen, Frankreich immerhin als Beispiel? Und sollte am Ende nicht doch nur ein internationaler Zusammenschluss als ein wirtschaftlicher Kooperationsfreiraum stehen?

Schmidt-Jortzig: Ich möchte eine in der Tat offene Frage stellen, nicht gewissermaßen eine parlamentarische, die dann einsetzen würde etwa mit der Formel „Sind Sie nicht auch wie ich, Frau Kollegin, folgender Meinung?", also wirklich eine offene, eine erkenntnissuchende Frage an Sie, verehrte Frau Kokott. Ich habe aber zunächst erst einmal wie andere Kollegen noch herzlich zu danken für die Unverstelltheit und Eindeutigkeit Ihrer Thesen. Wenn ich sodann Ihre These 2 richtig verstanden habe, und Sie haben die jedenfalls für meine Frage dazugehörenden Gedanken in den Thesen 12, 13, 17 und 20 wieder aufgegriffen, dann ist doch wohl das Thema „Ausländerwahlrecht" gewissermaßen die Nagelprobe für die Haltbarkeit Ihrer Überlegungen. Wirklich vom Ergebnis her ganz offen also die Frage: Müsste nicht die jetzt ungefähr 15 Jahre alte Entscheidung des Bundesverfassungsgerichts zum Ausländerwahlrecht von Bürgern anderer EG-Mitgliedstaaten (damals noch EG, heute sicherlich EU) nach Ihrer Argumentation heute anders ausgehen? Oder müsste nicht jedenfalls, wenn das Ergebnis einer solchen verfassungsgerichtlichen Entscheidung noch gleich lauten würde, die Begründung anders ansetzen? Ist die Auflockerung des Loyalitäts- und Schutzanspruchverhältnisses der Bürger zu ihren Staaten, die Sie beschrieben haben, nicht auch die Wurzel für eine Aufkündigung des Zusammenhangs zwischen Staatsangehörigkeit und aktivem Wahlrecht? Dazu hätte ich gern noch einige Verdeutlichungen von Ihnen.

Puttler: Frau Kokott, Sie haben den Mensch als Maßstab für Staatsrecht, Europarecht und Völkerrecht in den Mittelpunkt gestellt. Aus diesem Maßstab leiten Sie auch das Demokratiegebot auf internationaler Ebene ab, und zwar definieren Sie dabei Demokratie als Herrschaft durch die Betroffenen. Ist es nicht illusionär zu fordern, dass Demokratie - verstanden als Herrschaft durch die Betroffenen - auch auf internationaler Ebene verwirklicht werden soll? In Ihrer These 22 sagen Sie, das Demokratiegebot enthalte ein Optimierungsgebot, das auf Ausschöpfung der Partizipationsmöglichkeiten auf allen Ebenen abziele. Was verstehen Sie unter „Partizipationsmöglichkeiten“? Meinen Sie etwa weltweite Abstimmungen per Internet, wie schon vorgeschlagen wurde? Was machen 
wir dann mit den vielen Analphabeten in Entwicklungsländern, aber auch solchen in Industriestaaten? Was machen wir mit Bürgern, die in Staaten ohne ausreichenden Zugang zu Informationen leben (Extrembeispiel: Nordkorea)?

Andererseits bedeutet Demokratie nicht nur Ausschöpfung von Partizipationsmöglichkeiten, sondern vor allem auch Kontrolle. $\mathrm{Zu}$ den Voraussetzungen für effektive Kontrolle gehören klare Verantwortlichkeiten. In Ihrer These 23 sagen Sie: „Jede Ebene muss zu ihrer ganzen harten Verantwortung stehen“. Wir beobachten gegenwärtig aber eine Verflechtung von nationaler, europäischer und internationaler Ebene und eine daraus resultierende Verwischung der Verantwortlichkeiten. Der betroffene Bürger weiß daher oft nicht genau, wer verantwortlich ist und wen er kontrollieren soll. Zur Kontrolle gehört darüber hinaus die Möglichkeit zur Sanktion. Das heißt, der Verantwortliche muss durch ein entgegenstehendes Votum der Betroffenen abgelöst werden können.

Wie geht es in der Praxis aber auf internationaler Ebene zu? Staaten verpflichten sich in völkerrechtlichen Verträgen. Solche Abkommen erfordern im Vorfeld oft langjährige Verhandlungen zwischen Delegationen der beteiligten Staaten, besonders wenn es sich um multilaterale Verträge handelt. Teilweise werden Vertragstexte auch von Expertengremien, beispielsweise der International Law Commission, vorbereitet und damit maßgeblich geprägt. Das Verfahren ist für die letztlich betroffenen Bürger intransparent. Auf europäischer Ebene geht man dazu über, Vertragsänderungen durch Konvente vorbereiten zu lassen. Da die Mitglieder des Verfassungskonvents in der Mehrheit Parlamentarier waren, erhielt die Vorbereitung des Verfassungsvertrages immerhin ein demokratisches Mäntelchen. Wie man hörte, schien das Verfahren im Konvent unter der präsidialen Leitung von Herrn Giscard d'Estaing allerdings wenig transparent und nicht nach demokratischen Spielregeln abzulaufen. Die nach Unterzeichnung eines völkerrechtlichen Vertrages in der Regel noch erforderliche Ratifikation durch die nationalen Parlamente schafft ebenfalls keine Demokratie im Sinne einer Herrschaft durch die Betroffenen. Denn im allgemeinen können die Parlamentarier gerade bei komplizierten multilateralen Vereinbarungen die Konsequenzen für ihren Staat nicht absehen (Beispiel: die Folgen des WTO-Streitbeilegungsverfahrens) und haben nur die Wahl, dem vorgelegten Vertragstext in Gänze zuzustimmen oder ihn abzulehnen. Eine Sanktion durch Abwahl bringt hier nichts. Wir sollten daher ehrlich eingestehen, dass eine Verwirklichung des Demokratiegebots auf internationaler Ebene nicht möglich ist. Daher brauchen wir weiterhin den Staat, um zumindest auf dieser Ebene und zumindest für den staatlichen Kompetenzbereich Demokratie als Herrschaft durch die Betroffenen wahrmachen zu können. 
Vorsitzender: Dank der hervorragenden Zeitdisziplin können wir, das möchte ich ankündigen, vielleicht noch einige von der Reserveliste mit auf die Rednerliste nehmen. Ich möchte Herrn Ehrenzeller bitten, sich darauf entsprechend vorzubereiten: die Schweizer Sicht zum Thema „Demokratie“. Als nächsten aber Herrn Wyss, ebenfalls aus der Schweiz.

Wyss: Wie verschiedene Vorredner beziehe ich mich auf das Referat von Frau Kokott und ich habe - was mir als auf Konkordanz konditionierter Schweizer nicht unsympathisch ist - das Referat verstanden als Versöhnungsversuch zwischen dem Kleinklein des Nationalstaates und der Großbaustelle Weltgemeinschaft. Allerdings sehe ich Brüche, über die dieser Versöhnungsversuch nicht hinweg kommt, und es sind Brüche, für die ich von der Staatsrechtslehre Antworten, Reaktionen, und nicht nur Analysen erwarte. Irritierend ist für mich selber, dass mir die einzelnen Thesen sehr gut gefallen, dass mir aber das Gesamtbild dann doch irgendwie verschwommen vorkommt. Ich glaube, der wesentliche Bruch manifestiert sich zwischen den Thesen 2, 9 und 13. Ich verstehe die Thesen 2 und 13 so, als dass die verminderten Schutz- und Loyalitätsbeziehungen, die eine Folge des Bedeutungsverlustes der Staatsangehörigkeit sind, nur als beschränkt bedenklich einzustufen wären, weil neue übernationale Identitäts- und Loyalitätsangebote zur Verfügung stehen sollen was mir zu schön klingt, als es wahr sein kann. Es ist zwar so, dass die Staatsangehörigkeit an Bedeutung verloren hat, aber ist es denn so erfreulich, dass wir den Staat nur noch als Pannenhelfer begreifen, der sich seine Dienstleistungen, die er den eigenen Staatsangehörigen im Krisenfall erbringt, bezahlen lässt - zu denken ist dabei etwa an die in Deutschland und der Schweiz aufgeworfene Frage, ob die Kosten für ihre Befreiung den Sahara-Geiseln überwälzt werden dürfen. Und in welchem Verhältnis steht dieser Bedeutungsverlust der Staatsangehörigkeit zum Demokratiegebot in der Gestalt der These 9, wonach Staatsaufgaben Ableitungen von Bedürfnissen der Einzelnen sein sollen? Mir persönlich ist diese Idee außerordentlich sympathisch, weil ich die das schweizerische Verfassungsrecht prägende Figur des öffentlichen Interesses als staatsrechtliche Bedürfnisklausel zu rekonstruieren und als Legitimationsbasis einzelstaatlicher Strukturen darzustellen versucht habe. Wie aber können solche legitimierenden Bedürfnisse akzentuiert und artikuliert werden? Hier scheinen mir taugliche internationale und transnationale Alternativen noch nicht in Sicht zu sein. Hinzu kommt - jedenfalls für die Schweiz - auch ein Kontrast zu den politischen Diskussionen, die im Zusammenhang mit Einbürgerungsentscheiden in der Schweiz stehen. Populistisch wird nämlich dort das Demokratiegebot in Stellung gebracht, um Teilgehalte der Rechtsstaatlichkeit zu unterlaufen. Und schließlich: 
Wenn denn Staatsleistungen bezahlt werden müssen und nicht mehr an das Kriterium der Staatsangehörigkeit angeknüpft werden kann, dann wird damit zwar das Risiko der nationalitätsbedingten Diskriminierung ausgeschaltet, dafür aber entstehen ökonomische Gräben zwischen Leistungsfähigen und Leistungsunfähigen. Die in These $30 \mathrm{sehr}$ optimistisch umrissenen internationalen Entfaltungschancen und -optionen sind meines Erachtens doch auch nicht immer die günstigsten. Zeitlich und finanziell sind internationale Verfahren ressourcenintensiv und keine taugliche Alternative für die Angebote, die national der Einzelstaat anzubieten hat.

Hölscheidt: Ich möchte kurz Stellung nehmen zu der These 15 von Frau Kokott: „Entparlamentarisierung durch Europäisierung“. Erstens meine ich in Bezug auf den Bundestag: Ein Teil dieses Problems ist hausgemacht. Der Bundestag hat zwar ein umfangreiches rechtliches Reglementarium geschaffen im Zusammenhang mit der Maastricht-Umsetzung, aber dieses Instrumentarium wird nicht hinreichend genutzt. Der Bundestag orientiert sich nicht an dem Brüsseler Zeitplan, sondern wickelt unbeschadet davon seinen Zeitplan ab, das heißt also, es findet die Sommerpause statt, es findet der Wahlkampf statt, es findet die Konstituierung statt, und infolgedessen ein halbes Jahr keine Europapolitik. AuBerdem ist es so, dass die Unionsvorlagen zwar zugeleitet werden, der Bundestag aber auch in federführenden Ausschüssen sich oftmals damit nicht auseinandersetzt, sondern die Vorlagenlisten nur durchwinkt und Beschwerden dann kommen, wenn es an die Umsetzung dieser Richtlinien geht.

Zweitens will ich sagen: Der Europäische Konvent, ist - da stehe ich im Gegensatz zu Frau Puttler - schon ein sehr demokratisches Verfahren und hat nicht nur ein demokratisches Mäntelchen. Er hat wichtige neue Rechtsgrundlagen geschaffen, die das Verhältnis ein wenig umdrehen, so dass man sagen kann, hier hat es eine gewisse „Parlamentarisierung durch Europäisierung“ gegeben. Denn einmal ist es jetzt so, dass europäische Organe unmittelbar zahlreiche Dokumente den nationalen Parlamenten zuliefern müssen. Der Umweg über den Ministerrat, über die nationalen Regierungen entfällt. Zum anderen ist ein Frühwarnsystem installiert worden: Die mitgliedstaatlichen Parlamente haben nunmehr die Möglichkeit, ihre Subsidiaritätsbedenken vorzutragen und im Endeffekt unter Berufung auf diese Bedenken selbst den Europäischen Gerichtshof anzurufen.

Drittens hat Frau Kokott noch zu Recht die direktdemokratischen Elemente angesprochen. Ich meine, eine Diskussion über Referenden ist eine gute Sache, nicht nur im politischen Raum, sondern auch in der Staatsrechtswissenschaft. Hinweisen möchte ich auf ein direktdemokrati- 
sches Element, das eine Neuerung im europäischen Recht darstellt. Eingeführt worden ist die Möglichkeit, ein Bürgerbegehren zu starten. Mindestens eine Million Bürger der Europäischen Union haben nun die Möglichkeit, die Europäische Kommission aufzufordern, Gesetzesvorschläge zu unterbreiten. Dieses indirekte Initiativrecht gibt es bislang nur für Parlament und Rat. Es ist deshalb ein erheblicher direktdemokratischer Fortschritt, und ich hoffe, dass der auch so verwirklicht wird.

von Arnim: Die beiden schönen Referate haben gezeigt, dass man eine Staatslehre der Bundesrepublik Deutschland, wie ich sie vor zwanzig Jahren versucht habe, nicht mehr schreiben kann - jedenfalls nicht ohne europarechtliche und internationale Bezüge. Ich würde aber ganz gerne auf einen anderen Punkt, der in beiden Referaten und auch in der Diskussion bisher keine Rolle gespielt hat, eingehen. Frau Kokott hat darauf hingewiesen, wie wichtig es ist, die Realitäten einzufangen. Zu den Realitäten der Demokratie gehören auch die politischen Akteure, also zum Beispiel auch die Abgeordneten, besonders aber die politischen Parteien. In einer Parteiendemokratie, wie wir sie haben, ist das ja eigentlich selbstverständlich. Meine Frage ist nun, ob die Rolle der Parteien, die jedenfalls in der Bundesrepublik vom Bundesverfassungsgericht mühsam (und nur mit begrenztem Erfolg) gebändigt worden ist, nicht droht, von Europa her einen Wandel zu erfahren. Am Montag dieser Woche, also am 29. September 2003, standen zwei Entscheidungen im Rat an: Das eine war die Verordnung über den Status und die Finanzierung „politischer Parteien auf europäischer Ebene", das andere war das Europäische Abgeordnetenstatut - beide Gesetze hatte das Europäische Parlament im Juni 2003 mehrheitlich beschlossen. Bei den Europaparteien droht eine Umbildung des Parteibegriffs, denn es soll nun nicht mehr erforderlich sein, dass sie natürliche Mitglieder haben. Ebenso wenig müssen sie Kandidaten für Wahlen aufstellen. Auch die Grundsätze über ihre öffentliche Finanzierung, wie sie etwa in Deutschland gelten, werden ausgehebelt. Die ,relative Obergrenze“ - also höchstens 50 Prozent öffentliche Mittel - gilt nicht. Statt dessen sind 75 Prozent erlaubt, und da die Fraktionen und die nationalen Parteien ihrerseits Mitglieder sein können, die ganz oder teilweise aus Staatsmitteln finanziert werden, von den „Parteisteuern“ der Abgeordneten ganz zu schweigen, kommt man leicht auf einen noch sehr viel höheren „Staats"anteil. Auch die Anforderungen an die Offenheit und Chancengleichheit des politischen Wettbewerbs - das Verfassungsgericht hat bei uns ein halbes Prozent der Stimmen ausreichen lassen, damit eine Partei an der Staatsfinanzierung beteiligt wird - werden auf Europaebene weitgehend ignoriert: Man muss nach der Erweiterung in mindestens sieben Staaten Europaabgeordnete ins Parlament schicken 
oder in diesen sieben Ländern mindestens 3 Prozent der Stimmen bekommen. So werden von Europa her die demokratischen Grundsätze der Chancengleichheit und der politischen Willensbildung von unten nach oben, die eigentlich auch in den EU-Verträgen verankert sind, unterlaufen. Von dort her könnten sich im Laufe der Zeit Rückwirkungen auch auf die Beurteilung der nationalen Parteien und ihrer Finanzierung ergeben und unsere bisherigen Grundsätze in Frage stellen.

Ein Wort noch zum Europäischen Abgeordnetenstatut, das, jedenfalls am 29. September, nicht die Zustimmung des Rats fand, obwohl es auf seiner Tagesordnung stand - vielleicht ein wenig auch deshalb, lassen Sie nicht das pro domo sagen, weil wir von Speyer aus an alle Mitgliedstaaten und ihre ständigen Vertreter in Brüssel ein ins Englische übersetztes kritisches Discussion Paper geschickt hatten. Das Statut würde dem europäischen Gedanken, wie ich meine, schwer schaden: Wenn zum Beispiel ungarische EU-Abgeordnete monatlich 8671 Euro Diäten bekommen und damit das Doppelte des ungarischen Ministerpräsidenten oder wenn EU-Abgeordnete niedriger besteuert werden als ihre Wähler, ist Derartiges den Bürgern kaum noch zu vermitteln.

EU-Abgeordnete haben ohnehin schon jetzt einen üppigen Fonds für die Beschäftigung von Mitarbeitern. Ein ungarischer EU-Abgeordneter könnte davon zu Hause bis zu 25 Personen zum dortigen Durchschnittslohn beschäftigen, und diese Mitarbeiter werden vermutlich auch in den nationalen Parteien arbeiten. Das ergibt dann innerhalb der Parteien einen riesigen Wasserkopf, finanziert aus EU-Mitteln. Damit droht sich auch aus diesem Grund - innerhalb des Landes und innerhalb der nationalen Partei die Willensbildung von unten nach oben in ihr Gegenteil umzukehren.

Meine Frage nun an beide Referenten: Gehören diese Themen nicht zum Verfassungsrecht im materiellen Sinne und müssen wir sie deshalb nicht auch in die Diskussion mit einbeziehen?

Ehrenzeller: Frau Kokott, Sie haben in Ihrem Referat - und ich würde Ihnen vollkommen zustimmen - die Rolle des Staates, die Funktion des Staates als Mitgestalter definiert bei der neuen internationalen Ordnung und bei der Schaffung des internationalen Rechts. Gleichzeitig sagen Sie dann in Ihrer These 21, dass der parlamentszentrierte Ansatz an Bedeutung verschwinde, also seine Rolle verliere. Da frage ich mich: Wenn der parlamentszentrierte Ansatz, also die Mitwirkung der Parlamente, an Bedeutung verliert, ja wer gestaltet dann diese internationale Ordnung? Die Justiz? Vielleicht zu einem gewissen Anteil, ja, aber wohl in einem ganz hohen Masse in dem Fall die Exekutiven. Ist dann das, was Sie in Ihrer These 22 sagen, noch damit vereinbar? Sie sagen dort (These 22): „Das 
europarechtliche und internationale Demokratiegebot enthält ein Optimierungsgebot, das auf Ausschöpfung der Partizipationsmöglichkeiten auf allen Ebenen zielt“. Ich hätte gerne ein wenig mehr Auskunft darüber - Frau Puttler hat es ja auch schon angesprochen - was verstehen Sie unter Partizipationsmöglichkeiten? Das beschäftigt mich auch bei den Diskussionen über die europäische Verfassung. Sie müssen auch verstehen, für uns Schweizer: Partizipation, indem man einfach den Behörden ein Mail schicken darf, ,ich hab' diese und jene Auffassung“, also eine Art "Mailokratie“, unterscheidet sich doch noch, mindestens in unserem schweizerischen Verständnis, von Demokratie. Und ich möchte Ihnen schon ein wenig diese Gretchenfrage stellen, weil das ganz zentral ist. Wenn wir eine neue internationale Ordnung demokratisch legitimieren wollen, dann glaube ich, dann müssen wir den Bürger wirklich ernst nehmen und ihm echte Möglichkeiten der Mitwirkung geben. Wenn das nicht gelingt auf internationaler Ebene, dann zumindest durch eine stärkere Demokratisierung eben der mitgestaltenden Einheiten des Staates. Ich hätte gerne Ihre Vorstellungen dazu.

Vorsitzender: Wir kommen jetzt zum abschließenden thematischen Block. Ich darf vielleicht erläuternd dazu sagen, was die Referenten bei der Vorbesprechung wussten und was vielleicht nicht allgemein bekannt ist: Die Idee des Vorstands war, an konkreten einzelnen Feldern - vier verschiedenen - die ganze Tagung hindurch so eine Art Zwischenbilanz zu ziehen, wo stehen eigentlich Staatsrechts- und Verwaltungsrechtslehre heute, so dass ein wenig auch die Selbstreflexion auf das Fach, seine Gegenstände und seine Methoden die Vorträge begleiten sollte oder dazu anregen sollte, darüber nachzudenken. In diesem Sinne geht es im vierten Block um Konsequenzen für die Theoriebildung, für Methoden, auch für die universitäre Lehre.

Grimm: Ich weiß nicht, Herr Schulze-Fielitz, wie gut ich in diesem Block untergebracht bin. Ich wollte sagen, dass ich mit der Zustandsanalyse beider Referenten gänzlich übereinstimme. Wenn man sie auf einen kurzen Nenner bringt, lautet er: Öffentliche Gewalt und Staatsgewalt sind nicht mehr identisch. Indessen bleibt der Staat als ein unterscheidbarer Akteur präsent, er bleibt auf zahlreichen Feldern sogar prominent. Er verfügt auch noch - das ist bislang nicht erwähnt worden - über einen exklusiven Bereich: Das Gewaltmonopol in der Definition Max Webers ist ihm bis heute nicht streitig gemacht worden. Was er verloren hat, ist das Monopol, auch die Zwecke zu bestimmen, für deren Verwirklichung er notfalls Gewalt einsetzt. Deswegen ist die Aufgabe, vor die wir uns jetzt gestellt sehen, die Verrechtlichung und Demokratisierung der überstaat- 
lichen Ebenen, auf denen öffentliche Gewalt ausgeübt wird. Wenn man anschaut, welche Möglichkeiten dazu bestehen, dann lässt sich beobachten, dass die Verrechtlichung der überstaatlichen Ebene zwar nicht in demselben Ausmaß wie im Staat, aber doch mehr oder weniger gut gelingt. Die Demokratisierung der überstaatlichen Ebene - das ist schon mehrfach erwähnt worden - wird dagegen umso schwieriger, je weiter sie von der staatlichen entfernt ist. Das spricht dafür, nicht allzu bereitwillig vom Staat abzurücken, wenn man das Demokratieprinzip bewahren will. Allerdings diffundiert die Staatlichkeit nicht nur ins Supranationale, sondern auch ins Private hinein - das ist bei Herrn Vesting stärker zum Vorschein gekommen als bei Frau Kokott. Wenn wir uns dieser Seite zuwenden, dann zeigt sich, dass es hier nicht nur um die Demokratisierung, sondern auch um die Verrechtlichung schlecht bestellt ist. Denn die privaten Teilhaber an öffentlicher Gewalt können nicht ohne Verlust ihrer Privatheit den Bindungen unterworfen werden, die für den Staat gelten. Irgendwo muss der Preis für diese Entwicklungen bezahlt werden, und bezahlt wird er bei der Errungenschaft der Verfassung. Sie muss sich erhebliche Abstriche an ihrem Geltungsanspruch gefallen lassen. Deswegen finde ich es leichtfertig, in welchem Ausmaß in Bezug auf die überstaatlichen Ebenen neuerdings der Ausdruck Konstitutionalisierung gebraucht wird. Nicht jede Verrechtlichung auf dieser Ebene verdient schon den Namen Konstitutionalisierung. Wenn wir an einem einigermaBen gehaltvollen Begriff von Verfassung festhalten wollen, dann lässt sie sich nicht einfach auf die überstaatliche Ebene heben. Konstitutionalisierung ist eine Beruhigungsformel, die die wahren Verluste verdeckt.

Marauhn: Herr Vesting, die Kategorisierung der „Suchbewegungen“ in Ihrer These 4 halte ich für anregend und weiterführend. Auf den bekannten Argumentationstopos „offener Staat" möchte ich nicht näher eingehen. Zur Konstitutionalisierungsdebatte möchte ich nur anmerken, dass ich die Kritik an einer Überfrachtung der Debatte teile, auch wenn ich nicht so weit gehen möchte, wie Herr Grimm das soeben getan hat. Meines Erachtens verspricht das Konzept der Konstitutionalisierung in bestimmten Teilbereichen Erkenntnisfortschritte. Dies gilt insbesondere für die Vereinten Nationen und für den regionalen Menschenrechtsschutz im Rahmen des Europarates, um nur zwei Beispiele zu nennen.

Näher eingehen möchte ich auf den von Ihnen in die Debatte gebrachten „Rechtspluralismus“. Ich halte es für überzeugend, dass Sie die Netzwerkanalyse, die ursprünglich in den Sozialwissenschaften entwickelt wurde und dort als analytisches Werkzeug genutzt wird, an den Anfang Ihrer diesbezüglichen Überlegungen stellen und dass Sie damit eine neue Perspektive auf die Internationalisierung unseres Forschungsgegenstands 
eröffnen. Meines Erachtens kann man allerdings nicht ohne weiteres aus diesem analytischen Ansatz normative Schlussfolgerungen ziehen, wie sie mit dem Begriff des „Rechtspluralismus“ verbunden sind. Dieser Begriff wurzelt wesentlich in der Rechtsanthropologie, die in der deutschen rechtswissenschaftlichen Diskussion lange kaum beachtet wurde, zuletzt aber durch die Einrichtung einer Arbeitsgruppe am Max-Planck-Institut für ethnologische Forschung in Halle auch institutionell an Bedeutung gewonnen hat. In der Rechtsanthropologie versteht man unter Rechtspluralismus das Nebeneinander zweier oder mehrerer rechtlicher Systeme innerhalb einer (staatlichen oder gesellschaftlichen) Organisationsform. In seiner idealtypischen Ausformung bedeutet Rechtspluralismus die Anerkennung verschiedener kulturell-ethnischer Rechtssysteme als gleichwertig. Um Konflikte zwischen diesen Rechtssystemen zu lösen, hat sich weitgehend allerdings der relative Rechtspluralismus durchgesetzt, der Elemente einer Hierarchisierung beinhaltet und damit beispielsweise dem traditionellen (lokalen) Recht nur insoweit zur Geltung verhilft, als sich die staatliche Rechtsordnung selbst dafür öffnet. Rechtspluralismus wird also nicht ausschließlich horizontal verstanden. Vielmehr stellt sich auch die Frage einer Über- und Unterordnung der Rechtssysteme zueinander. Dies ist auch für die Internationalisierung der Rechtsordnung von Bedeutung. Auch dort sollten Über- und Unterordnung nicht völlig ausgeschlossen werden. Die Netzwerkanalyse hilft normativ hier nicht weiter. Sie verstellt allenfalls den Blick darauf, dass auch private Akteure Hierarchien schaffen können - Hierarchien auch im Verhältnis zum öffentlichen Diskurs. Meines Erachtens lässt sich eine Gleichstellung von privaten und öffentlichen Akteuren nicht ohne weiteres normativ begründen. Faktisch gibt es zwar zahlreiche Überlappungen, auch im Bereich internationalisierter Verwaltungskooperation. Normativ lassen sich hier aber Bedenken anmelden - nicht nur hinsichtlich der demokratischen Legitimation. Vielen Dank.

Calliess: Herr Vesting, Sie haben in Ihrem anregenden Vortrag drei Suchbewegungen - wie Sie es nannten - ausgemacht. Diese sind für das Verständnis der gegenwärtigen Debatte sicher hilfreich, indem sie eine Ordnungsfunktion erfüllen. Ihre Kategorisierung bei der Suche nach Alternativen birgt aber die Gefahr, dass der Blick auf die zwischen ihnen bestehenden Zusammenhänge verstellt wird. So hat die Alternative des offenen Staates, der sich über Normen wie Art. 23 und Art. 24 Grundgesetz dem europäischen und internationalen Recht verfassungsrechtlich öffnet, einen Zusammenhang zu Ihrer Suchbewegung des Konstitutionalismus. Denn der Konstitutionalismus will ja gerade die Verzahnung von nationalen und europäischen bzw. internationalen Verfassungen aufarbeiten. 
Stichworte sind hier: Der europäische Verfassungsverbund der EU, der europäische Menschenrechtsschutz sowie auf völkerrechtlicher Ebene die Verzahnung zwischen den Verfassungen von internationalen Organisationen - ich denke hier an EU und WTO oder WTO und ILO. Der Rechtspluralismus ist bei Ihren Suchbewegungen im Hinblick auf die sogenannte Globalisierung sicher von Erkenntniswert: Sie haben hier das Beispiel des Internet gebracht. Angesichts der Grenzen staatlicher Regulierung findet hier gegenwärtig eine Wiederentdeckung des Zivilrechts auf der globalen Ebene statt, die sich nicht zuletzt in der Nutzbarmachung der lex mercatoria Ausdruck verschafft. Aber handelt es sich, wenn man einmal an die konkreten Fälle denkt, nicht eher um Einzelfälle? Primär, so meine ich, reorganisiert sich doch wiederum der Staat auf der internationalen Ebene in Form von Internationalen Organisationen, die mit ihren Verfassungen die Suchbewegung des Rechtspluralismus an jene des Konstitutionalismus und des offenen Verfassungsstaates zurückbinden. So gesehen bilden der offene Verfassungsstaat und der Konstitutionalismus den notwendigen Rahmen für den Rechtspluralismus, in dessen Kontext NGO's und Netzwerke funktionieren können. Meine Frage daher an Sie: Muss hier nicht eigentlich statt der in Ihren Suchbewegungen zum Ausdruck kommenden Trennung eher ein Zusammenhang zwischen den Suchbewegungen erkannt und hergestellt werden?

Ruffert: Herr Vesting, Ihre Analyse der Entwicklung unter III. Ihrer Gliederung überzeugt mich sehr - die Diagnose sozusagen. Ich habe aber Zweifel an der Therapie. Ist die Orientierung an einem Rechtspluralismus, an Netzwerken die richtige Suchbewegung? Sie entkoppeln hier das Recht in letzter Konsequenz völlig vom Staat, und damit geht vielleicht etwas verloren, was der alte Rechtsstaatsbegriff geleistet hat, nämlich die Legitimation von Recht. Können Sie mich überzeugen, dass der Rechtspluralismus diese Leistung auch bewerkstelligen kann?

Isensee: Tod des Staates - aber was dann? Soeben wurden uns diverse Nachfolger und Surrogate vorgestellt: die Europäische Union, die UNO, die WTO, aber auch raumlose, anarchische Netzwerke. Ein Surrogat aber wurde nicht beim Namen genannt: das Weltreich der USA. Dieses Weltreich hat sich im Ernstfall des Terrorismus nachhaltig zur Geltung gebracht. Das Gesetz des Handelns lag nicht bei den Vereinten Nationen, auch nicht bei der NATO oder der Europäischen Union, sondern bei der einen Weltmacht. An zweiter Stelle agierten einzelne Nationalstaaten, soweit sie über relevantes Machtgewicht verfügten. Im Ernstfall zeigt sich die Wirklichkeit anders, als die Rechtskonstrukte wollen, die uns soeben geboten worden sind. Der Jurist fühlt sich freilich am wohlsten in einer 
Welt ohne Ernstfall, weil er in ihr leicht konstruieren und deduzieren kann, ohne auf den Widerstand der Wirklichkeit zu stoßen.

Eine Bemerkung zum Bild des geschlossenen Nationalstaates, das durch die Diskussion geistert. Das Bild entsprach noch nicht einmal der Wirklichkeit des 19. Jahrhunderts. Deren Gesellschaft war tendenziell international. Die erste globalisierte Institution der Weltgeschichte, die katholische Kirche, hat sich dem Nationalstaat gegenüber behauptet und seinem Anspruch auf Impermeabilität erfolgreich widerstanden. Im übrigen: Wirtschaft und Kultur haben sich immer über Staatsgrenzen hinweggesetzt. Herrscherhäuser und Adel waren europäisch versippt.

Gleichwohl sind erhebliche Änderungen der Staatenwelt festzustellen. Sind in den tektonischen Beben alle Begriffsgebäude zusammengebrochen, die des Staates, des öffentlichen Rechts, insbesondere des Staatsrechts? Die Wirklichkeit fließt. Begriffe aber sind etwas Festes. Wenn die Wissenschaft sie vorzeitig verabschiedet, verliert sie die Fähigkeit, notwendige Unterscheidungen zu treffen. Ich darf nur den Begriff der Souveränität nennen. Die äußere Souveränität ist von jeher nur ein völkerrechtliches Attribut des Staates gewesen, das nichts über dessen reale Macht und Unabhängigkeit sagt; es umfasst im wesentlichen die Fähigkeit zur Selbstbindung an völkerrechtliche Verträge. Die innere Souveränität aber war nie ein Rechtsbegriff, auch kein staatsrechtlicher Begriff, sondern eine Kategorie der Macht: der Macht, sich gegenüber widerstrebenden gesellschaftlichen Kräften zu behaupten. Diese Fähigkeit beanspruchen alle Erscheinungen des staatlichen Systems bis hin zur Gemeinde und zum Gerichtsvollzieher. Innere Souveränität nimmt auch die supranationale Gemeinschaft in Anspruch. Also alles in allem: so viel hat sich nicht gewandelt.

Radikaler als beide Referenten hat vor 125 Jahren Nietzsche den Tod des Staates verkündet in Vorfreude darauf, welche zweckmäßige Erfindung der kluge und eigennützige Mensch an seine Stelle setzen werde. Am Ende seiner schwunghaften Prophetie erschrickt aber der Philosoph und warnt: niemand dürfe aus seiner (natürlich unfehlbaren) Erkenntnis praktische Konsequenzen ziehen, solange noch kein vernünftiger Ersatz für den Staat bereitstehe. Nietzsche verfügt also ein Todesurteil mit Hinrichtungsaufschub. Seither lebt der Staat in der Todeszelle höchst komfortabel. Wir brauchen daher die Vereinigung Deutscher Staatsrechtslehrer noch nicht umzutaufen in „Vereinigung Europäischer Verfassungsrechtslehrer", auch nicht in „Vereinigung Kosmopolitischer Netzwerkexperten“. Rechtzeitig zu dieser Tagung hat übrigens der erste Vorsitzende der Vereinigung Deutscher Staatsrechtslehrer ein 900 Seiten starkes Buch mit dem lapidaren Einworttitel veröffentlicht: Staatswissenschaft. 
Winter: Ich fand an dem Vortrag von Herrn Vesting interessant, dass er die Entstehung des Rechtsstaats auf bestimmte Problemstellungen bezog, also von Funktionen ausging und auf sie dann den Rechtsstaat projizierte. Die Funktion sieht Herr Vesting in der Bändigung von Willkürpotential des Absolutismus. Ich würde noch hinzusetzen: Den absolutistischen Regimen stellte sich auch eine inhaltliche Aufgabe, nämlich die Entwicklung der Gesellschaft, die Herstellung von Wohlstand in einer Zeit der Unterdrückung, Armut und Stagnation. Der landesherrliche Absolutismus war sozusagen eine erste Etappe, um diese Aufgabe anzugehen. Die zweite war der Rechtsstaat, der die Entwicklungsdynamik und Wohlfahrtssicherung zum großen Teil in die Gesellschaft verlagerte und zugleich für Rechtssicherheit sorgte. Ich meine, wir sollten die Frage nach den Funktionen der Organisationsformen heute erneut stellen, also die Frage, welches die Probleme sind, auf die hin rechtliche Ordnung gestiftet werden muss. Dieses Problempotential hat heute globale Ausmaße. In den Naturwissenschaften ist man gewohnt, von einer Erdsystemanalyse zu sprechen. Ich glaube, ein entsprechender Begriff fehlt noch in den Sozialwissenschaften und in den Wissenschaften, die sich mit Institutionen befassen, also der Rechtswissenschaft. Welches sind solche Weltprobleme? $\mathrm{Zu}$ ihnen gehören die krasse Ungleichheit innerhalb und zwischen vielen Staaten, weiterhin massive Umweltprobleme wie der Klimawandel, der zur Austrocknung weiter Gebiete und dementsprechend auch zu zunehmendem Migrationsdruck führt. Wir müssen also in Betracht ziehen, welches die Probleme der Welt insgesamt sind und darauf die Ordnungsleistungen, die erbracht werden, beziehen. Wenn man diese Perspektive einnimmt, denke ich, ist es selbstverständlich und naheliegend, von Rechtspluralismus zu sprechen, davon zu sprechen, dass es eine Vielfalt von Ordnungen gibt, die versuchen, mit den Problemen fertig zu werden und zu vermeiden, dass die Lösungen willkürlich sind. $\mathrm{Zu}$ diesen Ordnungen gehören nicht nur die Strukturen der größeren Verbünde, in die hinein sich der Staat eingliedert, sondern dazu gehören - Herr Grimm hat darauf hingewiesen - vor allen Dingen auch die privaten Ordnungen, so zum Beispiel die Ordnungen, die die multinationalen Unternehmen erstellen. Die Zentrale eines multinationalen Konzerns steht vor vielen Rechtsordnungen, mit denen sie und ihre Tochtergesellschaften sich auseinandersetzen müssen. Angesichts dessen wird sie ihr eigenes konzerninternes Recht setzen und die Rechtsordnung suchen, in der diese sich durchsetzen kann. Staatliches Recht ist unter dieser Perspektive Angebotsrecht, nicht Souveränitätsrecht. Rechtspluralität ist auch in Gestalt transnational agierender Fachbürokratien beobachtbar. Heutzutage werden viele Aufgaben transnationaler Art über diese Netzwerke erledigt Herr Tietje hat das in seiner Habilitationsschrift sehr schön dargelegt -. 
Ich habe kürzlich einen Mitarbeiter eines Bundesamts gefragt, wie seine fachlichen Kommunikationskanäle aussehen. Seine Antwort war: „Ich bin einerseits in Kontakt mit den anderen Bundesämtern, aber das ist höchst kompliziert, weil ich da über zwei Präsidenten gehen muss, andererseits bin ich weltweit vernetzt, und das geht direkt übers Internet." In solchen Netzwerken wird informelles transnationales Recht geschaffen, das zusammen mit den informellen Ordnungen der Konzerne neben das formelle Recht tritt. Dies wird von dem Begriff des Rechtspluralismus recht gut beleuchtet. Aber, Herr Vesting, Sie müssten dann doch noch manches präzisieren. Drei Fragen dazu: Wie steht es mit der Hegemonie der USA in den pluralen Ordnungen, gibt es da manche Akteure, die gleicher als gleich sind? Zweitens, ist es nicht so, dass die Zerfaserung der Rechtsordnungen nur für manche Funktionen gilt und für andere nicht, dass sie etwa vor allem im Technischen zu beobachten sind, weniger dagegen im Bereich des Politischen. Drittens, wenn Sie sagen, wir brauchen eine Metadogmatik der Vernetzung der Rechtsordnungen, was bedeutet das konkret? Kann diese Metadogmatik wirklich nur lediglich in einer Kompatibilisierung, als bloß äußerlicher Abstimmung bestehen, oder muss sie sich nicht doch am Demokratieprinzip, an den Grundrechten und anderen mehr inhaltlichen Maßstäben orientieren?

Bausback: Meine Wortmeldung bezieht sich auf den Vortrag von Frau Kokott. Frau Kokott, Ihr System ist theoretisch bestechend, gleichwohl habe ich Zweifel daran, dass es sich so verwirklichen lässt, bzw. dass es so in der Realität anzutreffen ist.

Mein erster Einwand, bezogen auf These 8: Die Ungleichzeitigkeit des Wandels des Souveränitätsverständnisses, den wir in der Realität festzustellen haben, führt zu Konfliktsituationen auch in Zukunft. Die USA und auch Neustaaten wie zum Beispiel auf dem Balkan sind von einem Verständnis einer offenen Staatlichkeit meines Erachtens noch weit entfernt.

Mein zweiter Einwand: Ihre Forderung in These 23, dass in einem Mehrebenensystem jede Ebene ,zu ihrer ganzen, harten Verantwortlichkeit" stehen muss, ist sehr plausibel, aber in der politischen Praxis weder anzutreffen noch zu realisieren. Hier wird Verantwortung eher auf eine andere Ebene verlagert, als dass man zu der eigenen Verantwortung steht.

Mein dritter Einwand: Den Schwund der Bedeutung des positiven Rechts, den Sie in These 27 positiv sehen, würde ich eher negativ beurteilen, denn die Relativierung des Positivismus muss zwangsläufig zu der Gefahr von Willkür führen, und das ist eine negative Entwicklung, die es zu vermeiden gilt.

Insgesamt meine ich, Ihr System ist zwar bestechend, aber im Hinblick auf diese und andere Einwände, die ich jetzt hier nicht nennen kann, bin 
ich der Ansicht, dass der Staat auch in Zukunft eine höhere Bedeutung haben wird, als Sie es in Ihrem Referat andeuten.

Bryde: Anders als viele andere Redner halte ich die Ausführungen der Referenten, die Darstellung der Herausforderungen an unsere Wissenschaft durch Globalisierung überhaupt nicht für übertrieben, und anders als Frau Puttler halte ich das, was Frau Krokott gesagt hat, auch nicht für illusionär, sondern, wie häufig im Völkerrecht, für gleichzeitig sehr schwer, aber absolut notwendig. Wenn wir unsere Werte von demokratischer Selbstbestimmung ernst nehmen und Entscheidungen zunehmend international getroffen werden, müssen die internationalen Beziehungen demokratisch verfasst werden; das ist sehr schwierig, aber nicht illusionär. Ich definiere den Völkerrechtler in meiner Völkerrechtsvorlesung in der ersten Stunde immer als jemanden, der ein Glas halbvoll und nicht halbleer nennt. Und gerade deswegen müssen wir Konsequenzen in der Lehre ziehen, und da bin ich jetzt ganz pessimistisch - oder auch - wie Herr Isensee - optimistisch für die der Zukunft der deutschen Staatsrechtslehre für die nächsten 50 Jahre. Frau Kokott hat mit Recht darauf hingewiesen, dass das entscheidende Wort von Badura schon von 1964 stammt. Er hat gesagt, Demokratie und Rechtsstaat können nur überleben, wenn sie aus dem Gehäuse des Nationalstaats ausbrechen. Und das ist jetzt 40 Jahre her, und es hat sich nicht viel getan. Und das hat meines Erachtens Gründe in der Wissenschaftssoziologie des Staatsrechts. Ich würde drei Faktoren erwähnen, die uns allen bekannt sind. Das ist einmal unsere Lehrstuhlstruktur, in der das internationale Recht immer nur Nebenfach ist, und in der der junge Wissenschaftler gehalten ist, den meisten Schweiß im deutschen öffentlichen Recht zu vergießen, sonst ist er nicht berufungsfähig, und nur im Nebenfach darf er internationalistisch arbeiten; und in der zum Beispiel das öffentliche Recht und das Privatrecht strikt getrennt sind, obwohl ein Grossteil der Entwicklungen, die hier wichtig sind, im Privatrecht stattfinden. Das ist zweitens unsere Begrifflichkeit, die wir heute hier auch wieder kennen gelernt haben. Unsere Begriffe sind staatlich, wir sagen nicht Konstitutionalismus, wir sagen Verfassungsstaatlichkeit, wir sagen nicht rule of law, wir sagen Rechtsstaatlichkeit, und dann machen wir einen Zirkelschluss und sagen, „und folglich kann es das auf internationaler Ebene nicht geben“. Inzwischen liest man auch immer öfter „Demokratiestaatlichkeit“ - ein Wort, von dem ich dringend abrate. Und schließlich ist es die Organisation unseres Lehr- und Prüfungswesen. Wir können die ohnehin überlasteten Prüfungssysteme nicht noch durch weitere Pflichtfächer anreichern, z.B. ein Pflichtfach Völkerrecht: Das Internationale Recht ist zu vielgestaltig. Der eine wird die notwendige Internationalisierung der Lehre vorneh- 
men durch Integration von Verfassungsvergleichung in das Staatsrecht, der andere konzentriert sich auf das Recht der WTO, der dritte arbeitet menschenrechtlich. Das bedeutet, die Internationalisierung des Fachs lässt sich endgültig in der Universitätslehre und Prüfung nicht mehr bewältigen mit einem punktuellen Staatsexamen, das Gesamtwissen abprüft in einer Art und Weise, wie es ohnehin nicht Wissenschaftler, sondern nur Repetitoren vermitteln können. Solange wir unser Prüfungssystem, unser Ausbildungssystem nicht ändern, werden wir auch in 40 Jahren wieder eine Staatrechtslehrertagung haben, die die Internationalisierung unseres Fachs einfordern wird, und es wird nichts geschehen sein.

Goerlich: Nach diesem Beitrag von Herrn Bryde eine zurückhaltendere Frage zur Lehre: Herrn Vesting - und genauso Frau Kokott, die das ja eingeführt hat, diese Fragestellung in ihr Referat - möchte ich fragen, wo sie denn dann, angesichts dieser Analyse von Herrn Bryde, die Einbeziehung ihrer Thematik im Lehrbetrieb beheimaten wollen. Mein Eindruck ist, es bleiben nur die Lehrbücher; bisher sind die Lehrbücher jedenfalls insoweit Potemkin'sche Dörfer, womit ich hier vor allem das Staatsrecht anspreche. Kurz nur ein Beispiel: Wenn Rechtsquellen zugeordnet werden, wie es die Europäische Grundrechtecharta versucht, wenn sie am Ende ihres Textes sinngemäß sagt, dass das Schutzniveau der EMRK nie unterschritten werden solle, so hat das nicht nur materielle Folgen für den Rechtsraum der Europäischen Union; es ergibt sich daraus zugleich eine funktionelle Folge, hier nämlich für die Stellung des Europäischen Gerichtshofs für Menschenrechte in Strassburg. Er kann infolgedessen wie ein europäisches Verfassungsgericht auftreten; er wird maßgeblich auch für diesen Rechtsraum, zumal aufgrund des Art. 6 Abs. 2 EUV. Das ergibt sich mithin nicht nur aus seiner Rechtsprechung hinsichtlich des Wahlrechts in Gibraltar zum Europäischen Parlament oder aus der Dangeville-Rechtsprechung dieses Jahr; ich meine, dass solche Entwicklungen notwendig einbezogen werden müssen in die Lehrbücher Staatsrecht I und II; und wenn das dort nicht stattfindet, dann geschieht es, in der Tat, wie Herr Bryde meint, nirgends; und dann bleibt das so in den nächsten 40 Jahren.

Vorsitzender: Meine Damen und Herren, wir kommen zum Ende der Diskussion. Man könnte jetzt noch den einen oder anderen aufrufen, aber es ist vielleicht auch ganz gut, dass die Referenten die Möglichkeit haben, auf die vielen Dinge einzugehen, und die Zeit ist knapp mit zweimal siebeneinhalb Minuten. Entsprechend den Gepflogenheiten dieser Vereinigung übernimmt Herr Vesting als Erster das Schlusswort. 
Vesting: Ich greife das Stichwort von der „Warteliste“ auf - das stammt ja aus der Lufthansawelt - und werde mich bemühen, schnell durch die vielen Fragen, die gestellt worden sind, zu düsen. Es dürfte aber klar sein, dass ich in 7,5 Minuten diese Fragen nicht alle beantworten und natürlich auch nicht den „Rest“ nachliefern kann, den Herr Butzer eingefordert hat.

Aber vielleicht ein paar Anmerkungen. Das Referat war angelegt als Selbstreflexion, wie Herr Di Fabio das ausgedrückt hat: als „Selbstorganisation unseres eigenen Fachs“, und die Fragestellung, die mir aufgegeben worden ist, muss dann zunächst erkenntnisorientiert, nicht praxisorientiert beantwortet werden. Die erste Frage, die man sich stellen muss, lautet: Wird die Zukunft der Weltordnung eine Staatenordnung sein? Darauf haben viele Redner in ihren Einwänden rekurriert, etwa Herr Rauschning oder Herr Isensee, der sich sogar eine Einstaatsordnung - ,Vorherrschaft der USA“ - vorzustellen scheint. Wenn man sich diese Frage stellt, dann darf man sich aber nicht nur auf aktuelle Ereignisse (Irak etc.) beziehen, die den einen oder anderen Eindruck vermitteln, sondern man muss sich dann vielleicht doch stärker auch auf die Forschung einlassen, die es im politikwissenschaftlichen Bereich oder in der Soziologie gibt und keineswegs nur in der Systemtheorie. In dieser internationalen Diskussion findet man aber nur relativ wenige Autoren, die die These vertreten würden, dass auch in Zukunft ausschließlich der Staat die ,internationale Ordnung " ausmachen wird; und wenn ich hier von Staatsordnung spreche, dann meine ich nicht den Allgemeinbegriff Staat, der (griechische) Polis und (römisches) Imperium einbezieht, sondern den Territorialstaat der frühen Neuzeit, wie er sich seit ungefähr 1600 herausgebildet hat.

Wenn das die eher herrschende Auffassung in der einschlägigen Literatur ist, dann kann man sich als Rechtswissenschaftler dazu doppelt verhalten: Man kann weiter ontologische Aussagen treffen und sagen, der Staat bleibt doch; es gab doch schon immer Internationalität, und auch in Zukunft wird der Staat doch nicht einfach verschwinden, wir sehen ihn doch jeden Abend, zumindest auf der Wetterkarte der ARD. Das ist aber nicht mein Ansatz gewesen, sondern ich habe sozusagen versucht, keine ontologischen Aussagen zu machen, sondern vor dem Hintergrund des neueren Forschungsstandes zu schauen, mit welchen Unterstellungen das öffentliche Recht im 19. Jahrhundert gegründet worden ist, und ob diese Unterstellungen heute noch tragfähig sind. Und da muss man sich zunächst die Frage stellen, warum Staatsrecht, warum Staatsrechtslehre, warum hat man 1928 die Vereinigung nicht gleich „Vereinigung der deutschen Staats- und Völkerrechtslehrer" genannt? Warum hat Laband ein Staatsrecht geschrieben (und kein Demokratierecht, zum Beispiel)? Und ich glaube, dass man diese Tatsache sehr ernst nehmen muss. Es scheint 
mir eben dahinter doch die Auffassung zu stehen, nicht nur dass der Staat „da“ ist, sondern dass er im Öffentlichen Recht eine zentrale, ja die zentrale Rolle einzunehmen hat, und dass es eben eine Hierarchie zwischen dem Staatsrecht und allen anderen Materien des Öffentlichen Rechts gibt. Ich habe ja nicht gesagt, es gab im 19. Jahrhundert kein Völkerrecht. Das gab's, natürlich gab's das, und es ist auch klar, dass nicht jeder beansprucht hat, das Ganze zu erfassen. Aber wenn es so etwas gab wie den Anspruch, das Ganze zu erfassen, dann waren diese Unternehmen eben getragen von der Idee, dass das Staatsrecht sozusagen das Ganze ist oder doch zumindest das Zentrum des Ganzen.

Darüber habe ich dann gesprochen, über die Frage, ob man diese Unterstellung, an der sich das Staatsrecht des 19. Jahrhunderts offensichtlich orientiert hat, auch heute noch so aufrechterhalten kann. Kann man beispielsweise Normhierarchien so bauen, dass man Staatsgrenzen voraussetzt, also etwa sagt „die Verfassung ist die höchste Ebene, und dann gibt's erst mal nichts mehr“. Ich meine, dass man davon eben nicht mehr ausgehen kann. Vielmehr gibt es so etwas wie eine Verselbständigung eines „transnationalen Rechts“ gegenüber dem Nationalstaat, d.h. dass sich Rechtsschichten herausbilden, die sich verselbständigen und dann auf den Nationalstaat und sein Recht zurückwirken. Und das, meine ich, kann man, entgegen mancher Einwände wie z. B. denen von Herrn $O p$ permann, durchaus auch auf das Europarecht beziehen. Mir scheint gerade der europäische Verfassungsentwurf als solcher zu zeigen, dass hier eine kleine politische Elite, die die europäische Verfassung für etwas Wichtiges hält, so etwas macht. Dazu kann man sich als Rechtswissenschaftler so oder so verhalten, aber es ist doch nicht so, dass diese Idee sozusagen „von unten“ gewachsen wäre, oder dass dieser Prozess angeregt worden wäre von den unterschiedlichen Ministerien oder Regierungen der Länder. Insofern scheint es mir eine Verselbständigung auf rechtlicher Ebene zu geben, und die Frage ist, wie gehen wir damit um.

Im Referat habe ich versucht, einige Suchbewegungen aufzuzeigen, und eine gewisse Sympathie, vorsichtige Sympathie, für die Idee des Rechtspluralismus erkennen lassen. Hier scheint mir zunächst einmal Folgendes wichtig zu sein: Ich habe nicht gesagt, dass es in Zukunft keine Staaten und kein staatlich gesetztes Recht mehr geben wird, regionale politische Systeme und ihr Recht, die werden vielmehr bleiben. Sie sind auch (rechts-)empirisch wichtig, etwa für die Legitimationsbeschaffung, oder für alle Rechtsbildung, die auf den staatlichen Rechtssystemen aufbaut. Aber vorgeschaltet ist wieder die Frage: Kann der Staatsbegriff der Begriff sein, der diese Gesamtentwicklung abbilden kann? Ist der Staatsbegriff sozusagen der tragende Begriff, von dem aus man diese Entwicklung erfassen kann? Hier gibt es verschiedene Vorschläge, eine Alterna- 
tive zum Rechtspluralismus ist der „offene Verfassungsstaat". Meinen Einwand dagegen habe ich formuliert. Man kommt hier allenfalls zu gradualisierten Begrifflichkeiten von mehr oder weniger offenem Staat. Aber das ist vermutlich auf Dauer zu wenig.

Abschließend möchte ich noch eine Bemerkung zum „Normativen“ machen. Herr Di Fabio hat gefragt: Ja muss man dann, angesichts dieser Lage, nicht wenigstens normativ dagegenhalten? Das haben viele andere auch eingefordert, aber auch eine solche „normative“" Reaktion, so glaube ich, wird eben auf Dauer nicht funktionieren. Das Recht ist auf eine adäquate kognitive Wahrnehmung der Realität angewiesen, und wenn das Recht sozusagen Bilder der Realität voraussetzt, die überhaupt nicht mehr stimmen, dann funktioniert es irgendwann selbst nicht mehr. Insofern gibt es einen Zusammenhang zwischen der Wirklichkeit und den normativen Ansprüchen, die wir formulieren. Natürlich müssen wir als Juristen und Öffentlichrechtler weiterhin normative Ansprüche formulieren. Aber wir müssen eben auch darüber nachdenken, wie man diese Ansprüche so modellieren kann, dass sie auf die neue Situation, die „neue Weltordnung" passen.

Kokott: Zum ersten Themenkomplex „Entsouveränisierung“: Wo genau ist die Souveränität verloren gegangen, fragte Herr Di Fabio. Erstens, der Souveränitätsbegriff ist völlig unbestimmt, und deshalb aus meiner Sicht entbehrlich. Wenn man Souveränität so definiert wie Sie, Herr Di Fabio, als Freiheit der Bürger, dann würde ich mich voll anschließen. Ich bin auch für Freiheit der Bürger. Jedoch sind eben diese traditionellen Attribute des herkömmlichen Souveränitätsbegriffs verlorengegangen: Entscheidungsmonopol, Letztentscheidung und volle Verantwortlichkeit für das innerstaatliche Recht. Deshalb mein Plädoyer für Aufgabe dieses letztlich inhaltsleeren Begriffs. Herr Doehring teilt meine Analyse, ist aber etwas traurig über den Verlust der Souveränität des Staates. Aus der Sicht einer relativ saturierten rechtsstaatlichen Bundesrepublik kann ich eine solche „Traurigkeit" teilen, aber ich habe an alle Staaten gedacht, auch an solche, wo kein Wohlstand herrscht, keine Menschenrechte und kein Rechtsstaat. Und für die Menschen in diesen Staaten ist es ein Gewinn, wenn sie rauskommen können, und wenn Menschenrechte überhaupt ein Diskussionsgegenstand sind - ein international indizierter Diskussionsgegenstand. Herr Eckart Klein fragte, ob ich nicht zu sehr von Europa ausgegangen sei. Hier kann ich wiederholen: Gerade in solchen Staaten, wo das, was in der EMRK, aber auch in unseren Verfassungen ohnehin garantiert ist, wo das eben nicht selbstverständlich ist - da sind doch diese souveränität einschränkenden internationalen Mindeststandards umso wichtiger. Herr Streinz fragte, ,ist das Demokratiegebot denn universell 
oder eine europäische Idee?“. Entwickelt wurde das Demokratiegebot im Wesentlichen von amerikanischen Völkerrechtlern. Und, um Herrn Leisner gleich zuvorzukommen - er hat bestritten, dass es ein internationales Demokratiegebot gibt: Ich habe in meinem Manuskript aus Vorsicht und Zurückhaltung geschrieben: „Das Demokratiegebot ist zumindest eine Völkerrechtsnorm in statu nascendi“, und das ,in statu nascendi“ habe ich in Klammern gesetzt. Meiner Auffassung nach ist Demokratie bereits jetzt völkerrechtlich geboten. Welche Folgen hat das überhaupt? Einmal, dass internationale Organisationen, Weltwährungsfonds, Weltbank, EU die Kreditvergabe, Projektförderung, Entwicklungshilfe, an Good Governance Standards binden. Zweitens, dass der Sicherheitsrat in Resolutionen bisweilen die Demokratie einfordert, etwa in der Resolution zu Haiti. Weiter hat schon vor langer Zeit - ich glaube es war in den 70er Jahren die interamerikanische Menschenrechtskommission sehr progressiverweise zum Sturz des diktatorischen Somosa Regimes in Nicaragua aufgerufen, weil ihrer Auffassung nach (der interamerikanischen Menschenrechtskommission) nur eine Demokratie mit der bestmöglichen Wahrung der Menschenrechte vereinbar ist. Zu dem Thema gleich weiter: „Was ist nun eigentlich Demokratie?, das kann man doch gar nicht definieren", meinte Herr Leisner. Man mag Demokratie vielleicht nicht positiv definieren können - längere Erörterungen wären hier notwendig -, aber es gibt sicherlich Evidenzfälle: So gibt es eine Reihe von Staaten, wo man klar sagen kann, das ist nun keine Demokratie, das unterstützen wir nicht, hier gehen keine Projekte hin. Herr Häberle fragte sodann, „was ist eigentlich der Unterschied zwischen Europäisierung und Internationalisierung?" Europäisierung momentan (man weiß ja nicht, was die Zukunft bringt) ist eine besonders intensive Internationalisierung. Zur noch offenen Frage von Herrn Schmidt-Jortzig. Ich habe in meinem Referat Demokratie im Grundsatz als Betroffenenherrschaft definiert. Führt das denn nicht zum Ausländerwahlrecht? Nein, denn immer noch sind die Staatsbürger von der eigenen Staatsgewalt besonders betroffen, deshalb also nicht der Schluss, Demokratie als Betroffenenherrschaft führt zum Ausländerwahlrecht. Zu Frau Puttler kann ich ergänzen: Das Demokratiegebot hat im Völkerrecht natürlich einen begrenzten Anwendungsbereich. Einmal ist es aber schon wichtig, dass Demokratie überhaupt ein Gegenstand des Völkerrechts ist - das ist ja ganz neu. Das traditionelle Völkerrecht sagte, „ihr Staaten könnt machen was ihr wollt in eurem Innern, Hauptsache, die Staatsgewalt ist effektiv“. Darüber sind wir Gott sei Dank hinausgewachsen. Dass Demokratie überhaupt völkerrechtlich geboten ist, bewirkt schon etwas. Jedoch - und darauf zielte wohl Ihre Intervention - ist der Anwendungsbereich doch recht gering. Demokratie, Betroffenenherrschaft - oft ist der Einzelne ja nicht direkt vom Völker- 
recht betroffen. So gibt es wenige Fälle, wo der Einzelne gegenüber Völkerrechtssubjekten, internationalen Organisationen und überhaupt im internationalen Bereich Grund hätte, sich auf das Demokratiegebot zu berufen. Ein Fall sind immerhin die Projektvergaben der Weltbank, dass die Weltbank nicht einfach irgendwo einen Staudamm fordern kann ohne die Bürger, die da wohnen, in irgendeiner Weise zu beteiligen. Es passt zum Demokratiegebot - Demokratiegebot auch verstanden als Partizipationsrecht -, dass es jetzt Beschwerdeverfahren gibt, durch die die Bürger beteiligt werden, wenn solche Projekte internationaler Organisationen in ihrem Wohnbereich oder in ihrer Nähe aufgebaut werden. Herr $\mathrm{Höl}$ scheidt wies auf die Rolle der Parlamente, auf eine gewisse Parlamentarisierung durch Europäisierung hin. Das ist ein interessantes Feld, das ich nur aus Zeitgründen ausgelassen habe, also die demokratischen Grundsätze, innerstaatlich, aber auch international, zu verwirklichen. Ich bin nur auf die postnationale Demokratie eingegangen, aber natürlich erwachsen den innerstaatlichen Parlamenten auch neue Aufgaben. Herr Pernice beispielsweise hat hierzu geforscht. Und dann sagte Herr Bausback, dass die Idee, dass jeder zu seiner Verantwortung stehen muss, irrealistisch sei. Aber gerade deshalb brauchen wir ja eine Norm, Normen sind Antworten auf unerwünschte Zustände. Wenn alles gut und ideal laufen würde, dann bräuchten wir nicht dieses Postulat, was ich hiermit fordere, dass klare Verantwortlichkeiten bestehen müssen und dass man insbesondere hieran arbeitet. Herrn Isensees Rede schließlich kann ich nur zustimmen. Der Staat ist nicht tot, bloß ist er eben nicht mehr souverän, und seine Aufgaben wandeln sich.

Vorsitzender: Meine Damen und Herren, wenn es ein Aufgabe von Staatsrechtslehrertagungen ist, dass es wissenschaftlich nicht langweilig, sondern spannend zugeht, dann meine ich, unabhängig davon, was Sie zu den einzelnen Referaten sagen, sie haben uns einen spannenden Vormittag beschert! Wir machen pünktlich weiter um 14.00 Uhr. 